\title{
Analysis of Thermal Energy Collection from Precast Concrete Roof Assemblies
}

\author{
Ashley Burnett Abbott \\ Master's thesis submitted to the faculty of \\ Virginia Polytechnic Institute and State University \\ in partial fulfillment of the requirements for the degree of \\ Master of Science \\ in \\ Mechanical Engineering
}

Committee Members:

Dr. Michael W. Ellis, Chair

Dr. Douglas J. Nelson

Dr. Yvan J Beliveau

Friday, July 16, 2004

Blacksburg, VA

Keywords: Solar Water Heating, Solar Concrete Collector, Precast Concrete, Solar Assisted Heat Pump

Copyright 2004, Ashley Burnett Abbott 


\title{
Analysis of Thermal Energy Collection from Precast Concrete Roof Assemblies Ashley B. Abbott
}

\begin{abstract}
The development of precast concrete housing systems provides an opportunity to easily and inexpensively incorporate solar energy collection by casting collector tubes into the roof structure. A design is presented for a precast solar water heating system used to aid in meeting the space and domestic water heating loads of a single family residence. A three-dimensional transient collector model is developed to characterize the precast solar collector's performance throughout the day. The model describes the collector as a series of segments in the axial direction connected by a fluid flowing through an embedded tube. Each segment is represented by a two-dimensional solid model with top boundary conditions determined using a traditional flat plate solar collector model for convection and radiation from the collector cover plate.
\end{abstract}

The precast collector is coupled to a series solar assisted heat pump system and used to meet the heating needs of the residence. The performance of the proposed system is compared to the performance of a typical air to air heat pump. The combined collector and heat pump model is solved using Matlab in conjunction with the finite element solver, Femlab.

Using the system model, various non-dimensional design and operating parameters were analyzed to determine a set of near optimal design and operating values. The annual performance of the near optimal system was evaluated to determine the energy and cost savings for applications in Atlanta, GA and Chicago, IL. In addition, a life cycle cost study of the system was completed to determine the economic feasibility of the proposed system. The results of the annual study show that capturing solar energy using the precast collector and applying the energy through a solar assisted heat pump can reduce the electricity required for heating by more than $50 \%$ in regions with long heating seasons. The life cycle cost analysis shows that the energy savings justifies the increase in initial cost in locations with long heating seasons but that the system is not economically attractive in locations with shorter heating seasons. 


\section{Acknowledgements}

Over the past 2 years, I have had lots of encouragement, words of wisdom, and gracious contributions from many people that made this research possible. First, I would like to thank my primary advisor, Dr. Michael Ellis. Thanks for all your guidance and support over the past 2 years. Those working vacation days are greatly appreciated. I would also like to thank my thesis committee members, Dr. Doug Nelson and Dr. Ivan Beliveau. I would also like to thank fellow graduate student Ian Doebber for his work with Energy Plus that contributed to inputs for my energy system model.

Thanks to fellow graduate students, Nathan Siegel, Ian Doebber, and Josh Sole for making the lab a fun and interesting place to come to work everyday. At least I could always leave with a good story! Finally, I'd like to thank Kenneth Armstrong for everything over the past 5 years. I definitely could not have finished the long road without you helping me along every step of the way. 


\section{Dedication}

To Kenneth for all the words of encouragement, smiles along the way, late nights, and positive reinforcement. 


\section{Table of Contents}

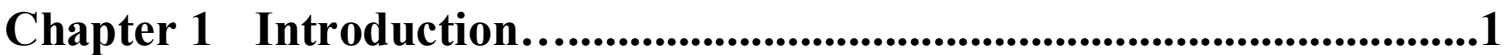

1.1 Multi-functional Precast Panels

1.2 Solar Thermal Collectors

1.3 Research Objectives

Chapter 2 Literature Review..........................................6

2.1 Concrete Solar Thermal Collectors

Experimental Investigations

Analytical Models

Summary of Concrete Collectors

2.2 Solar Assisted Heat Pump Systems

2.3 Relation of Current Research or Prior Research

Chapter 3 Modeling Apprach...........................................20

3.1 Precast Collector

Governing Equations for Precast Collector

3-Dimensional, Transient Energy Equation

1-Dimensional Fluid Equation

Segmented Model

Overall Loss Coefficient from the Concrete Collector to the Ambient

3.2 Energy System Analysis

Energy System Configuration

Storage Tank Model

Heat Pump Model

Circulating Pump Models

3.3 Residential Energy Requirements

Domestic Hot Water

Domestic Hot Water Usage Profiles

Domestic Hot Water Energy Usage

Space Heating

3.4 Weather Data

3.5 Solution Approach

Program Structure

Initial Condition

\section{Chapter 4 Validation of Modeling and}

Sizing of System Parameters.

4.1 Precast Solar Collector Validation

Timestep Analysis

Down the Channel Partition Analysis

4.2 Base Case Parameters and Heat Pump Characteristics

Heat Pump Sizing

Tank Sizing

4.3 Evaluation of System Performance

4.4 Parametric Studies 
Number of Pipes

Collector Thickness

Collector Length

Collector Pipe Diameter

Number of Transfer Units

4.5 Optimal Parameters

Chapter 5 Annual Energy and Cost Analysis............................71

5.1 System Description

5.2 System Operation Strategy

5.3 Results from Annual Analysis

Temperature Distribution in Precast Collector

Temperature of Water Leaving Collector

Precast Solar Efficiency

Solar Assisted Heat Pump Performance

5.4 Economic Analysis

Chapter 6 Conclusions and Recommendations........................88

6.1 Conclusions from Model

6.2 Future Recommendations

6.3 Closing Remarks

References..............................................................91

Appendix............................................................93 


\section{List of Figures}

Figure $1 \mathrm{a}$ and $1 \mathrm{~b}$

Figure 2

Figure 3

Figure 4

Figure 5

Figure 6

Figure 7

Figure 8

Figure 9

Figure 10

Figure 11

Figure 12

Figure 13

Figure 14

Figure 15

Figure 16

Figure 17

Figure 18

Figure 19

Figure 20

Figure 21

Figure 22

Figure 23

Figure 24

Figure 25

Figure 26

Figure 27

Figure 28

Figure 29
Multi-function Precast Panel 3

Traditional Solar Thermal Collector

Typical Concrete Solar Collector

Parallel, Series, and Dual-Source

Solar Heat Pump Systems

15

Location of Precast Collectors

Diagram of Precast Collector Showing

Symmetry Condition

22

Boundary Conditions of Solid Model 24

Segmented Model 26

Overall Losses from the Top Plate of the Collector 29

Resistance Diagram of Heat Flow from the Surface

of the Concrete Collector to the Ambient

29

Energy System for the House

33

Heat Capacity as a Function of Incoming Fluid

Temperature

36

Work Input as a Function of Incoming Fluid

Temperature

36

Fraction of Domestic Hot Water Used by the Hour for a Typical U.S. Family

Average Daily Hot Water Usage for a "Typical" U.S.

Family varying with Month

41

Monthly Space Heating Loads for Chicago, IL and Atlanta, GA

Monthly Total Heating Energy for Chicago, IL and Atlanta, GA

U.S. Climates

Coding Diagram for Forward Movement in

Time and Length

48

Flowchart for the Matlab Program $\quad 50$

Solid Model Timestep - Flowing Fluid 53

Segment Timestep Error - Flowing Fluid 54

Stability and Error Associated with Segment Timestep

Stagnant Fluid

55

Effect of the Number of Segments on the Estimate

Of the Daily Energy Gain

56

Rate of Net Heat Gained by the Fluid and Incident

Radiation throughout the Day for the Base Case.

58

Collector Efficiency in Atlanta, GA in Jan.

59

Work Input Needed for Heat Pump System in

January (Base Case Design)

60

Ratio of Heat Extracted to Heat Gained versus

Number of Tubes

62 
Figure 30

Figure 31

Figure 32

Figure 33

Figure 34

Figure 35

Figure 36

Figure 37a

Figure $37 b$

Figure 37c

Figure 38a

Figure $38 b$

Figure 38c

Figure 39

Figure 40

Figure 41

Figure 42

Figure 43

Figure 44
Performance

63

Effect of Dimensionless Length on system Performance

Effect of Dimensionless Pipe Size on System

Performance

65

Effect of the Number of Transfer Unites on System

Performance

67

Effect of the Fourier Number on System Performance $\quad 68$

Effect of the Width on System Performance

69

Total Heating Load for a Typical Day in Atlanta, GA

During Each Month of the Year

Total Heating Load for a Typical Day in Chicago, IL

During Each Month of the Year

Temperature Distribution in the Initial Segment of the

Precast Solar Collector for Hour 10 in January

76

Temperature Distribution in the Middle Segment of the

Precast Solar Collector for the Hour 10 in January

Temperature Distribution in the Final Segment of the

Precast Solar Collector for the Hour 10 in January

Temperature Distribution in the $8^{\text {th }}$ Segment of the

Precast Solar Collector in January at the Beginning of

Hour 12

Temperature Distribution in the $8^{\text {th }}$ Segment of the

Precast Solar Collector in January at the Middle of

Hour 12

Temperature Distribution in the $8^{\text {th }}$ Segment of the

Precast Solar Collector in January at the End of

Hour 12

Temperature of the Fluid Leaving the Precast

Solar Collector

80

Heat Gain in the Fluid and Incident Radiation

throughout the Day

81

Collector Efficiency in Atlanta and Chicago

82

Annual Heating Performance in Atlanta, GA

83

Annual Heating Performance in Chicago, IL

Annual Required Work Comparison
84

85 


\section{List of Tables}

Table 1

Table 2

Table 3

Table 4

Table 5

Table 6

Table 7

Table 8

Table 9

Table 10
Preliminary Dimensions of Precast Panel

Assumptions for Model

Hourly Domestic Water Heating Profiles for a "Typical" U.S. Family in Gallons/day 42 Average Monthly Ground Temperature in ${ }^{\circ} \mathrm{C}$

Typical House Characteristics by Location Heat Pump Sizing and Maximum Loads 57 Parameters for Parametric Study 61 Optimal Dimensions for Concrete Collect Initial Fluid Temperature, K, for Atlanta, GA and Chicago, IL 72

Initial cost of Prototypical Energy System 


\section{Nomenclature}

\begin{tabular}{|c|c|}
\hline $\mathrm{A}_{\mathrm{C}}$ & Cross Sectional Area of Concrete Solar Collector, $\mathrm{m}^{2}$ \\
\hline $\mathrm{A}_{\mathrm{S}}$ & Surface Area of Concrete Solar Collector, $\mathrm{m}^{2}$ \\
\hline $\mathrm{C}_{\mathrm{A}}$ & Specific Heat of Air, J/kgK \\
\hline $\mathrm{C}_{\mathrm{C}}$ & Specific Heat of Concrete, $\mathrm{J} / \mathrm{kgK}$ \\
\hline $\mathrm{C}_{\mathrm{f}}$ & Specific Heat of Working Fluid, J/kgK \\
\hline $\mathrm{D}$ & Diameter of the Pipe, $m$ \\
\hline $\mathrm{h}_{\mathrm{C}, \mathrm{A}}$ & $\begin{array}{l}\text { Convective Heat Transfer Coefficient from the Cover Glass to the } \\
\text { Ambient, } \mathrm{W} / \mathrm{m}^{2} \mathrm{~K}\end{array}$ \\
\hline $\mathrm{h}_{\mathrm{C}, \mathrm{P}}$ & $\begin{array}{l}\text { Convective Heat Transfer Coefficient from the Concrete Collector Plate to } \\
\text { the Cover Glass, } \mathrm{W} / \mathrm{m}^{2} \mathrm{~K}\end{array}$ \\
\hline $\mathrm{h}_{\mathrm{R}, \mathrm{A}}$ & $\begin{array}{l}\text { Radiative Heat Transfer Coefficient from the Cover Glass to the Ambient, } \\
\mathrm{W} / \mathrm{m}^{2} \mathrm{~K}\end{array}$ \\
\hline$h_{R, P}$ & $\begin{array}{l}\text { Radiative Heat Transfer Coefficient from the Concrete Collector Plate to } t \\
\text { he Cover Glass, } W / \mathrm{m}^{2} \mathrm{~K}\end{array}$ \\
\hline$h_{f}$ & Heat Transfer Coefficient of the Fluid, W/mK \\
\hline $\mathrm{h}_{\mathrm{f}, \mathrm{p}}$ & Lumped Heat Transfer Coefficient of the Fluid and Pipe, W/mK \\
\hline $\mathrm{I}$ & Solar Insolation, $\mathrm{W} / \mathrm{m}^{2}$ \\
\hline $\mathrm{k}_{\mathrm{A}}$ & Thermal Conductivity of Air W/mK \\
\hline $\mathrm{k}_{\mathrm{C}}$ & Thermal Conductivity of the Concrete, $\mathrm{W} / \mathrm{mK}$ \\
\hline $\mathrm{k}_{\mathrm{f}}$ & Thermal Conductivity of the Working Fluid, W/mK \\
\hline $\mathrm{L}$ & Spacing Between Concrete Collector Plate and Glass Cover, $\mathrm{m}$ \\
\hline $\mathrm{L}_{\mathrm{P}}$ & Segment Length, $\mathrm{m}$ \\
\hline $\mathrm{Nu}$ & Nusselt Number \\
\hline $\operatorname{Pr}$ & Prantl Number \\
\hline $\mathrm{r}$ & Radius of the Pipe, $\mathrm{m}$ \\
\hline $\mathrm{Ra}$ & Rayleigh Number \\
\hline $\mathrm{T}_{\mathrm{a}}$ & Ambient Air Temperature, $\mathrm{K}$ \\
\hline $\mathrm{T}_{\mathrm{C}}$ & Cover Glass Temperature, $\mathrm{K}$ \\
\hline $\mathrm{T}_{\mathrm{f}}$ & Fluid Temperature, $\mathrm{K}$ \\
\hline $\mathrm{T}_{\mathrm{M}}$ & Average Air Temperature, $\mathrm{K}$ \\
\hline $\mathrm{T}_{\mathrm{S}}$ & Solid Temperature, $\mathrm{K}$ \\
\hline $\mathrm{T}_{\mathrm{SB}}$ & Average Solid Inner Boundary Temperature, $\mathrm{K}$ \\
\hline $\mathrm{T}_{\text {Sky }}$ & Sky Temperature, $\mathrm{K}$ \\
\hline $\mathrm{T}_{\mathrm{T}}$ & Tank Temperature, $\mathrm{K}$ \\
\hline $\mathrm{T}_{\mathrm{TP}}$ & Concrete Collector Plate Temperature, $\mathrm{K}$ \\
\hline $\mathrm{T}_{\mathrm{W} \_\mathrm{In}}$ & Fluid Temperature Entering Evaporator, $\mathrm{K}$ \\
\hline $\mathrm{U}_{\mathrm{L}}$ & Overall Loss Coefficient off the Top of the Collector, $\mathrm{W} / \mathrm{m}^{2} \mathrm{~K}$ \\
\hline $\mathrm{V}$ & Volume of Concrete Solar Collector, $\mathrm{m}^{3}$ \\
\hline$V_{f}$ & Velocity of the Fluid, $\mathrm{m} / \mathrm{s}$ \\
\hline $\mathrm{V}_{\mathrm{w}}$ & Average Wind Speed, $\mathrm{m} / \mathrm{s}$ \\
\hline$\alpha$ & Thermal Diffusivity, $\mathrm{m}^{2} / \mathrm{s}$ \\
\hline$\varepsilon_{\mathrm{C}}$ & Emissivity of the Glass Cover \\
\hline$\varepsilon_{\mathrm{P}}$ & Emissivity of the Concrete Collector Plate \\
\hline$\lambda_{\mathrm{f}}$ & Friction Factor \\
\hline
\end{tabular}


$\mu_{\mathrm{f}}$

$v_{\mathrm{A}}$

$\rho_{\mathrm{A}}$

$\rho_{\mathrm{c}}$

$\rho_{\mathrm{f}}$

$\sigma$

Absolute Viscosity of Fluid, Pa s

Kinematic Viscosity, $\mathrm{m}^{2} / \mathrm{s}$

Density of Air, $\mathrm{kg} / \mathrm{m}^{3}$

Density of Concrete, $\mathrm{kg} / \mathrm{m}^{3}$

Density of Working Fluid, $\mathrm{kg} / \mathrm{m}^{3}$

Stefan-Boltzmann Constant, $\mathrm{J} / \mathrm{K}^{4} \mathrm{~m}^{2} \mathrm{~s}$ 


\section{Chapter 1: Introduction}

Housing accounts for approximately 55 to 60 percent of annual construction spending. As the housing market expands, increases in the amount of resources used to build and maintain these residences increases. Over the next 40 years, traditional energy resources are expected to dwindle appreciably. Traditional energy sources such as fossil fuels also contribute to the greenhouse effect and, hence, global warming, which is thought to be caused by carbon dioxide, chlorofluorocarbons (CFC's), and sulfur dioxide emissions. As environmental consciousness grows, further investigation into alternative ways to meet the energy needs for constructing and operating housing is inevitable.

Over the past twenty years, the housing industry in conjunction with the Department of Energy has worked to find new ways to reduce the energy and material use for residential buildings. One way to reduce the amount of materials used in construction is through the construction of multi-functional precast panels. Multi-functional precast panels enable a whole house concept for the design and construction of residential buildings. These panels are pre-manufactured at the factory and can contain the structure, finishes, insulation and energy systems needed for the building. Multi-functional precast panels also offer opportunities for collecting energy from the building envelope to help meet the need for space and water heating.

Multi-functional precast roof panels can be used to collect solar energy to meet space and domestic water heating needs, which constitute two of the largest energy consumers in residential buildings. Space heating is conventionally provided by a furnace or a heat pump system depending on climate. Water heating is typically provided by an electric or gas water heater. If multi-functional precast panels can be coupled with a more traditional energy system to meet the space and water heating load of the residence, then the electricity consumption of the residence can be reduced. 
The impact of reducing residential heating requirements can be very important. For example, hot water is the second largest energy consumer in American households nationwide. It is estimated that a family of four will expend approximately 150 million BTU of energy costing as much as $\$ 3,600$ dollars (at a rate of 8 cents per $\mathrm{kWh}$ ) over the seven-year life span of an electric water heater [1]. A variety of solar heating products have been developed to help meet residential heating needs. For example, a conventional solar water heater can be used as a pre-heater to an instantaneous or conventional water heater or as a stand-alone heater when no backup is required. This helps meet part of the energy requirements of the house by taking advantage of "free", renewable energy. Acceptance of these systems has been limited by maintenance requirements, cost, and poor integration with the overall building design.

Incorporation of a solar collector system within a precast roofing panel can help to reduce system cost and improve integration. The following sections provide a more detailed description of multi-functional precast panels and solar thermal collectors. In the following chapters, these concepts are combined by designing and evaluating a precast panel with energy collection integrated into the construction.

\subsection{Multi-functional Precast Panels}

Multi-functional precast panels provide structure, finished surfaces, weatherproofing, insulation and the energy collection. They promote a whole house concept to homebuilding, which requires that the house be viewed as a single system that provides a set of functions including space conditioning, structure, and weather proofing. A typical precast panel without an energy collection device is shown in Figure 1. Figure 1a illustrates the overall concept. Figure $1 \mathrm{~b}$ illustrates a specific implementation of the concept in a product called T-mass, which was developed by DOW Chemical Company. The T-mass system consists of an insulated precast sandwich panel with interstitial insulation and plastic ties connecting the inner and outer layers. 

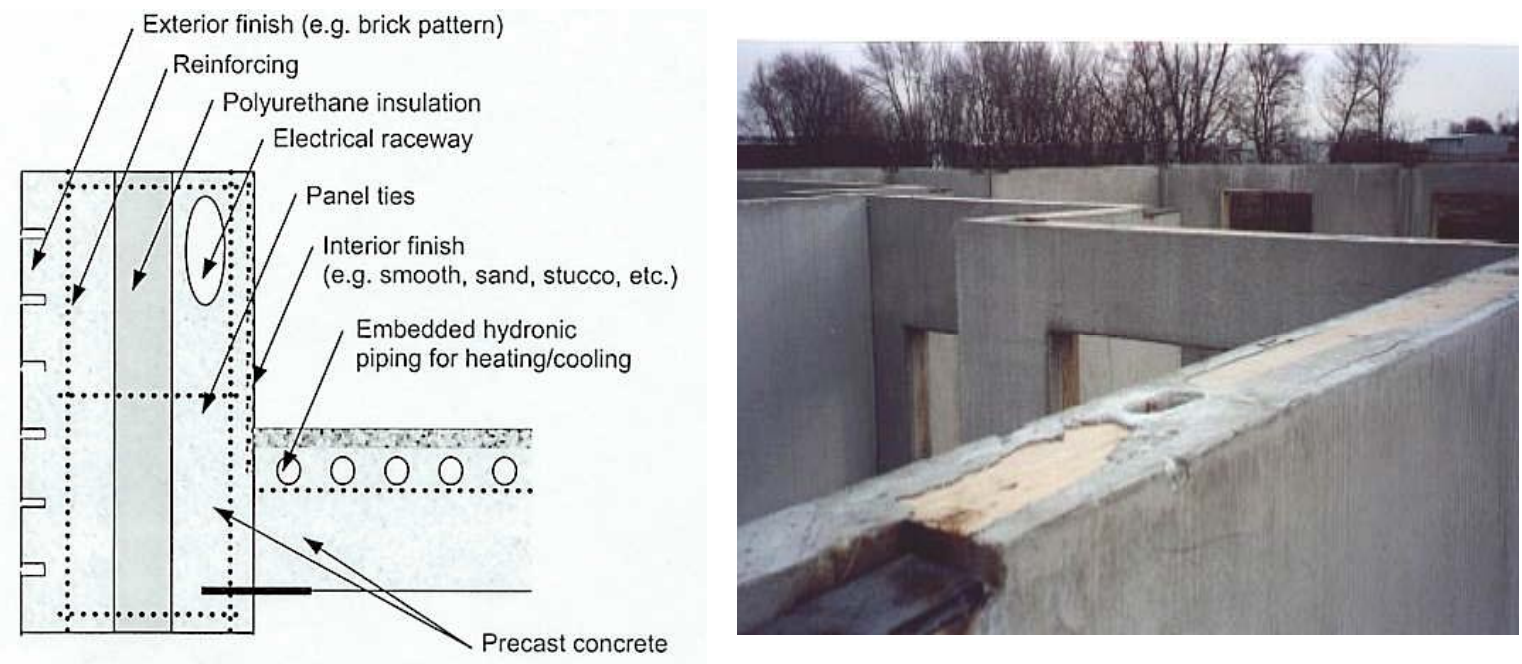

Figure 1a and 1b: Multi-functional Precast Panel

Reference: Research Proposal Document [2] and http://www.t-mass.com/ [3]

Precast concrete used in housing construction is a natural fire retardant and is resistant to decay, insect damage, and water damage. Precast panels can be constructed at the factory to include all of the layers of traditional construction. This helps in reducing the amount of waste inherent in on-site construction. In contrast with more traditional types of building construction, precast panels offer an increased efficiency and reliability because they are constructed in a more controlled environment [4].

Although it is evident that they offer many advantages over traditional construction practices, there are several reasons that multi-functional precast assemblies are not commonly used in practice today. First and foremost, there is not a large knowledge base for this type of construction. The construction industry relies heavily on experience to guide design and construction practices, and the industry is reluctant to adopt new technologies which have not been widely demonstrated. In addition, the infrastructure at the factory level is not present for large scale production [2]. Furthermore, since it is a relatively new idea to the housing industry, the long term economic benefits associated with reduced operating costs have not been established. 


\subsection{Solar Thermal Collectors}

Solar water heaters capture the sun's energy and store it as thermal energy that can then be supplied to a residence. Most traditional solar water heaters are comprised of copper tubes enclosed in a casing with a glass cover to reduce both the radiative and convective losses from the top of the collector. To maximize the amount of solar radiation absorbed, a selective surface is used as a coating on the outside of the tubes. Figure 2 illustrates a typical solar water heater used for residential energy collection.

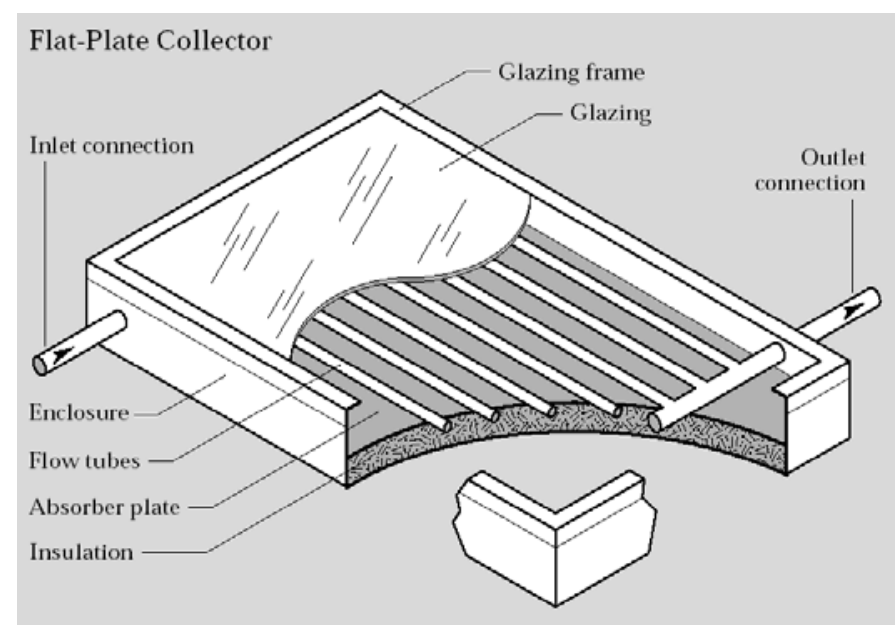

Figure 2: Traditional Solar Thermal Collector

Source: http://www.eere.energy.gov/erec/factsheets/solrwatr.pdf [5]

Part of the incident radiation passes through the glazing and becomes either absorbed or reflected off the absorber plate. The absorbed energy is conducted through the absorber plate to the water in the flow tubes. The flowing water transports energy to a storage tank or to an end use.

Currently solar water heating alone is not, in most cases, a cost effective solution to meet the heating needs of a residence. However, this technology can work well in supplementing conventional domestic hot water and space heating systems. Consequently, solar heating can help to reduce the use of more traditional energy resources. Unfortunately, solar thermal collectors have often been implemented as an afterthought and thus not well integrated with the overall house construction. This has 
led to higher expense, poor reliability, and failures at the interfaces between the collector and the other housing elements.

\subsection{Research Objectives}

The goal of this research is to determine whether solar collectors embedded within precast roof panels can be used economically to help meet residential heating requirements. To address this research question, a multi-functional precast panel with an embedded solar energy collection device will be investigated. This type of panel will not only serve as the roofing structure for the residence, but will also capture thermal energy from the sun. The heated water exiting the precast panels can then be supplied to a storage tank. This tank can then supply energy to a heat pump system to meet the hourly space and water heating loads of the residence.

A systematic approach was taken to analyze the proposed system. The detailed objectives of the research are to:

(1) Develop a 3-dimensional, transient computational model to predict the annual performance of a precast concrete solar collector for a residence.

(2) Couple the collector model with a heat pump system model.

(3) Conduct a parametric study to determine design and operational parameters for the precast concrete water heater that lead to efficient operation of the overall collector/heat pump system.

(4) Compare the energy and economic characteristics of the precast collector working in conjunction with a heat pump to the energy and economic characteristics of conventional energy systems. 


\section{Chapter 2: Literature Review}

A survey of the literature was conducted to identify prior research on concrete solar thermal collectors as well as solar assisted heat pump systems. Two succeeding sections are presented, which include a concrete collector section and a solar assisted heat pump section. The literature review failed to identify any references that examined the concept of using low grade thermal energy from a concrete collector in conjunction with a solar assisted heat pump to meet residential heating requirements.

Research advances in solar energy were sparked in the 1970's because of the oil embargo, but have tapered off since energy prices stabilized. Traditional solar collectors were invented as a special kind of heat exchanger that transfers solar radiant energy into thermal energy. A large body of information exists concerning solar collectors. One of the best summaries of solar collector research is Solar Engineering by Duffie and Beckman originally published in the 1970s [6]. This book explains the fundamentals of solar engineering and gives an overview of the advances and in research and technology for solar collectors over the past 30 years. Another useful source for information is the 1999 ASHRAE Applications Handbook Chapter 32 on Solar Energy Use [7]. This chapter provides an overview of solar energy basics.

One type of collector found in the literature was an integral collector storage, ICS, system. These types of solar collectors are passive devices that combine some type of tank usually liquid mass for collection with an energy-absorbing surface. The design of these systems varies greatly depending on the type of storage and amount of storage needed. These types of collectors are usually used on a partial time basis, in which the water that has been heated throughout the day is flushed from the system when there is insufficient incident radiation. This helps to overcome the convective and radiative losses during the evening. The precast solar collector behaves like an ICS collector, but uses the concrete as both the means for thermal storage and structural support. 
The greatest difference between concrete collectors and traditional solar collectors that use copper tubing is the high thermal capacitance and relatively low conductivity of the concrete collector. These characteristics lead to a longer warm-up period and lower water temperature. On the other hand, the concrete collector can continue to warm the circulating fluid even after the incident radiation has declined. Because of the unique characteristics of concrete solar collectors arising from their high thermal capacitance, the literature review will focus on research related to concrete collectors.

\subsection{Concrete Solar Thermal Collectors}

Solar thermal collectors that are integrated into the building envelope have not been widely described in the literature. There have only been a few published reports of concrete solar collectors that can be integrated into a building's structure to meet the building's heating needs. As described in the literature, concrete solar collectors are composed of several main components, but vary widely in their structural arrangements. A typical concrete solar collector is exhibited in Figure 3.

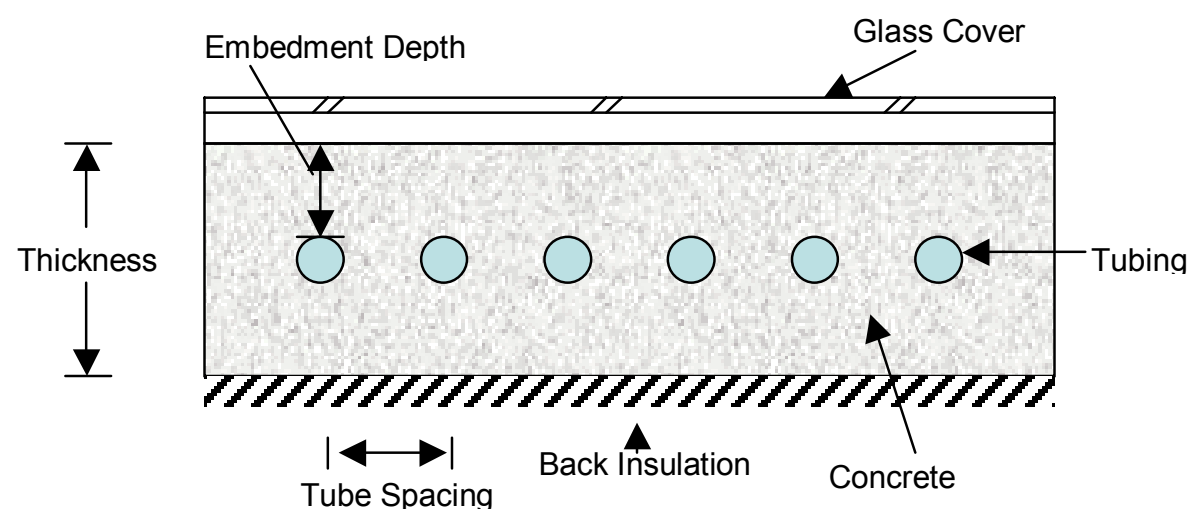

Figure 3: Typical Concrete Solar Collector

The collectors surveyed in the literature used a variety of piping, concrete, surface texturing, and coverings to improve solar gains. In addition, the dimensions of the concrete collector varied widely in terms of spacing between tubes, concrete thickness, and pipe diameter. 


\section{Experimental Investigations}

The concrete collectors reported in the literature exhibited differences in the collector dimensions, tubing type, tube embedment, collector cover, and collector insulation. The thickness of the concrete slabs ranged from $.035 \mathrm{~m}$ to $0.1 \mathrm{~m}$. Thicker slabs of concrete allow for greater thermal storage, while serving as the existing building structure. Three types of concrete were found to be used in the literature; regular cement concrete, concrete with embedded galvanized steel mesh, as well as glass reinforced concrete. Researchers have considered the effects of tube spacing within the concrete. Bopshetty, Nayak, and Sukhatme [8] performed a parametric study in which tube spacing was varied from 0.06 to $0.15 \mathrm{~m}$. The authors noted that an increase in the concrete between the tubes causes an increase in the thermal storage that is available. However, the increase in concrete also causes an increase in thermal resistance between the incident radiation and the tube, thus creating a longer conduction path for the thermal energy has to conduct through to reach the fluid. The experimental set up by Bilgen and Richard [9] used tubes that were spaced $0.06 \mathrm{~m}$ from one another. These authors concluded that a smaller spacing would promote a more equal distribution of heat throughout the entire concrete surface as the water flows through the network of piping.

The tubing type used in concrete collector systems can be metal or plastic piping. As in traditional solar collectors, copper piping has been used in several designs as well as cheaper aluminum piping. Traditionally, metal pipes were used because of their high conductivity; however, metals tend to be an expensive part of the system especially if they are copper. Aluminum tubes were used in an experimental design set up by Chaurasia [10]. To reduce the cost Bopshetty, Nayak, and Sukhatme [8]used PVC piping cast into the system instead of metal piping. The Bopshetty, Nayak, and Sukhatme design uses a $20 \mathrm{~mm}$ outer diameter PVC pipe with a $17 \mathrm{~mm}$ inner diameter. The main disadvantage of using PVC piping is the increased resistance to heat flow resulting from a less conductive material as well as a thicker tube wall. They accounted for the difference in outer and inner diameter by using a lumped heat transfer coefficient from the concrete to the water. 
There are a variety of designs in the literature for embedding the pipes in the concrete. One experimental design described by Chaurasia partially exposed the metal pipes to the surface and covers the remaining section within the concrete [10]. This allows direct solar gain to the metal pipe, while also utilizing the thermal storage of the concrete. Conversely, during evening hours this design increases the losses from the top surface of the collector due to the highly conductive pipe in direct contact with the cooler air. The study conducted by Chaurasia used pipes that were seventy percent covered by concrete leaving the remaining thirty percent exposed. The author concluded that this type of system with no covering would have to be selectively used during the daytime hours to overcome great losses seen in the evening hours. If the pipes are completely embedded in the concrete, there will be a delay before the night cooling begins and the effects are felt by the water. In the experimental apparatus developed by Bopshetty, Nayak, and Sukhatme, the pipes were embedded completely within thin slabs of concrete [8].

The collector cover and surface treatment are also important collector design considerations. Many of the traditional collectors have a black surface to emulate a blackbody absorber. This aids the collector in absorbing incident solar radiation. Bopshetty, Nayak, and Sukhatme and Chaurasia used blackboard paint to cover the top surface of the collector. Chaurasia found that when blackboard paint was used as an exterior treatment for the top surface of the concrete, the temperatures were found to increase an average of 3 to $5^{\circ} \mathrm{C}[10]$.

Glass coverings are sometimes used to reduce the losses experienced by concrete collectors during the night and cool seasons. Single panes of window quality glass were used for several designs by Bopshetty, Nayak, and Sukhatme [8] and Jubran, Al-Saad, and Abu-Faris [11]. The air gap between the collector top plate and the glass ranged from $0.004 \mathrm{~m}$ to $0.04 \mathrm{~m}$. One study noticed that the air gap tended to cause slight thermal stratification because the hot air plumes began to rise. Furthermore, if the air gap was large enough, it could actually enhance the convective losses. This is also noted by Duffie and Beckman in their discussion of flat plate collectors. They concluded that for 
very small plate spacing, convection is suppressed and the heat transfer through the gap is by conduction and radiation [6]. However, once air movement is enhanced by thermal stratification, the heat loss from the top of the collector is increased until a maximum is reached at $20 \mathrm{~mm}$. Increasing the plate spacing further will not significantly enhance the losses.

Finally, in completing the collector design some type of collector insulation is installed to reduce losses from the back of the collector. If the collector is going to serve as part of the building structure, it is important to trap as much heat in the collector as possible to minimize summer heat gain through the roof. Chaurasia used slabs of cellular concrete that are light in weight and have very low conductivity called Siporex to insulate the back surface of their collector [10]. The Chaurasia study used no back insulation as a worse case scenario, and showed that the heat transfer to the water increased as the thickness of the Siporex was increased. Rock wool insulation was used by Jubran, Al-Saad, and AbuFaris [11] with a $.05 \mathrm{~m}$ thickness and a thermal conductivity of $0.036 \mathrm{~W} / \mathrm{mC}$.

Other topics addressed by the experimental literature include the proper collector angle and the anticipated life of the collector. Solar collectors, including both concrete and traditional, will increase in performance if angled toward the sun. Chaurasia found that an angle approximately equal to latitude maximized the temperatures reached by the water in the collector [10]. This is also concluded by Duffie and Beckman [6] and is an accepted rule of thumb unless more rigorous studies are conducted. The anticipated life was explored by Chaurasia who exposed his experimental apparatus to the elements for a period of five years with no sign of degradation to the concrete collector itself.

\section{Analytical Models}

Analytical models of concrete collectors facilitate parametric studies to determine the influence of design parameters on collector performance. Each parameter can be studied in great detail without the expense of modifying an experimental apparatus. This helps to determine the optimal characteristics of a concrete collector prior to actual construction. 
Several analytical models were presented in the literature that characterized concrete collectors and their performance under varying solar conditions.

Bopshetty, Nayak, and Sukhatme [8] present a two-dimensional (radial and axial) transient model of a concrete collector. The authors assume that conduction in the down the pipe direction is of an order of magnitude less than that in the other two directions and neglected it in their evaluation. The initial condition was set to the ambient temperature. The collector was made of concrete containing reinforcing steel mesh with embedded PVC piping. The top was painted with blackboard paint and covered with glass leaving only an air gap of $0.04 \mathrm{~m}$. They accounted for the conductive resistance of the PVC tube wall in their analysis. A finite element model with symmetry conditions was used to analyze the temperature distribution of the collector. To model the insolation, they took linear interpolated values for every 10 minutes of weather data and assumed them constant over their analysis. They also validated their model with experimental data. The results demonstrated that the collector's daily efficiency decreased linearly with an increase in the fluid temperature. The authors also showed that raising the temperature of the water coming into the collector increases the convective and radiative losses, thus the useful energy gained by the system is decreased. Increasing the flow rate of the water through the collector helps decrease the losses of the system; however, it also decreases the overall outlet fluid temperature.

A transient model for glass reinforced concrete was derived by Reshef and Sokolov [12] for a one dimensional circular cross-section of the solar concrete collector. This model assumed the collector is wide enough so that the end effects may be neglected. Since the temperature gradients in the direction of the flowing water are much smaller than those perpendicular to the flow, they were neglected. The physical properties of the system were assumed to be constant over the given temperature range. The heat transfer coefficient between the pipe and the concrete was chosen to represent both the pipe wall resistance and the contact resistance between the pipe wall and the concrete. The explicit finite difference method was used to solve for the temperature distribution in the radial direction. The solution was assumed constant in the down the pipe direction. It could 
then be superimposed along the down the pipe axis creating a two-dimensional slice of the collector.

Bilgen and Richard derived a two-dimensional transient model to simulate the response of a solid concrete slab to a heat flux that could represent incident solar radiation. All sides of the solid slab except the surface exposed to the heat flux were assumed to be insulated [9]. The heat flux was varied on the top surface and a finite element model was used to predict the temperature distribution. The modeling done by Bilgen and Richard showed that over fifty percent of the incident heat flux was absorbed during the first three hours that the concrete slab was exposed to the radiative flux. Over the next nine hours, the amount of heat absorbed by the concrete began to decline until a quasi-steady state condition was reached after twelve hours. Once the heat flux was turned off, the losses off the top surface continued until the temperature of the solid reached the temperature of the ambient conditions. Although this model did not address the effects of having embedded tubes and flowing water, it did demonstrate the effects of the radiative and convective losses from the top of the system.

\section{Summary of Concrete Collectors}

Concrete collectors have been studied both experimentally and analytically. Experimental models have used a variety of features to improve performance including covers, surface treatment, and various approaches for embedding the tubes within the concrete. Analytical models have been developed using 1-dimensional and 2dimensional transient analyses. Since there are clearly 2-dimensional distributions in the plane perpendicular to the tube and changes in the down the tube direction, a 3dimensional or pseudo-3-dimensional model is needed. The development of a 3dimensional transient analytical model and the application of the model to improve collector design would make a significant contribution to the current literature. 


\subsection{Solar Assisted Heat Pump Systems}

Heat pumps use electrical energy to transfer thermal energy from a source at a lower temperature to a sink at a higher temperature. Several advantages of an electrically driven heat pump are a coefficient of performance, COP, greater than one for heating and the ability to be used as an air conditioner by running a reverse cycle in the summer months. A solar assisted heat pump takes water preheated by the sun and uses it to raise the evaporator temperature of the heat pump, thus increasing the COP of the heat pump and using less work to meet the heating load of the house. Solar assisted heat pumps can help to boost low grade thermal energy from a concrete collector to temperature that are useful for meeting residential heating requirements. A literature survey was conducted to identify the types of solar assisted heat pump systems that have been proposed.

Traditional heat pump systems use ambient air as the main heat source. The working fluid, usually some type of refrigerant, receives energy from the environment through the evaporator heat exchanger [13]. The refrigerant vapor is then compressed to a high pressure and heat is transferred to water or air at the condenser. The pressure of the condensed refrigerant is reduced by passing through an expansion valve back to the evaporator pressure completing the cycle. An air source heat pump uses outdoor air as the source of heat for the evaporator. The major disadvantage of an air source heat pump is the wide fluctuation in the outdoor temperature. The air is the coldest when heating is desired. Another disadvantage of an air source heat pump is the energy required by the fan that blows air across the evaporator. On the other hand, ground source heat pumps use the soil as the heat transfer media instead of ambient air. The advantage of using a ground source heat pump is the relatively steady nature of the ground temperature [14]. This helps to raise the COP of the system during heating and cooling.

A solar assisted heat pump, SAHP, system where a heat pump system is combined with a solar collector offers several advantages over traditional solar based heating systems. One of the main problems with stand alone solar energy systems is the inability to satisfy all the heating needs of the building due to collector area limitations. A collector large 
enough to meet all of the homes heating requirements would be very uneconomical for those areas that do not have ideal solar conditions. However with a SAHP, the energy collected by the solar collector that is not warm enough to use directly to meet the heating needs of the house can be used as the source for the heat pump and increase the thermal performance of the system. By incorporating a solar collector into the energy system of the house, the heat pump lift will be reduced, thus less power will be used for heating.

Solar assisted heat pump systems can be configured three different ways; in parallel, in series, and in a dual-source configuration. The parallel solar assisted heat pump configuration combines an air source heat pump with a traditional solar energy system. The heat pump serves as an independent auxiliary source of heat for the residence. When the energy collected by the solar energy system is not sufficient to meet the load of the house, the heat pump system is used instead. In contrast, a series solar assisted heat ритр uses the energy collected from the solar energy system and supplies it directly to the heat pump evaporator. The water can bypass the heat pump if the temperature of the water coming out of the solar collector is hot enough to directly meet the needs of the house. Both the solar energy system and the heat pump are used in conjunction with one another to meet the load of the house at all times in a series configuration [6]. A dualsource heat pump takes energy from either a solar heated collector or from another source, usually ambient air, and supplies it to the evaporator. The controls of the system can be arranged so that the source leading to the heat pump can provide the best COP for the system. 


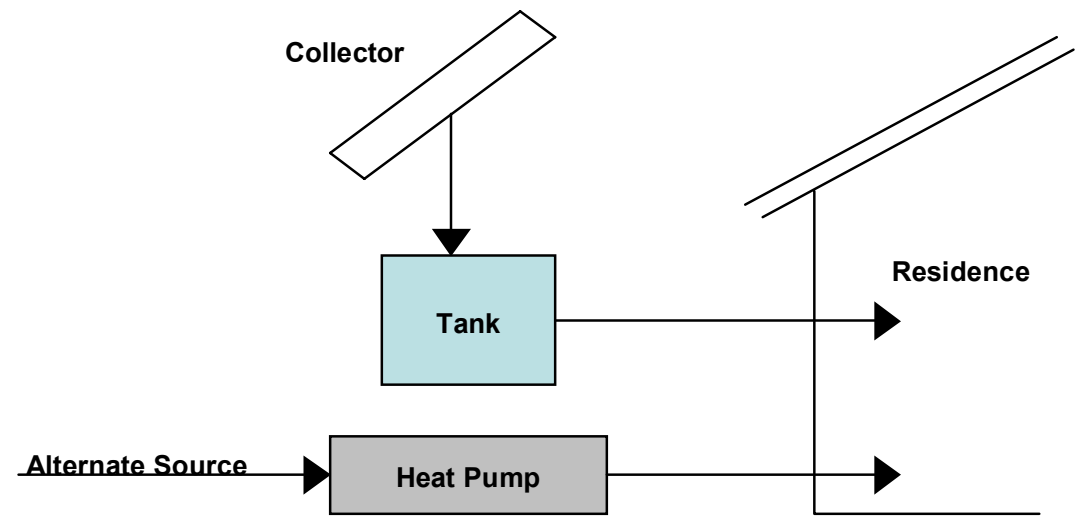

(A) Parallel Solar Heat Pump System

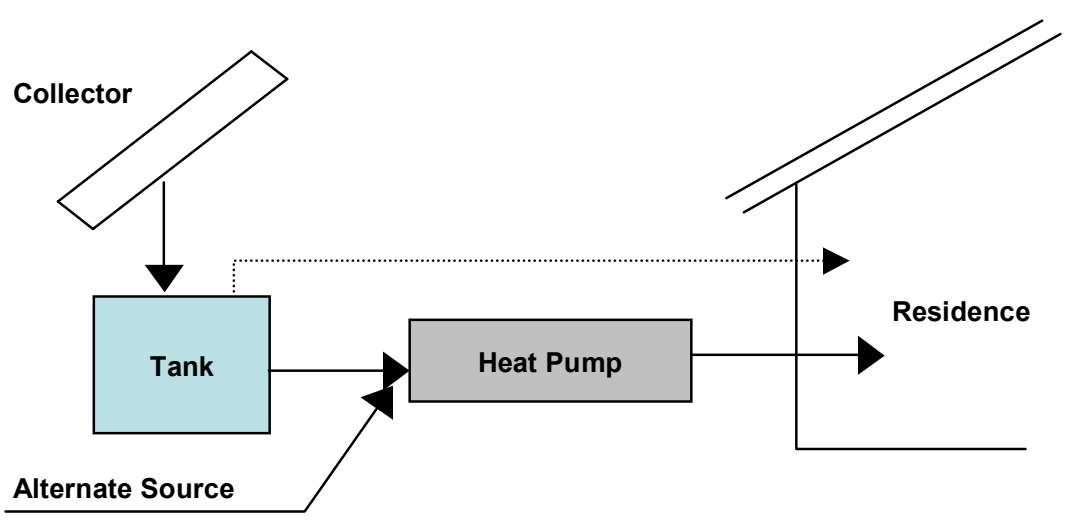

(Dual Source Heat Pump Only)

(B) Series Solar Heat Pump System or Dual-Source Solar Heat Pump System

Figure 4: Parallel, Series, and Dual-Source, Solar Heat Pump Systems

In a solar integrated heat pump, SIHP, the solar collector acts directly as the evaporator. The working fluid is passed through the solar water heater, preheated, and evaporated. Once the working fluid is evaporated in the collector, it continues through the system as it would in a traditional air source heat pump. Solar integrated heat pumps do not require an additional fan. The higher temperature of the working fluid in the solar heated evaporator increases the thermal performance of the system.

Karman, Al-Saad, and Abu-Faris [15] conducted a study that compared several different configurations of solar assisted heat pump systems. The systems tested included both air 
and water collecting systems combined with an air to air, water to air, or hybrid heat pump system. Using the solar energy simulation program TRNSYS ${ }^{\circledR}$, each system was modeled and evaluated based upon annual performance. Hourly values of solar radiation were used in the study and the liquid storage tanks were assumed to be fully mixed in the study. The study concluded that the dual source heat pump operates like a series solar heat pump with a separate air to air heat pump as an auxiliary energy source. The authors found that the same amount of solar energy was being absorbed by both solar systems regardless of configuration. However, it was determined that the added work used to run the dual source heat pump was equivalent to the amount of heat extracted from the auxiliary system. The amount of energy that was saved by using the ambient source heat pump was then equal to the amount of heat extracted from the air. The authors proved that any configuration of solar assisted heat pump always yielded a net savings when compared to electric heating. However, when compared to other solar assisted heat pump configurations, those savings were minimized. The dual-source heat pump had the best thermal performance, while also having the highest initial investment. This type of system is effective for small collector areas. Of all the systems simulated, the single source water system seemed to be advantageous for large collector areas. In conclusion, there was an added benefit of solar radiation to the heat pump systems regardless of configuration.

Mitchell, Freeman, and Beckman [16] also conducted a study that simulated a series, dual-source, and parallel heat pump system using the computer simulation program TRNSYS ${ }^{\circledR}$ for Madison, WI. They concluded that combined systems can be built if properly designed to require less auxiliary energy that a stand alone system. However, the initial cost of a combined system is double that of a stand alone system since both components have to be purchased. While combining the two systems does increase the energy savings, the additional cost of adding another system was not offset by the magnitude of the additional energy savings. The parallel system was found to work best under warmer conditions, but did not use solar energy to match the load in colder conditions. The series and dual source heat pump systems show higher solar energy contribution as to be expected with reduced collector temperature, but also showed an 
increase in purchased energy. In the Mitchell, Freeman, and Beckman study [16], the parallel configuration was deemed to be the best configuration in terms of relative energy gained by the collector and used during the heating season.

Aye, Charters, and Chaichana [17] performed both experimental and computational studies on a solar heat pump, an air source heat pump, and a stand alone solar water heater. The study was conducted in Australia where 40 percent of the total energy consumption in a typical household goes to water heating. A thermosyphon solar water heater was used that had $6.0 \mathrm{~m}^{2}$ of collector area. This type of solar water heater circulates the water using natural means; the warmer, less dense water moves upward towards the storage tank, while the cooler, denser water flows into the collector. The air source heat pump used R22 as the working fluid and a $1.1 \mathrm{~kW}$ compressor in the system. A small $35 \mathrm{~W}$ fan was used to blow air across the evaporator coil. The solar heat pump used the same thermosyphon solar water heater and compressor, but did not have an additional fan in the system. All systems had the same heating capacity and the initial water temperature was set to 20 degrees $\mathrm{C}$ throughout the entire year in the simulation. In areas where the solar radiation is high the stand alone thermosyphon water heater was recommended; however, there are not many of these climates in the world. Consequently, the solar heat pump is suggested for low solar radiation climates because it was deemed to have the lowest electricity use. The air source heat pump used more energy in all testing locations than the combined system due to the lower evaporating temperatures. The cost analysis using a 15 year life span and an 8 percent interest rate showed that the air source heat pump and solar heat pump were very comparable in life cycle cost, while there was an increased expense of implementing a stand alone water heating system.

M. N. A. Hawlader, Chou, and Ullah [18] conducted an experimental and analytical study on a solar integrated heat pump. The system consisted of a heat pump with a variable speed compressor, R-134a working fluid and a serpentine solar collector with back insulation. The system was tested in Singapore. The mathematical model assumed the two-phase mixture within the tubes to be homogenous and assumed negligible heat loss 
from the back of the collector due to proper insulation. For a given insolation an increase in compressor speed leads to a decrease in the temperature of the refrigerant running through the collector/evaporator apparatus. This in turn will result in a lower COP and higher collector efficiency. The overall COP for the annual performance ranged from 4 to 9 . The authors concluded that this justifies the benefit gained from the solar integrated heat pump.

Another solar integrated heat pump study was conducted by Huang and Chyng [19]. They investigated a Rankine refrigeration cycle using a solar collector as the evaporator. The refrigerant was directly expanded in the solar collector. The experimental apparatus was a tube in sheet type collector that took advantage of the buoyancy effects like a typical thermosyphon solar water heater. The total surface area of the collector was 1.86

$\mathrm{m}^{2}$ with a black painted top surface. The system included R-134a as the working fluid combined with a $250 \mathrm{~W}$ compressor. The quantitative model assumes quasi-steady operation for all system components except storage tank. Both the experimental apparatus and the quantitative model resulted in a COP that ranged from 1.7 to 2.5 daily total year round. The system operated longer in the wintertime, 6 to 8 hours a day, than in the summer, 4 to 7 . The author's concluded it was better to keep heat pump operation close to a saturated vapor cycle in order to obtain maximum efficiency.

\subsection{Relation of Current Research to Prior Work}

In the research described here, a precast concrete collector is combined with a series solar assisted heat pump to meet the energy needs of a house. The hypothesis is that the relatively low cost of the precast collector combined with the ability of the series solar heat pump to use low temperature thermal energy will yield an economically attractive system.

The work will focus on developing a quantitative model that predicts the performance of a precast solar collector throughout the day. This model will differ from prior concrete 
collector models in the literature because it will be a 3-dimensional transient model of a solar precast collector. The precast solar collector will be combined with a heat pump system in a series solar assisted heat pump configuration. A model of the overall system will be used to evaluate the energy and cost required to meet the needs of the residence. Finally, the overall system performance will be compared to a typical air to air heat pump in order to determine the effectiveness of the combined energy system. 


\section{Chapter 3: Modeling Approach}

Homes constructed using precast panel assemblies offer the opportunity for easily and inexpensively incorporating solar thermal energy collection. Roofing panels with embedded tubes located on the south face of the house can serve as energy collection devices. The precast system will thus serve both as the roofing structure while allowing for low grade energy collection from the roof. Energy collected from the precast panels can be used in a series solar assisted heat pump system. Challenges associated with precast collectors include the added cost associated with the tubing and glass cover assembly. In addition, it is unknown whether the precast system will actually be able to transfer enough energy to the working fluid to provide a life cycle cost savings.

A detailed model was developed to determine the annual performance of the precast solar collector. A three-dimensional transient model of the concrete collector was written in Matlab [19] and incorporates the finite element program, Femlab [20]. These programs were used to solve the energy equations for the concrete and the fluid. The collector model was combined with heat pump and storage tank models to described overall performance. The combined model was used to investigate the design and operating conditions that lead to improved performance of the collector/heat pump system. Based on a chosen set of design parameters the system was evaluated to determine its economic merit in two locations, Atlanta, GA and Chicago, IL. A detailed description of the model geometry, equations, assumptions, constraints, code, and validation are given in the following sections of this chapter. The design and operational parameters are investigated in Chapter 4 and the annual energy savings and economic impact of the resulting design are described in Chapter 5. 


\subsection{Precast Collector}

Precast concrete panels are factory built to include the structure, insulation, weather proofing, energy collection devices and components, and inside and outside finishes. Precast solar collectors are precast concrete panels with added energy collection devices integrated into the structure. By embedding tubing, adding a glass covering, and a top surface treatment, precast panels can be used to collector solar energy throughout the day.

The precast concrete collector is part of the roofing structure of the house. As shown in Figure 5, the collector can span the entire length of the roof from the eave to the peak. For this study, the distance is assumed to be a maximum of $5.72 \mathrm{~m}$. The precast solar collector lies on the south facing side of the house to gain maximum exposure to sunlight. The angle of the roof is assumed to be equal to the latitude at each city, $33^{\circ}$ for Atlanta and $41^{\circ}$ for Chicago. This is consistent with typical roof slopes and will optimize the amount of sun incident upon the solar collector. The tubes run parallel to the plane of the roof and the number of tubes within each panel will be determined later based on a parametric study of the design. The roof of the house is comprised of multiple precast panels. The tubes within the panels are connected by a main manifold spanning the width of the collector area. Manifolds for adjacent panels are connected together, so that the working fluid runs simultaneously through each of the tubes before exiting to the tank.

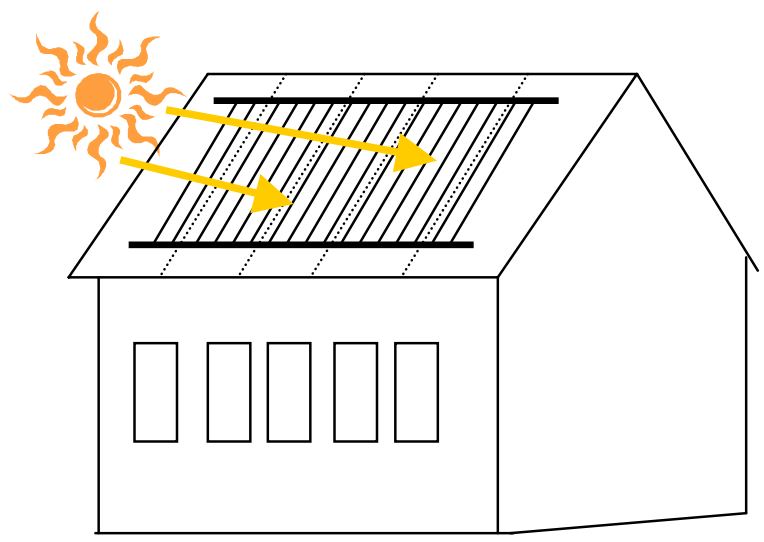

Figure 5: Location of Precast Collectors 


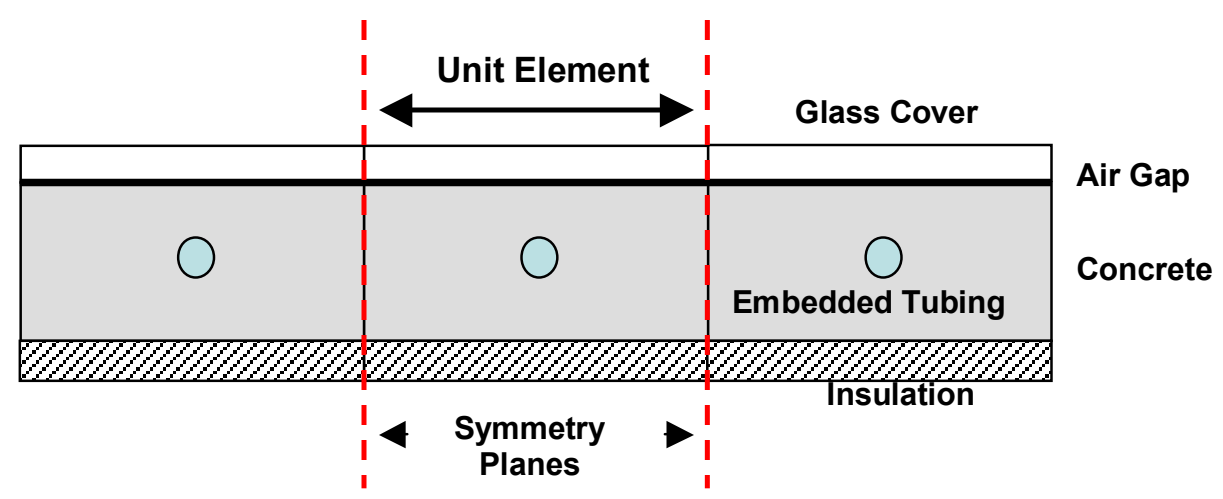

Figure 6: Diagram of Precast Collector Showing Symmetry Condition

The collector model was based on the analysis of a unit element defined by adiabatic symmetry planes which were assumed equidistance between pipes within a panel. A unit element of the collector is illustrated in Figure 6. The distance between tubes which corresponds to the width of the unit element was initially based upon conventional flat plate solar water heating systems. The concrete thickness and pipe radius were also initially assigned values based on convention or on values based from the literature. The dimensions were evaluated as described in Chapter 4 to determine an improved set of dimensions. The preliminary dimensions of the precast panel are presented in Table 1.

Table 1: Preliminary Dimensions of Precast Panel

\begin{tabular}{cc}
\hline Width & $0.2032 \mathrm{~m}$ \\
Length & $5.72 \mathrm{~m}$ \\
Thickness & $0.0381 \mathrm{~m}$ \\
Pipe Radius & $0.00635 \mathrm{~m}$ \\
\hline
\end{tabular}

The piping inside the collector is constructed of polyethylene and is capable of handling the stresses of thermal expansion and contraction produced by the concrete. To enhance the absorbtivity of the collector, the top surface was treated with a high absorption coating such as flat black paint with an emissivity of 0.95 . In addition, there is a single pane piece of glass located $0.025 \mathrm{~m}$ above the concrete collector to help reduce convective losses and increase the reabsorbtion of reflected solar radiation. 


\section{Governing Equations for Precast Collector}

The numerical model for the precast solar collector is based upon the solution of a 3dimensional transient energy equation in the solid and a 1-dimensional transient energy equation in the fluid. The resulting model is simplified by assuming conduction in the axial direction of the solid and fluid is negligible. With this assumption, the collector is divided into discrete segments for analysis. Additional assumptions are presented in Table 2. The model predicts performance of the collector based upon "typical" days that are representative of each month at a specified location.

Table 2: Assumptions for Model

Constant density, specific heat, and thermal conductivity for the concrete and the fluid.

Fully developed laminar flow for the fluid flowing through the collector.

Fluid properties based on $15 \%$ glycol water mixture.

Typical Meteorological Year, TMY2, data was used to predict weather conditions [21].

PV Design Pro was used to predict solar insolation [22].

The tilt angle of the collector corresponds to the latitude at each location.

"Typical" days were used to reflect the monthly performance of the model.

The circulating fluid through the collector and tank loops has the properties of water.

\section{3-Dimensional, Transient Energy Equation}

Figure 7 shows the boundaries and heat fluxes acting on the solid model. The 3dimensional transient energy equation and boundary equations governing the heat transfer through the concrete are

$$
\begin{aligned}
& \rho_{C} C_{C} \frac{\partial T_{s}}{\partial t}=-k_{C} \nabla^{2} T_{s}, \\
& -k_{C} \nabla T_{S}=0 \text { on surfaces } 1,3,4, \text { and end surfaces } \\
& -k_{C} \nabla T_{S}=h_{f}\left(T_{S B}-T_{f}\right) \text { on surface } 5, \text { and } \\
& -k_{C} \nabla T_{S}=I-U_{L}\left(T_{A}-T_{T P}\right) \text { on surface } 2 .
\end{aligned}
$$

Equation 1a balances the energy stored by the solid over time with the energy being conducted. 


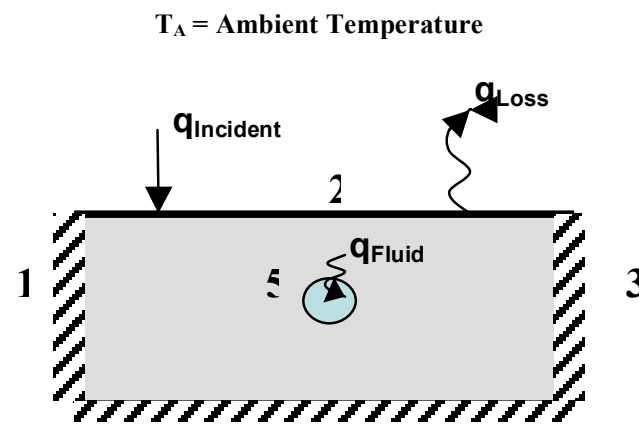

4

Figure 7: Boundary Conditions of Solid Model

The left and right boundary of the solid, 1 and 3, are assumed to be adiabatic due to the symmetry condition as given by Equation $1 \mathrm{~b}$. At the top boundary, 2, the incident solar radiation is balanced by convective and radiative losses to the surroundings, $\mathrm{q}_{\mathrm{Loss}}$, and conduction as shown in Equation 1d. To determine the convective and radiative losses from the top of the collector, an overall loss coefficient, $\mathrm{U}_{\mathrm{L}}$, was calculated and is further explained later in this section. The bottom boundary, 4, was assumed to be adiabatic. This assumption can be made if ample insulation is used in construction, so that the convection from the insulated surface is small relative to the heat transfer to the tube. At the inner boundary of the solid, surface 5, energy is transferred to the circulating fluid from the solid as demonstrated by Equation 1c.

\section{1-Dimensional Fluid Equation}

The fluid can be treated as a 1-dimensional flow with temperature gradients only in the axial direction. 1-Dimensional flow with temperatures gradients in the axial direction modeled explicitly and temperature gradients in the radiation direction addressed implicitly through the wall heat transfer coefficient, which is assumed to be constant. In addition, axial conduction in the fluid is typically small relative to the other effects and can be neglected. With these assumptions, the energy equation for the fluid reduces to

$$
-\rho_{f} C_{f} V_{f} A_{C} \frac{\partial T_{f}}{\partial z}+h_{f} A_{S}\left(T_{S B}-T_{f}\right)=\rho_{f} C_{f} V \frac{\partial T_{f}}{\partial t} .
$$


Equation (2) balances convection resulting from the fluid velocity and convection from the surrounding concrete against the energy being stored in the fluid. The storage term is small relative to the convective terms when the fluid is flowing at a moderate velocity. However, when the fluid is stagnant in the precast collector, the storage term is no longer negligible, and thus is taken into consideration at all times. The inlet boundary of the fluid has a specified temperature. Assuming fully developed laminar flow for the fluid in the pipe the Nusselt, $\mathbf{N u}$, number is ranges from 4.36 for a constant heat flux boundary to 3.66 for a constant temperature boundary [23]. Here, the boundary condition lies somewhere between these two conditions and a value of 4 is used for the Nu number. Knowing the Nu number, the heat transfer coefficient is given by

$$
h_{f}=\frac{N u k_{f}}{D} \text {. }
$$

However, since the pipe used in this analysis is made of poly-ethylene, the resistance between the inner and outer pipe diameters must be considered. In order to do this, a lumped heat transfer coefficient for the fluid is used. The inner and outer diameters are based upon manufactures specifications for cross linked polyethylene tubing in particular, PEX-C®. Equation 3a can then be modified to include this added resistance and the new heat transfer coefficient, $\mathrm{h}_{\mathrm{f}, \mathrm{p}}$, is given by

$$
h_{f, P}=\pi D_{o}\left[\frac{1}{\pi D_{o} h_{f}}+\frac{\ln \left(r_{o} / r_{i}\right)}{2 \pi k_{P}}\right]^{-1},
$$

where $D_{o}$ is the outer diameter of the pipe in meters, $r_{o}$ is the outer radius of the pipe in meters, $r_{i}$ is the inner radius of the pipe in meters, and $k_{p}$ is the thermal conductivity of the pipe in $\mathrm{W} / \mathrm{mK}$. For a poly-ethylene pipe, the thermal conductivity is assumed to be $0.39 \mathrm{~W} / \mathrm{mK}$.

However, the heat transfer coefficient, $\mathrm{h}_{\mathrm{f}, \mathrm{P}}$, changes when the fluid in the collector is stagnant. Consequently, the Nusselt number can not longer be assumed to be 4 . For this condition, the flow is treated as 1-dimensional conduction through a plane fluid layer 
with a Nusselt number equal to 1 . This drastically reduces the heat transfer coefficient in Equation $3 b$ to reflect the free convection within the tube during stagnant conditions.

\section{Segmented model}

The system of coupled differential equations represented by Equation 2 and 3 could be solved simultaneously using a finite element program such as FEMLAB to determine the performance of the solar collector. However, preliminary studies indicated difficulties coupling an equation with three spatial dimensions and one with only one spatial dimension. Moreover the preliminary studies suggested that solution times would be excessive since the model would have to be run repeatedly to simulate a 24 hour day for each of the 12 months of the year. Conducting annual studies of the influence of various parameters would compound the problem. Thus, an approximate description of the model was developed in which the collector was divided into segments as illustrated in Figure 8.

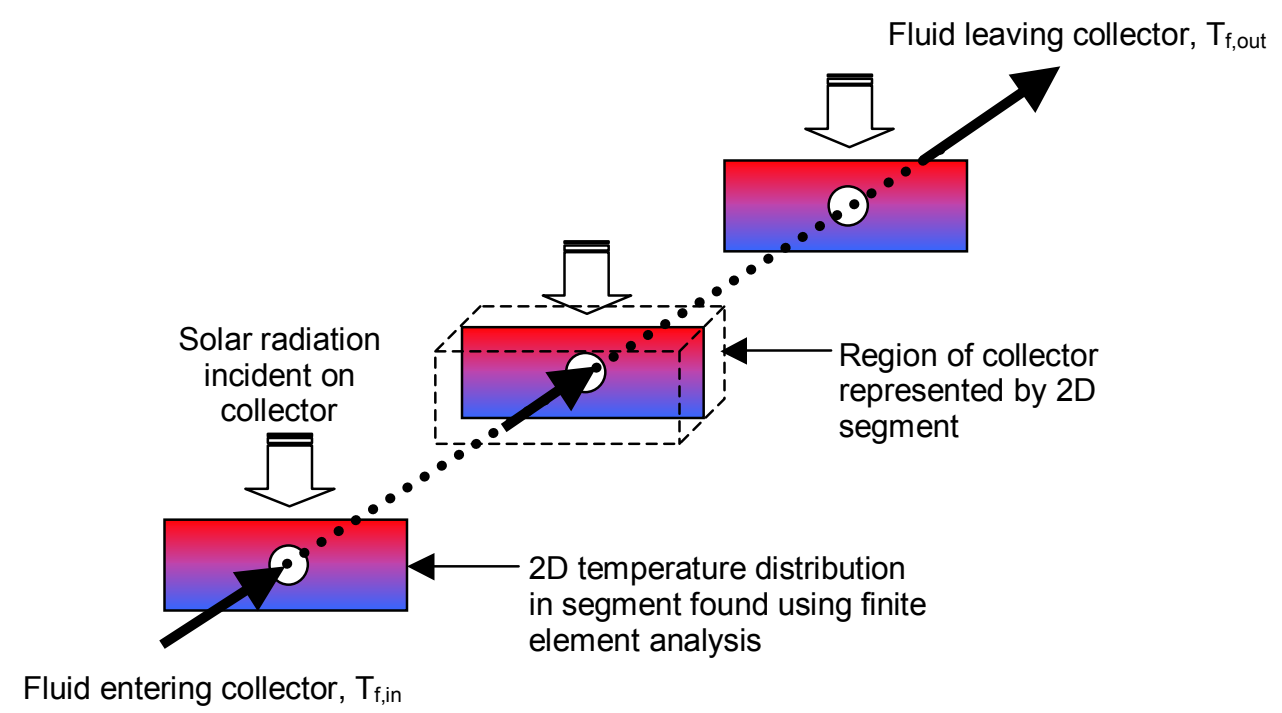

Figure 8: Segmented Model

The segmented model approach assumes that the temperature within a segment does not vary axially and that axial conduction between segments is negligible relative to other 
effects. This assumption is later justified in the results section of Chapter 4 . With this simplification, the governing equation and for the solid becomes

$$
\rho_{\mathrm{C}} \mathrm{C}_{\mathrm{P}, \mathrm{C}} \frac{\partial \mathrm{T}_{\mathrm{s}}}{\partial \mathrm{t}}=-\mathrm{k}_{\mathrm{C}}\left(\frac{\partial^{2} \mathrm{~T}_{\mathrm{s}}}{\partial \mathrm{x}^{2}}+\frac{\partial^{2} \mathrm{~T}_{\mathrm{s}}}{\partial \mathrm{y}^{2}}\right) \text {. }
$$

which is subject to the boundary conditions described by Equations $1 \mathrm{~b}-1 \mathrm{~d}$. In the boundary condition expressed by Equation 1c, the temperature of the fluid is taken to be the temperature of the fluid entering the segment.

The behavior of the fluid passing through each segment is governed by Eq. (2) which can be discretized to yield:

$$
-\rho_{f} C_{f} V_{f} A_{C} \frac{\left(T_{1 f}^{t}-T_{2 f}^{t}\right)}{L_{P}}+h_{f} A_{S}\left(T_{S B}-T_{1 f}^{t}\right)=\rho_{f} C_{f} V \frac{\left(T_{f_{-} a v g}^{t}-T_{f \_a v g}^{t-1}\right)}{\Delta t}
$$

In Eq. (5), the temperature of the solid boundary, $\mathrm{T}_{\mathrm{SB}}$, which drives convection to the fluid is the average of the temperatures around the perimeter of the interface with the solid. Equation (5) can be rearranged to yield:

$$
\mathrm{T}_{2 \mathrm{f}}^{\mathrm{t}}=\frac{\frac{\mathrm{C}_{1}}{\mathrm{~L}_{\mathrm{P}}} \mathrm{T}_{1 \mathrm{f}}^{\mathrm{t}}+\mathrm{C}_{2}\left(\mathrm{~T}_{\mathrm{SB}_{-} \text {avg }}-\mathrm{T}_{1 \mathrm{f}}^{\mathrm{t}}\right)-\frac{\mathrm{C}_{3}}{2 \Delta \mathrm{t}} \mathrm{T}_{1 \mathrm{f}}^{\mathrm{t}}+\frac{\mathrm{C}_{3}}{\Delta \mathrm{t}} \mathrm{T}_{\mathrm{f}_{-} \text {avg }}^{\mathrm{t}-1}}{\frac{\mathrm{C}_{1}}{\mathrm{~L}_{\mathrm{P}}}+\frac{\mathrm{C}_{3}}{2 \Delta \mathrm{t}}}
$$

where $\mathrm{C}_{1}, \mathrm{C}_{2}$, and $\mathrm{C}_{3}$ are coefficients and are defined as

$$
\begin{aligned}
& C_{1}=A_{C} C_{f} V_{f} \rho_{f}, \\
& C_{2}=A_{S} h_{f}, \text { and } \\
& C_{3}=\rho_{f} C_{f} V .
\end{aligned}
$$

The outlet fluid temperature from one segment becomes the inlet fluid temperature for the next segment.

With the segmented model approach, the collector is described as a series of segments each having a 2-dimensional temperature distribution and each coupled to the previous segment by the fluid flow. This description of the collector requires substantially less 
computer time to solve than a fully 3-dimensional transient description of the collector coupled to a 1-dimensional transient fluid equation.

During times when the working fluid in the collector is stagnant, the fluid temperature at the current timestep is based solely upon the time average value of the solid boundary as well as the fluid temperature from the previous timestep. Since there is no spatial dependence for a stagnant fluid, there is only one temperature that represents the entire segment. The fluid temperature at the end of the timestep can be calculated using

$$
T_{f}^{t}=\frac{C_{2} \Delta t}{C_{3}}\left(T_{S B_{-} \text {avg }}-T_{f}^{t-1}\right)+T_{f}^{t-1}
$$

where the coefficients are given by Equation 6. Due to the explicit nature of Equation 7, it is important to choose a timestep that does not violate the stability criteria.

\section{Overall Loss Coefficient from the Concrete Collector to the Ambient}

The overall energy losses from the top surface of the concrete collector are a combination of radiative and convective effects. They are dependent upon the top plate temperature of the solid, the ambient temperature, as well as the surface properties of the layers. Adding glass to the top surface aids in decreasing the losses by reducing convective losses and by capturing some of the energy reflected from the concrete surface. The incident radiation can either be transmitted through or reflected from the surface of the glass cover. The incident radiation that gets transmitted through to the concrete collector is then either absorbed by the concrete or reflected off the top surface. The fraction of incident radiation that is absorbed by the concrete is conducted through the solid towards the inner boundary around the tube wall. 


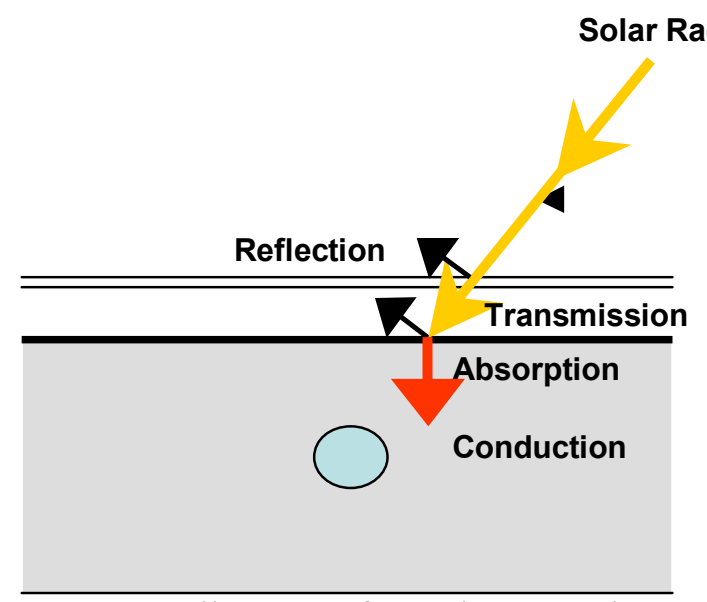

Figure 9: Overall Losses from the Top Plate of the Collector

To quantify the overall energy loss, an overall loss coefficient was calculated by treating the various effects as a network of resistances between two parallel plates. This approach is described in full detail by Duffie and Beckman in Chapter 6 of Solar Engineering [6]. The series of resistances is shown in Figure 10, where $T_{A}$ is the ambient Temperature, $T_{C}$ is the cover glass temperature and $T_{P}$ is the temperature of the concrete surface.

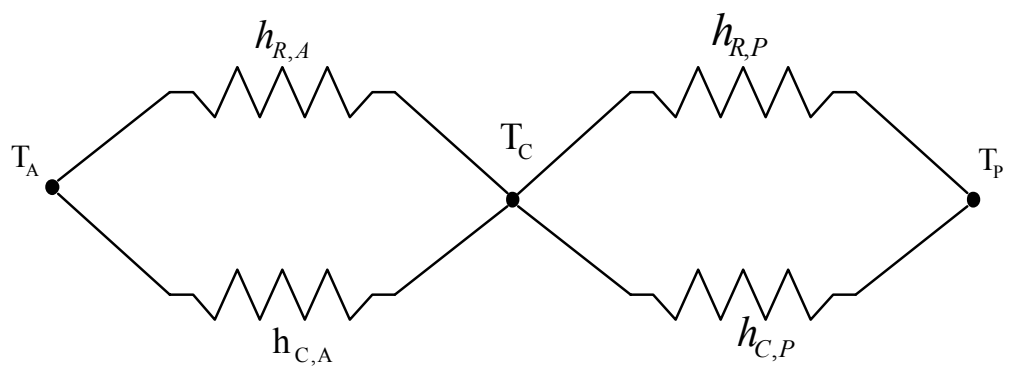

$\mathrm{h}_{\mathrm{R}, \mathrm{A}}$ is the radiative heat transfer coefficient from the cover glass to the ambient, $\mathrm{h}_{\mathrm{C}, \mathrm{A}}$ is the convective heat transfer coefficient from the cover glass to the ambient, $h_{R . C}$ is the radiative heat transfer coefficient from the concrete plate to the cover glass, and $\mathrm{h}_{\mathrm{C}, \mathrm{P}}$ is the convective heat transfer coefficient from the concrete plate to the cover glass

Figure 10: Resistance Diagram of Heat Flow from the Surface of the Concrete Collector to the Ambient

The overall loss coefficient from the concrete surface to the ambient is given by

$$
U_{L}=\frac{1}{R_{1}+R_{2}}
$$


where $R_{1}$ is the resistance from the concrete collector plate to the glass cover and $R_{2}$ is the resistance from the cover glass to the ambient air. The resistance from the concrete collector plate to the glass cover includes a convective and a radiative component and is given by

$$
R_{1}=\frac{1}{h_{C, P}+h_{R, P}} .
$$

Likewise, the resistance from the glass cover to the ambient includes both components and is given by

$$
R_{2}=\frac{1}{h_{C, A}+h_{R, A}} .
$$

Combining Equations $8-10$ yields

$$
U_{L}=\frac{1}{\left(\frac{1}{h_{C, P}+h_{R, P}}\right)+\left(\frac{1}{h_{C, A}+h_{R, A}}\right)} .
$$

Heat transfer from the surface of the concrete to the glass cover by free convection is described by the heat transfer coefficient, $\mathrm{h}_{\mathrm{CP}}$, which is determined by the Nusselt, $\mathbf{N u}$, and Rayleigh, Ra, numbers [6]. The convective heat transfer coefficient from the concrete collector plate to the cover glass is

$$
h_{C, P}=N u \frac{k}{L} .
$$

The Nusselt number is found using the tilt angle, $\beta$, and the Rayleigh number, Ra, and is given by

$$
\begin{aligned}
N u= & 1+1.44\left[1-\frac{1708(\sin 1.8 \beta)^{1.6}}{R a \cos \beta}\right]\left[1-\frac{1708}{R a \cos \beta}\right]^{+}+ \\
& {\left[\left(\frac{R a \cos \beta}{5830}\right)^{\frac{1}{3}}-1\right]^{+} }
\end{aligned}
$$

where $\beta$ is the tilt angle of the collector in degrees and $\mathbf{R a}$ is the Rayleigh number and is given by

$$
R a=\frac{g \beta^{\prime} \Delta T L^{3}}{v \alpha}
$$


where

$\mathrm{g}$ is gravity $\left[\mathrm{m} / \mathrm{s}^{2}\right]$,

$\mathrm{L}$ is the spacing between plates $[\mathrm{m}]$,

$\beta^{\prime}$ is the volumetric coefficient of expansion (for an ideal gas, $1 / \mathrm{T}$ ) $[1 / \mathrm{K}]$,

$\Delta \mathrm{T}$ is the temperature difference between plates $[\mathrm{K}]$,

$v$ is the kinematic viscosity $\left[\mathrm{m}^{2} / \mathrm{s}\right]$, and

$\alpha$ is the thermal diffusivity $\left[\mathrm{m}^{2} / \mathrm{s}\right]$.

Terms in Equation 13 which are denoted with a + are only included if they result in a positive term. Otherwise, they are be zeroed.

The radiative heat transfer coefficient from the concrete collector surface to the cover glass is

$$
h_{R, P}=\frac{\sigma\left(T_{P}^{2}+T_{C}^{2}\right)\left(T_{P}+T_{C}\right)}{\frac{1}{\varepsilon_{P}}+\frac{1}{\varepsilon_{C}}-1} .
$$

The convective heat transfer coefficient from the cover glass to the ambient, $\mathrm{h}_{\mathrm{C}, \mathrm{A}}$, is also known as the wind coefficient and was described by Watmuff et all [6] to be

$$
h_{C, A}=2.8+3.0 V_{w}
$$

where $V_{w}$ is the wind speed in $\mathrm{m} / \mathrm{s}$.

The radiative heat transfer coefficient, $\mathrm{h}_{\mathrm{R}, \mathrm{A}}$, from the cover glass to the ambient is

$$
h_{R, A}=\varepsilon_{C} \sigma\left(T_{C}^{2}+T_{S}^{2}\right)\left(T_{C}+T_{S}\right) .
$$

The heat transfer coefficients as described in equations $12,15,16$, and 17 depend on the cover glass temperature. The cover glass temperature can only be found by equating the heat flux from the concrete surface to the cover glass as described by

$$
q_{L_{-} P C}=h_{C, P}\left(T_{P}-T_{C}\right)+\frac{\sigma\left(T_{P}^{4}-T_{C}^{4}\right)}{\frac{1}{\varepsilon_{P}}+\frac{1}{\varepsilon_{C}}-1}
$$

with the heat flux from the cover glass to the ambient as described by

$$
q_{L_{-} C A}=h_{C, A}\left(T_{C}-T_{A}\right)+\frac{\sigma\left(T_{C}^{4}-T_{A}^{4}\right)}{\frac{1}{\varepsilon_{C}}-1} .
$$


Solving for $\mathrm{T}_{\mathrm{C}}$ yields

$$
T_{C}=T_{P}-\frac{U_{L}\left(T_{P}-T_{A}\right)}{h_{C, P}+h_{R, P}} .
$$

Determination of the overall loss coefficient, $\mathrm{U}_{\mathrm{L}}$, is thus an iterative process. Initially, the cover glass temperature is guessed. Heat transfer coefficients are found using Equations 12, 15, 16, and 17. The cover temperature is then calculated by Equation 20. The coefficients are updated and the process is repeated until the cover glass temperature changes by less than 0.01 percent. The overall loss coefficient is then known and used in the top boundary condition of the solid as seen in Equation 1d.

The system of equations consisting of Equations 1, 5, and 20 is solved for each segment of the collector with the outlet temperature from one segment serving as the inlet temperature for the next segment. The outlet temperature from the final segment is the temperature of the fluid available from the collector to the energy system. An energy system model is needed to determine the performance of the concrete collector in conjunction with a solar assisted heat pump and a storage tank. This energy system model accounts for the heat pump performance and quantifies the energy and cost required to meet the house's heating requirements. The energy system model is described in Section 3.2. Loads and weather data are discussed in sections 3.3 and 3.4. Details of the approach used to solve the collector model as well as the overall system model subject to loads and weather data are discussed in section 3.5.

\subsection{Energy System Analysis}

The precast solar collector is coupled to a storage tank and a liquid to air heat pump that supplies the thermal energy required to meet both the space conditioning and domestic hot water requirements. The performance of the solar collector must be evaluated in the context of the overall system that includes thermal storage and a heat pump. 


\section{Energy System Configuration}

The energy system is comprised of the precast solar collector, a thermal storage tank, a heat pump, and circulating pumps. Figure 11 depicts the overall configuration of the energy system for the house.

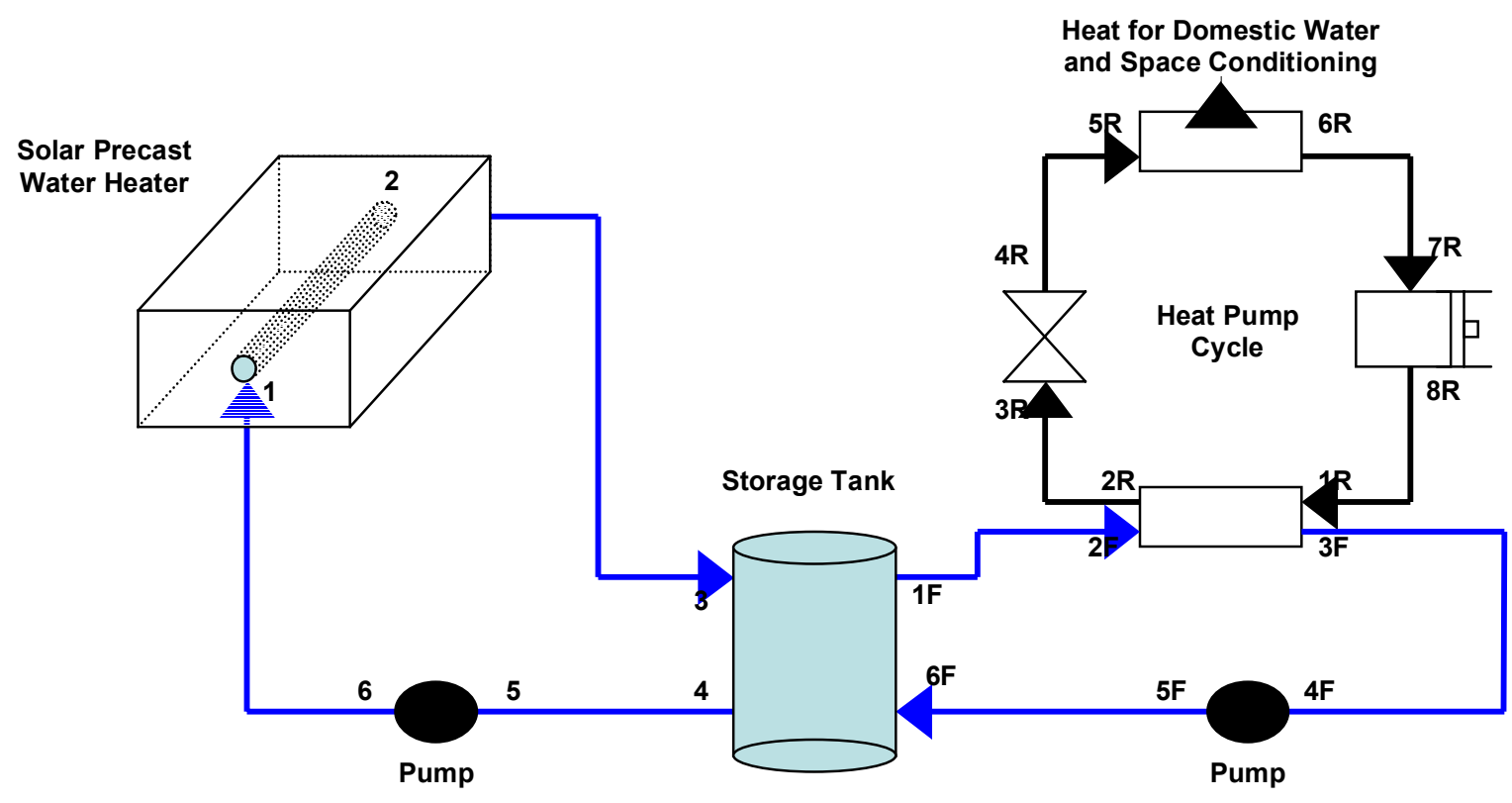

Figure 11: Energy System for the House

The numbers next to each device indicate the inlet and outlet points for the system. An " $\mathrm{R}$ " next to the number denotes the refrigeration cycle, while an " $F$ " refers to the water loop of the heat pump system. The water enters the tubes at point 1 and traverses the precast solar collector. The water flows through the collector pipes embedded in the roof, while gaining solar energy from the precast solar collector. After passing through the collector, the water enters the storage tank where the collected energy is stored. As long as the temperature of the water exiting the collector is greater than the tank temperature, the circulation continues. Simultaneously, the water flows from the tank to the evaporator of a heat pump, which operates in a series solar assisted heat pump cycle. This heat pump cycle is used to provide domestic hot water and space conditioning for the house. If the load on the house requires heating, energy is extracted from the storage tank and supplied to the evaporator. The return from the evaporator enters the tank, 
completing the cycle. Once the heating requirement of the house has been met for a particular hour, the flow from the tank to the evaporator is stopped. A separate evaporator not seen in Figure 11 is used in the air conditioning mode. In the air conditioning mode, flow from the tank to the heating cycle evaporated is stopped.

\section{Storage Tank Model}

The solution of the segmented model yields the collector outlet temperature, which is also the temperature of the fluid entering the storage tank. Energy leaves the tank through the flow of hot water to the heat pump. The rate of energy storage within the tank is equal to the difference between the inlet and exit energy flows. The storage tank is assumed to be fully mixed, so that it can be characterized by a single temperature, $\mathrm{T}_{\mathrm{T}}$, which is equal to the tank exit temperature. Conservation of energy in the tank can be expressed as

$$
\rho_{f} C_{f} V_{T} \frac{\partial T_{T}}{\partial t}=\rho_{f} V_{f} A_{C} C_{f}\left(T_{3}-T_{4}\right)+\rho_{f} V_{f, F} A_{C F} C_{f}\left(T_{6 F}-T_{1 F}\right)-Q_{T, \text { Loss }}
$$

where the numbers associated with the inlet and outlet temperatures coincide with Figure 10. Equation 21 is solved using a finite difference approximation for the time derivative. A backward difference approximation is used in an implicit approach, where the temperature at the current step is based on the temperatures of the incoming fluids at the current timestep. The temperature exiting the tank can then be found using

$$
\begin{aligned}
& \rho_{f} C_{f} V_{T} \frac{\left(T_{T}^{t}-T_{T}^{t-1}\right)}{\Delta t}=\rho_{f} V_{f} A_{C} C_{f}\left(T_{3}^{t}-T_{4}^{t}\right)+\rho_{f} V_{f_{-} F} A_{O F} C_{F}\left(T_{6 F}^{t}-T_{1 F}^{t}\right) \\
& -2 \pi_{T} h_{T} U_{L, T}\left(T_{t}^{t}-296\right)
\end{aligned}
$$

In Equation 22, $\mathrm{T}_{4}, \mathrm{~T}_{1 \mathrm{~F}}$, and $\mathrm{T}_{\mathrm{T}}^{\mathrm{t}}$ are equal as a result of the fully mixed tank assumption. The overall loss coefficient of the tank is determined by analyzing the resistance in the tank wall due to the added thermal insulation and was found to be $2.73 \mathrm{~W} / \mathrm{m}^{2} \mathrm{~K}$. Thus, the temperature of the tank at the current iteration can be determined based on the incoming temperatures from both the collector and the evaporator loops and the temperature of the tank at the previous timestep as shown by Equation 22. 


\section{Heat Pump Model}

The heat pump provides space heating and domestic water heating using the heated fluid from the storage tank as the heating source. The use of a higher fluid temperature from the storage tank increases the evaporator temperature in the heat pump cycle and thus increases the coefficient of performance, COP. The heat pump size and hourly energy use are determined by the domestic water heating and space conditioning loads which are known for each hour of the year as explained in Section 3.3. The heat pump size is based on the larger of the peak cooling load or the peak heating load, which includes both space and water heating.

The electrical energy used by the heat pump during each hour is based on the heating load and the heat pump COP, which in turn depends on the heat source temperature. The influence of temperature on heat pump capacity and COP is modeled using manufacturer's data and cubic functions of the incoming water temperature (or air temperature for the air-to-air heat pump). These expressions are like the ones in Energy Plus which are used to determine the performance of the heat pump at specific operating conditions. The total heating capacity varies with the temperature of the fluid entering the evaporator as given by

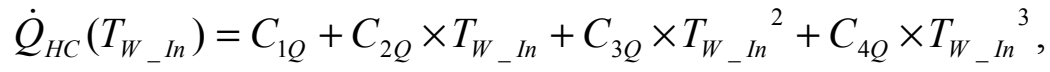

where $\mathrm{C}_{1 \mathrm{Q}}, \mathrm{C}_{2 \mathrm{Q}}, \mathrm{C}_{3 \mathrm{Q}}$, and $\mathrm{C}_{4 \mathrm{Q}}$ are coefficients and are based upon the type of heat pump system being used. The total heating capacity is also a function of the flow rate and condenser temperature. However, both the flow rate and condenser temperatures were assumed constant for this study, so there was no dependence. Thus, the COP is strictly a function of heat source evaporator temperature. The power required can be found by dividing the capacity by the COP. Alternately, since both the capacity and the COP are solely dependent upon the incoming fluid temperature, the power can be expressed directly as a function of temperature:

$$
\dot{W}_{H P}\left(T_{W_{-} I n}\right)=C_{1 W}+C_{2 W} \times T_{W_{-} I n}+C_{3 W} \times T_{W_{-} I n}{ }^{2}+C_{4 W} \times T_{W}{ }_{-i n}{ }^{3},
$$


where $\mathrm{C}_{1 \mathrm{~W}}, \mathrm{C}_{2} \mathrm{~W}, \mathrm{C}_{3 \mathrm{~W}}$, and $\mathrm{C}_{4 \mathrm{~W}}$ are coefficients determined by the manufacturer's heat pump data. Figures 12 and 13 are the curves for the heating capacity and power input for a typical water to air heat pump system.

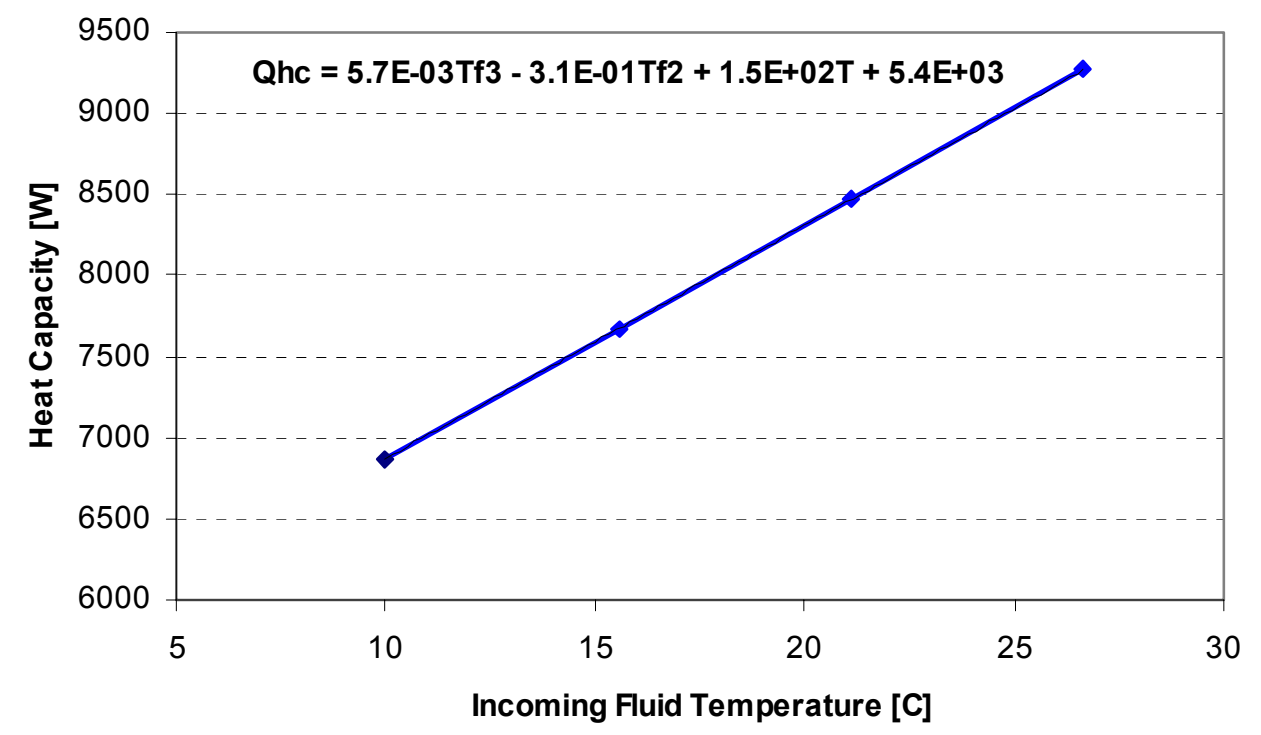

Figure 12: Heat Capacity as a Function of Incoming Fluid Temperature [14]

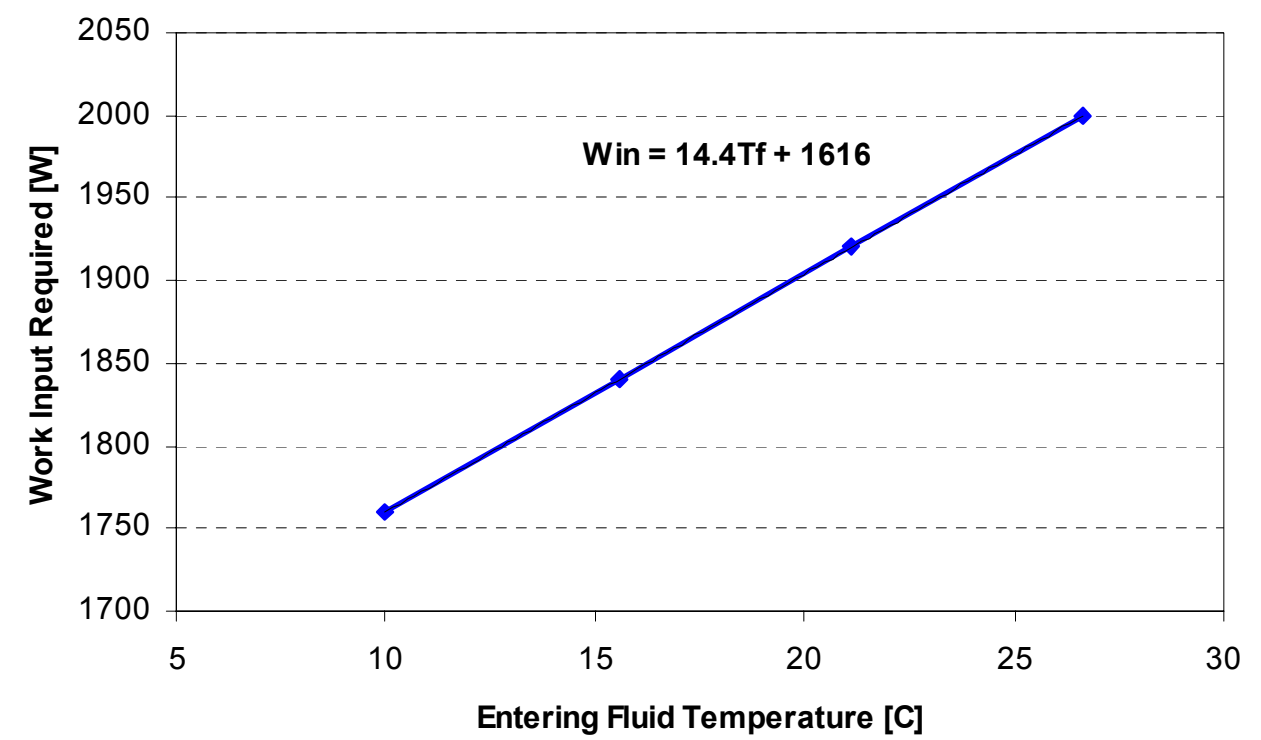

Figure 13: Work Input as a Function of Incoming Fluid Temperature [14]

As illustrated in Figures 12 and 13, the heat output and electrical input for the heat pump are determined by the fluid temperature. 
For each hour, the heat provided by the heat pump is matched to the heating load by adjusting the fraction of the time that the heat pump operates. The runtime fraction for the heat pump can be determined by

$$
f_{R T}=\frac{\dot{Q}_{L o a d}}{\dot{Q}_{H C}}
$$

where $\dot{Q}_{\text {Load }}$ is the hourly space and domestic water heating load. When the load is less than the capacity of the heat pump, the runtime fraction is less than one. To simulate heat pump operation, each hour is divided into equal timesteps. The runtime fraction is calculated based on the loads and heat pump capacity at the start of the hour and assumed constant across that hour. The number of timesteps for which the heat pump operates is determined by multiplying the number of timesteps by the runtime fraction and rounding down to the nearest integer while the heat pump is operating. The amount of heat extracted from the incoming water is then calculated is given by

$$
\dot{\mathrm{Q}}_{\mathrm{L}}=\dot{\mathrm{Q}}_{\mathrm{HC}}-\dot{\mathrm{W}}_{\mathrm{HP}} \text {. }
$$

The exit temperature of the water that is recirculated to the tank can then be calculated for the time when the heat pump is running by

$$
T_{E, W-e x i t}=\frac{-\dot{Q}_{L}}{\rho_{f} C_{f} A_{C} V_{f, F}}\left(\frac{f_{R T}}{f_{P}}\right)+T_{T}^{t} .
$$

Since the number of operating timesteps was rounded down, the heat removed and thus the exiting temperature will be slightly less than required. To correct for this, the heat extraction is corrected by multiplying by the ratio of the actual runtime fraction to the runtime fraction actually executed in the program. This will account for any gain or loss of energy due to the round off error. For simulation timesteps when the heat pump is not running, the fluid is not circulated, $\mathrm{V}_{\mathrm{f}, \mathrm{F}}=0$.

\section{Circulating Pump Models}

A circulating pump is used to move the fluid through the collector side of the energy system. In general, the pressure loss across the concrete collector is dependent upon the 
flow velocity, pipe length, pipe diameter, the type of flow, and the roughness of the pipe. To determine the flow type, the Reynolds number, Re, was calculated from

$$
\operatorname{Re}_{\mathrm{D}}=\frac{\rho_{\mathrm{f}} \mathrm{V}_{\mathrm{f}} \mathrm{D}}{\mu_{\mathrm{f}}} .
$$

The $\mathbf{R e}_{\mathbf{D}}$ number was calculated to be 2012 for the fluid flowing through the concrete collector using the base case parameters. This is under the 2300 limitation for laminar flow, so the flow was found to be laminar. For fully developed laminar flow, the friction factor is solely dependent upon the $\mathrm{Re}_{\mathrm{D}}$ number and is described by

$$
\lambda_{\mathrm{f}}=\frac{64}{\operatorname{Re}_{\mathrm{D}}}
$$

Assuming steady flow and constant velocity, the pressure losses can be calculated by

$$
\Delta \mathrm{p}_{\mathrm{C}}=\lambda_{\mathrm{f}}\left(\frac{\mathrm{L}}{\mathrm{D}_{\text {pipe }}}\right)\left(\rho_{\mathrm{f}} \frac{\mathrm{V}_{\mathrm{f}}^{2}}{2}\right) \text {. }
$$

The pressure loss was calculated to be $166 \mathrm{~Pa}$ across the collector for the base case conditions.

The working fluid travels through the rest of the network of pipes at an increased flow rate once all of the pipes converge at the manifold. The total pipe length was calculated to be $17 \mathrm{~m}$, using a maximum roof height of $6.17 \mathrm{~m}$, a house width of $10 \mathrm{~m}$, and a roof length of $5.72 \mathrm{~m}$. Using a common design guideline for plumbing that there is $0.9144 \mathrm{~m}$ of head loss for every $30.48 \mathrm{~m}$ of pipe ( 3 feet of head per 100 feet of pipe), the head loss incurred in the system is $0.537 \mathrm{~m}$. The head loss is converted to a pressure loss by

$$
\Delta p_{p}=h_{L} \rho_{f} g .
$$

The pressure loss through the pipes was found to be $4.99 \mathrm{kPa}$. Adding $20 \%$ for fitting losses and including the collector pressure drop yields a total pressure loss through the collector side of the energy system of $5.15 \mathrm{kPa}$.

The specific work required by the pump to circulate the working fluid is calculated by

$$
\mathrm{w}_{\mathrm{P}}=\frac{1}{\rho_{\mathrm{f}}} \Delta \mathrm{p}_{\mathrm{T}}
$$


where $\Delta \mathrm{p}_{\mathrm{T}}$ is the total pressure loss through the energy system. Assuming a pump efficiency, $\eta_{\mathrm{p}}$, of $50 \%$, a motor efficiency, $\eta_{\mathrm{m}}$, of $90 \%$, the power required by the circulating pump is

$$
\dot{W}_{\text {Pump }}=\left(\frac{\dot{m}_{f} w_{p}}{\eta_{m} \eta_{p}}\right) .
$$

For the base case conditions and a collector having 25 tubes, the mass flow rate is 0.77 $\mathrm{kg} / \mathrm{s}$ and the power required to run the circulating pump from the concrete collector to the storage tank and back to the concrete collector is approximately $10 \mathrm{~W}$. Similar calculations can be performed for the heat pump side of the circulating loop.

\subsection{Residential Energy Requirements}

The hot water from the solar collector will supply energy to the heat pump at a temperature higher than the ambient air thereby reducing the work required to meet the space heating and water heating loads. Although they vary greatly depending on location and time of year, these loads represent the two largest thermal energy loads for a residence. Since the water from the precast solar collection system might not be sufficient to meet the needs of the house year around, it is coupled to a heat pump system that can provide both space conditioning and domestic hot water. To determine the overall performance of the proposed energy collection system, the domestic hot water and space heating loads for the house must be determined first.

\section{Domestic Hot Water}

Domestic water heating is the second largest use of thermal energy in residential buildings. Although the space heating load for the house greatly varies with climate, the domestic water heating load tends to be relatively uniform throughout the United States. The use of hot water varies greatly depending on factors such as age, income, and occupation. The analysis discussed here averages theses factors to determine a daily mean volume of hot water use. The hourly profiles are based on a typical U.S. family of 
four and reflect the changes in consumption throughout the day. Also, monthly variations are presented that are independent of location. Previous studies have been conducted by Becker and Stogsdill [24, 25] and are summarized in the 1999 ASHRAEHVAC Applications Handbook, Chapter 48 [26]. Although these studies have thoroughly investigated the water used profiles, the energy required to heat the water will depend upon the incoming cold water temperature, the design hot water temperature, as well as the volume of water needed to be heated.

\section{Domestic Hot Water Usage Profiles}

A "typical" family in the U.S. is described as two adults and two children that have an automatic dishwasher and washing machine. The average daily hot water use for a typical family is $0.239 \mathrm{~m}^{3}$ per day according to ASHRAE [26]. This number can deviate from the average for senior citizens or those that are renting the house. However, the daily use is not evenly distributed throughout the day. The usage profile varies greatly depending on the time of the day and is shown in Figure 14. The hot water usage profile by hour is taken from the ASHRAE study. The figure shows that the biggest draws are taken in the morning when the family awakens and in the evening when everyone gets home from work and school.

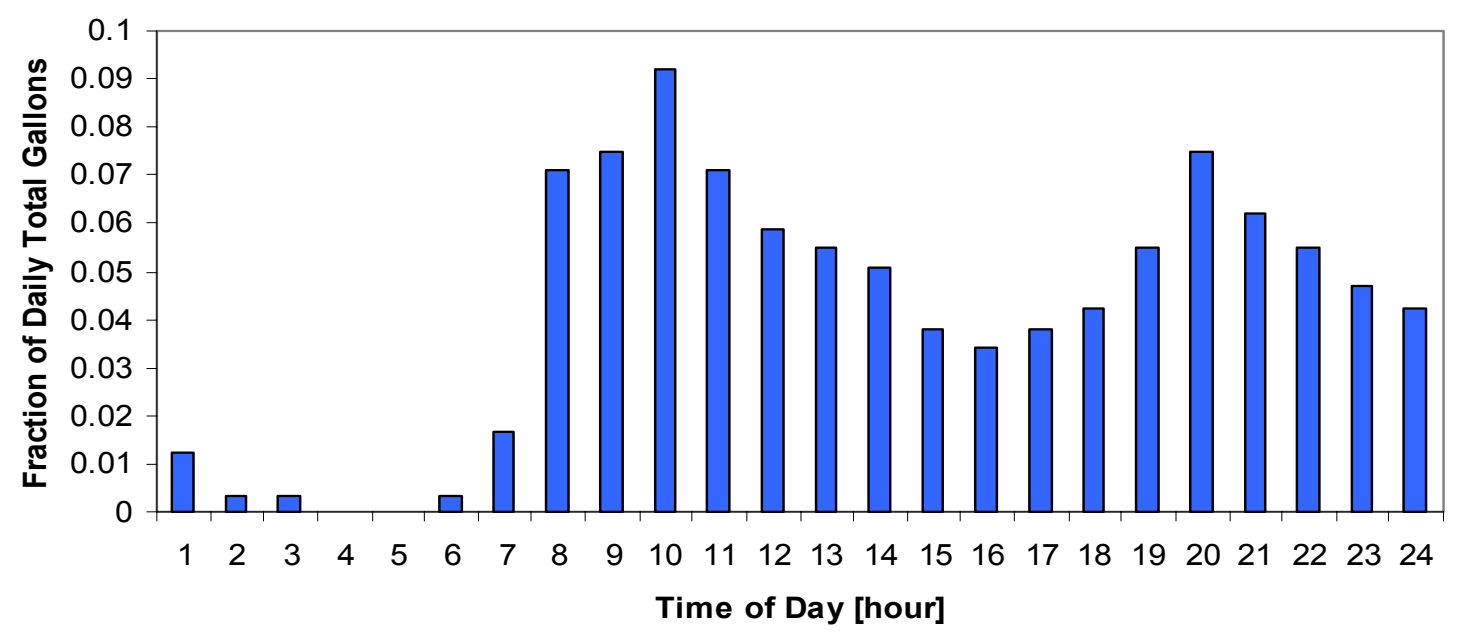

Figure 14: Fraction of Domestic Hot Water Use by Hour for a Typical U.S. Family [26] 
Becker and Stogsdill also conducted a hot water study and found that domestic use profiles did not depend on location as much as month of the year [24,25]. The average daily usage changes according to the month. Figure 15 demonstrates the variance of total daily usage for a "typical" family with month.

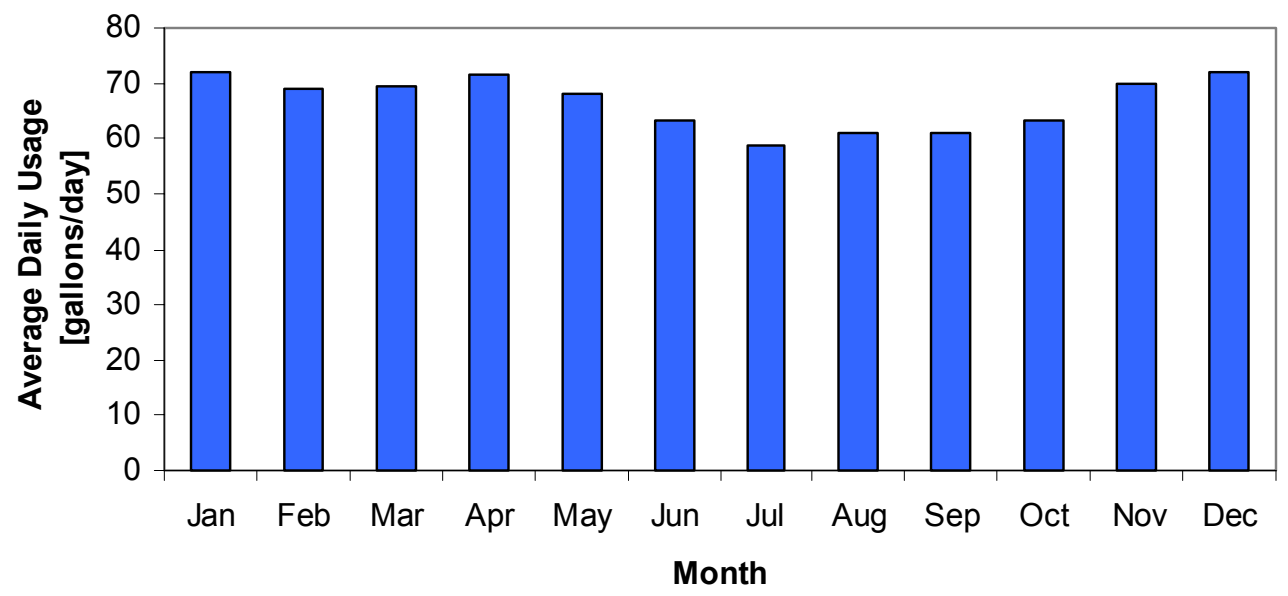

Figure 15: Average Daily Hot Water Usage for a "Typical"

U.S. Family varying with Month [24, 25]

Although the usage does not change dramatically, it can be noticed that the water heating requirements are higher during the winter months than in the summer.

To determine an hourly profile for each month, both the ASHRAE hourly data [26] and Becker and Stogsdill $[24,25]$ monthly averages were combined. The result is an average of the hourly hot water use for each month of the year for a "typical" U.S. family. The entire data set is shown in Table 3. Since both studies found the effects of location to be negligible on domestic hot water use, Table 3 represents the data for all locations in the U.S. 
Table 3: Hourly Domestic Water Heating Profiles for a

"Typical" U.S. Family in Gallons per Day

\begin{tabular}{|c|c|c|c|c|c|c|c|c|c|c|c|c|}
\hline & Jan & Feb & Mar & Apr & May & Jun & Jul & Aug & Sep & Oct & Nov & Dec \\
\hline Hour 1 & 0.9 & 0.8625 & 0.8688 & 0.8938 & 0.85 & 0.7875 & 0.7375 & 0.7625 & 0.7625 & 0.7875 & 0.875 & 0.9 \\
\hline Hour 2 & 0.252 & 0.2415 & 0.2433 & 0.2503 & 0.238 & 0.2205 & 0.2065 & 0.2135 & 0.2135 & 0.2205 & 0.245 & 0.252 \\
\hline Hour 3 & 0.252 & 0.2415 & 0.2433 & 0.2503 & 0.238 & 0.2205 & 0.2065 & 0.2135 & 0.2135 & 0.2205 & 0.245 & 0.252 \\
\hline Hour 4 & 0 & 0 & 0 & 0 & 0 & 0 & 0 & 0 & 0 & 0 & 0 & 0 \\
\hline Hour 5 & 0 & 0 & 0 & 0 & 0 & 0 & 0 & 0 & 0 & 0 & 0 & 0 \\
\hline Hour 6 & 0.252 & 0.2415 & 0.2433 & 0.2503 & 0.238 & 0.2205 & 0.2065 & 0.2135 & 0.2135 & 0.2205 & 0.245 & 0.252 \\
\hline Hour 7 & 1.1952 & 1.1454 & 1.1537 & 1.1869 & 1.1288 & 1.0458 & 0.9794 & 1.0126 & 1.0126 & 1.0458 & 1.162 & 1.1952 \\
\hline Hour 8 & 5.112 & 4.899 & 4.9345 & 5.0765 & 4.828 & 4.473 & 4.189 & 4.331 & 4.331 & 4.473 & 4.97 & 5.112 \\
\hline Hour 9 & 5.4 & 5.175 & 5.2125 & 5.3625 & 5.1 & 4.725 & 4.425 & 4.575 & 4.575 & 4.725 & 5.25 & 5.4 \\
\hline Hour 10 & 6.624 & 6.348 & 6.394 & 6.578 & 6.256 & 5.796 & 5.428 & 5.612 & 5.612 & 5.796 & 6.44 & 6.624 \\
\hline Hour 11 & 5.112 & 4.899 & 4.9345 & 5.0765 & 4.828 & 4.473 & 4.189 & 4.331 & 4.331 & 4.473 & 4.97 & 5.112 \\
\hline Hour 12 & 4.248 & 4.071 & 4.1005 & 4.2185 & 4.012 & 3.717 & 3.481 & 3.599 & 3.599 & 3.717 & 4.13 & 4.248 \\
\hline Hour 13 & 3.96 & 3.795 & 3.8225 & 3.9325 & 3.74 & 3.465 & 3.245 & 3.355 & 3.355 & 3.465 & 3.85 & 3.96 \\
\hline Hour 14 & 3.636 & 3.4845 & 3.5098 & 3.6108 & 3.434 & 3.1815 & 2.9795 & 3.0805 & 3.0805 & 3.1815 & 3.535 & 3.636 \\
\hline Hour 15 & 2.736 & 2.622 & 2.641 & 2.717 & 2.584 & 2.394 & 2.242 & 2.318 & 2.318 & 2.394 & 2.66 & 2.736 \\
\hline Hour 16 & 2.448 & 2.346 & 2.363 & 2.431 & 2.312 & 2.142 & 2.006 & 2.074 & 2.074 & 2.142 & 2.38 & 2.448 \\
\hline Hour 17 & 2.736 & 2.622 & 2.641 & 2.717 & 2.584 & 2.394 & 2.242 & 2.318 & 2.318 & 2.394 & 2.66 & 2.736 \\
\hline Hour 18 & 3.024 & 2.898 & 2.919 & 3.003 & 2.856 & 2.646 & 2.478 & 2.562 & 2.562 & 2.646 & 2.94 & 3.024 \\
\hline Hour 19 & 3.96 & 3.795 & 3.8225 & 3.9325 & 3.74 & 3.465 & 3.245 & 3.355 & 3.355 & 3.465 & 3.85 & 3.96 \\
\hline Hour 20 & 5.4 & 5.175 & 5.2125 & 5.3625 & 5.1 & 4.725 & 4.425 & 4.575 & 4.575 & 4.725 & 5.25 & 5.4 \\
\hline Hour 21 & 4.4856 & 4.2987 & 4.3299 & 4.4545 & 4.2364 & 3.9249 & 3.6757 & 3.8003 & 3.8003 & 3.9249 & 4.361 & 4.4856 \\
\hline Hour 22 & 3.96 & 3.795 & 3.8225 & 3.9325 & 3.74 & 3.465 & 3.245 & 3.355 & 3.355 & 3.465 & 3.85 & 3.96 \\
\hline Hour 23 & 3.384 & 3.243 & 3.2665 & 3.3605 & 3.196 & 2.961 & 2.773 & 2.867 & 2.867 & 2.961 & 3.29 & 3.384 \\
\hline Hour 24 & 3.024 & 2.898 & 2.919 & 3.003 & 2.856 & 2.646 & 2.478 & 2.562 & 2.562 & 2.646 & 2.94 & 3.024 \\
\hline
\end{tabular}

\section{Domestic Hot Water Energy Usage}

Since the hourly and monthly loads have been determined for the system, the energy needed to heat the water can be determined with the addition of several other factors. The design hot water temperature is assumed to be set at $48^{\circ} \mathrm{C}$ in accordance with standard practice to prevent scalding. Thus, the energy needed to heat the water is calculated by

$$
Q_{D H W}=\rho_{f} V C_{f}\left(T_{H W_{-} S e t}-T_{C W}\right)
$$

where $\mathrm{T}_{\mathrm{CW}}$ is the temperature of the cold water coming from the city lines. The cold water temperature varies significantly depending on location and time of year. It can be assumed that for a long enough pipe that the water temperature will be equal to the 
ground temperature. The temperature can be found by analyzing the ground as a transient heat conduction problem in a semi-infinite medium [27]. The ground temperature(and thus the cold water temperature) is assumed to be a sinosoidal function of time of year for a specific location and is given by

$$
\mathrm{T}_{\mathrm{G}}=\mathrm{T}_{\mathrm{M}}-\mathrm{A}_{\mathrm{SS}} \operatorname{Exp}\left[-\mathrm{x}\left(\frac{\pi}{365 \alpha_{\mathrm{S}}}\right)^{1 / 2}\right] \operatorname{Cos}\left[\frac{2 \pi}{365}\left(\mathrm{t}-\mathrm{t}_{0}-\frac{\mathrm{x}}{2}\left(\frac{365}{\pi \alpha_{\mathrm{S}}}\right)^{1 / 2}\right)\right],
$$

where $T_{M}$ is the mean Earth Temperature $\left[{ }^{\circ} \mathrm{C}\right]$,

$\mathrm{A}_{\mathrm{S}}$ is the annual surface swing $\left[{ }^{\circ} \mathrm{C}\right]$,

$\alpha_{S}$ is the thermal diffusivity of the soil $\left[\mathrm{W} / \mathrm{m}^{\circ} \mathrm{C}\right]$, and $t$ is the time [days].

The constants are available from Oak Ridge National Laboratory and are location dependent. The average monthly ground temperatures for Atlanta, GA and Chicago, IL calculated in accordance with Equation 35 are presented in Table 4.

\begin{tabular}{ccc}
$\begin{array}{c}\text { Table 4: } \\
\text { Month }\end{array}$ & $\begin{array}{c}\text { Monthly Ground } \\
\text { Atlanta, GA }\end{array}$ & $\begin{array}{r}\text { Temperatures in } \\
{ }^{\circ} \mathrm{C}\end{array}$ \\
Chicago, IL \\
\hline Jan. & 14.7 & 6.5 \\
Feb. & 13.0 & 4.1 \\
Mar. & 12.7 & 3.3 \\
April & 13.8 & 4.4 \\
May & 16.2 & 7.2 \\
Jun. & 19.2 & 10.9 \\
July & 21.9 & 14.4 \\
Aug. & 23.7 & 17.0 \\
Sept. & 24.0 & 17.8 \\
Oct. & 22.8 & 16.6 \\
Nov. & 20.4 & 13.8 \\
Dec. & 17.4 & 10.1 \\
\hline
\end{tabular}

The annual surface swing is assumed to be $10^{\circ} \mathrm{C}$ for both locations.

\section{Space Heating:}

The space heating loads were calculated using Energy Plus [28] based on typical wood frame construction. The study was conducted by Doebber [29] and used to calculate the hourly heating loads for a typical U.S. household of 4 . The wall insulation values were 
assumed to satisfy the minimum requirements as specified by ASHRAE Standard 90.2, Efficient Design of Low Rise Residential Buildings. However, the R-values were further reduced by $30 \%$ to account for construction frame and detail effects such as the wall/floor connections and are shown for both city locations in Table 5. The work by Doebber shows that properly built concrete wall systems have annual heating requirements that are less than or equal to the requirements for standard wood frame construction. Heating requirements for wood frame construction are used as a basis for evaluating the solar thermal heat pump because wood frame construction is the standard to which precast wall construction is compared.

Table 5: Typical House Characteristics by Location

\begin{tabular}{ccc} 
& Chicago, IL & Atlanta, GA \\
\hline Number of Floors & 1 & 1 \\
Floor Area & $211.35 \mathrm{~m}^{2}$ & $211.35 \mathrm{~m}^{2}$ \\
Foundation Type & Basement & Basement \\
Conditioned Wall R- & & \\
Value & $4726 \mathrm{~m}^{2} \mathrm{~F} / \mathrm{kW}$ & $4726 \mathrm{~m}^{2} \mathrm{~F} / \mathrm{kW}$ \\
Unconditioned Wall & & \\
R-Value & $4726 \mathrm{~m}^{2} \mathrm{~F} / \mathrm{kW}$ & $3348 \mathrm{~m}^{2} \mathrm{~F} / \mathrm{kW}$ \\
Floor R-Value & $6429 \mathrm{~m}^{2} \mathrm{~F} / \mathrm{kW}$ & $4479 \mathrm{~m}^{2} \mathrm{~F} / \mathrm{kW}$ \\
Ceiling R-Value & $7811 \mathrm{~m}^{2} \mathrm{~F} / \mathrm{kW}$ & $7811 \mathrm{~m}^{2} \mathrm{~F} / \mathrm{kW}$ \\
Basement Walls R- & & \\
Value & $5576 \mathrm{~m}^{2} \mathrm{~F} / \mathrm{kW}$ & $2393 \mathrm{~m}^{2} \mathrm{~F} / \mathrm{kW}$ \\
Window Insulation R- & & \\
Value & $514 \mathrm{~m}^{2} \mathrm{~F} / \mathrm{kW}$ & $514 \mathrm{~m}^{2} \mathrm{~F} / \mathrm{kW}$ \\
Shading Coefficient & 0.539 & 0.539 \\
Window Area & $0.151 \mathrm{~m}^{2}$ & $0.151 \mathrm{~m}^{2}$ \\
\hline
\end{tabular}

The HVAC system for each of the cities was sized based upon the autosize function in Energy Plus. This determines the heating capacity, cooling capacity, and air flow rates to be used for the energy analysis. 


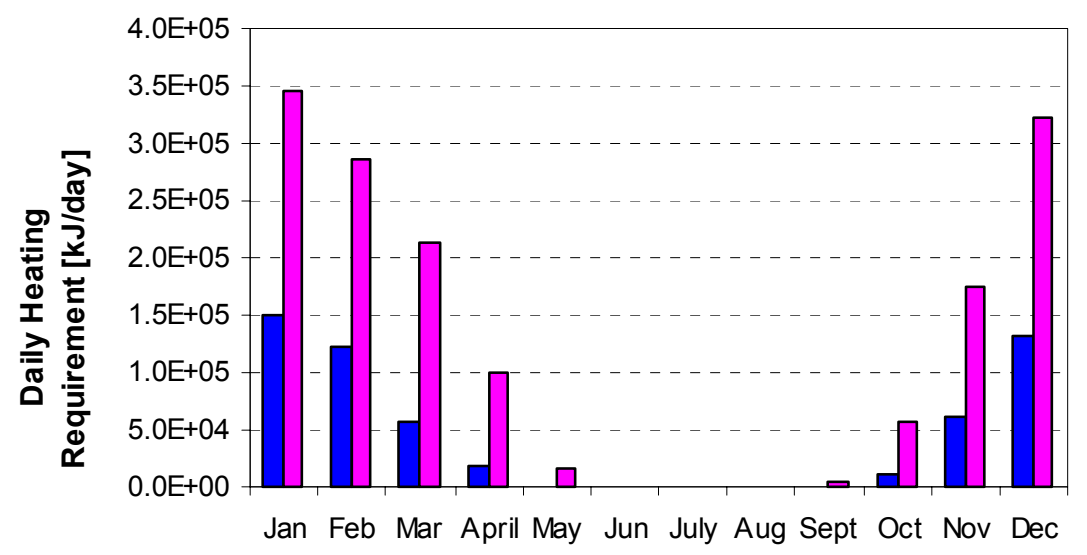

Month

\begin{tabular}{|l|}
\hline Atlanta \\
\hline
\end{tabular}

Figure 16: Monthly Space Heating Loads for Chicago, IL and Atlanta, GA

The daily energy requirements for space heating for each month are shown for both Chicago and Atlanta in Figure 16. The heating requirements for the house were combined with the domestic water heating loads to determine the total heating energy needed for the house for each hour of a typical day in each month. Figure 17 displays the monthly total heating requirement for each location. The heating requirements were used as a basis for calculating the energy required by the solar assisted heat pumps system and by a conventional heat pump system.

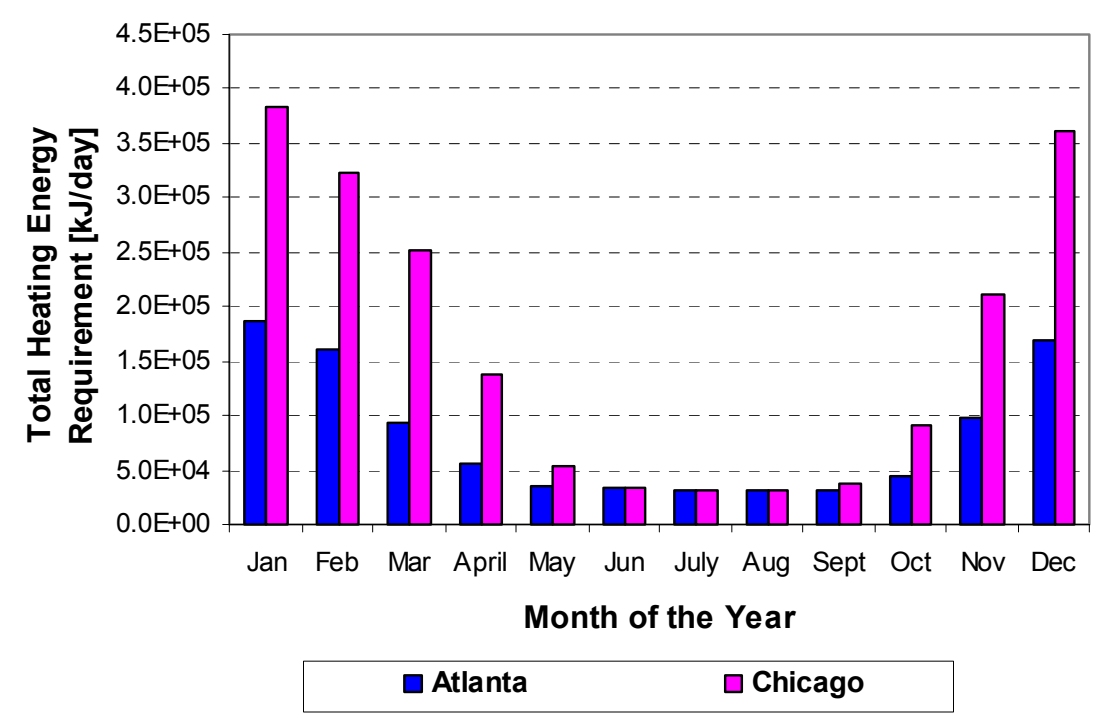

Figure 17: Monthly Total Heating Energy for Chicago, IL and Atlanta, GA 


\subsection{Weather Data}

TMY2, Typical Meteorological Year [21], weather files were used to get average representative hourly weather for the entire year at various locations. These data files take data spanning over various years and use different parts of different years to make an entire yearly file. A full data file for a specified location was sorted by month and then by hour. Data for each hour of the day was then averaged over each month. The end result is an average value for the meteorological and solar radiation data for each hour of a typical day in each month of the year. To account for the slope of the roof, PV Design Pro [22] was used to convert the horizontal radiation to the radiation on the collector at the specified slope. Each of the collector slopes was assumed to be equal to the latitude at which the collector is located, $33^{\circ}$ for Atlanta and $41^{\circ}$ for Chicago. PV Design Pro uses TMY2 weather files and converts the horizontal radiation to the radiation on the sloped surface using the angle of incidence, azimuth angle, and the geometric view factor as furthered detailed by Duffie and Beckman [6].

Typical days were constructed for Atlanta, GA and Chicago, IL. As illustrated in Figure 18 , these cities are representative of two of the major U.S. Climate Zones.

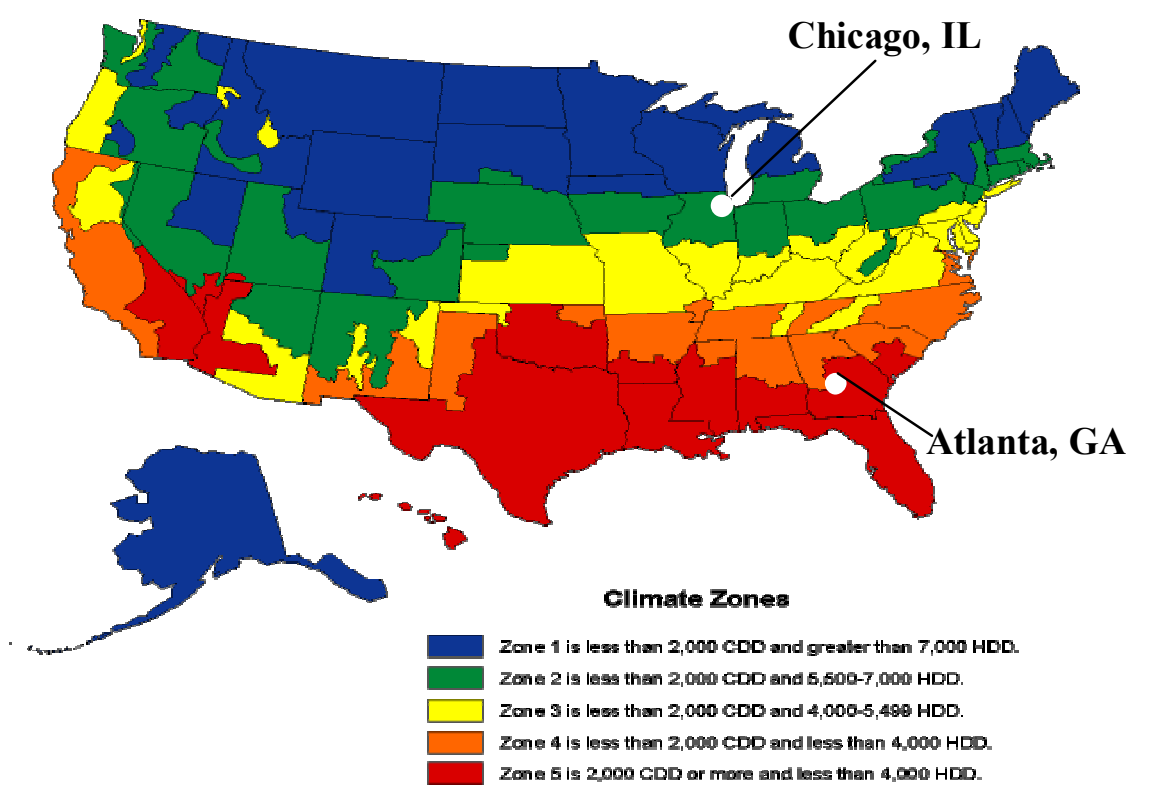

Figure 18: U.S. Climates

Source: EIA (http://www.eia.doe.gov/emeu/cbecs/climate_zones.html) [30] 
Atlanta, GA, Zone 4, is more of a moderate to warm climate, while Chicago, IL, Zone 2, is a cooler, moderate climate. Differences between the climates in these locations are reflected by the large difference in heating and cooling degree days in the above figure. The operation of the precast solar collector and solar assisted heat pump will be analyzed in each location to determine the merit of the proposed energy system in comparison with more conventional energy systems.

\subsection{Solution Approach}

The previous sections described in detail the three main parts of the complete energy system: the precast solar collector, the storage tank, and the heat pump system and discussed the heating loads and weather data that affect system operation. An integrated model of the complete energy system was implemented in a Matlab program. In this model, the solid region of the precast solar collector is solved using a finite element analysis implemented in Femlab. The tank system is described using a finite difference approach and the heat pump system performance is predicted using manufacturers data. The solid model is solved first, and then the temperature of the fluid leaving the last segment is sent to the storage tank if the temperature leaving the collector exceeds the

previous temperature of the tank. A new tank temperature is then calculated based on the entering water temperatures. If the fluid is circulating, the temperature of the tank is taken as the inlet temperature for the collector. The tank temperature is also taken as the inlet temperature for the heat pump model. Based on this inlet temperature, the work required to run the system to meet the heating load of the house for each hour is calculated. The fluid temperature exiting the evaporator is then calculated and sent to the tank model as one of the inputs. 


\section{Program Structure}

The temperature distribution in the precast collector is determined using the finite element technique. More specifically, the temperatures are calculated using Femlab [20], finite element modeling laboratory, a program developed by Comsol Inc, to run in conjunction with Matlab that allows the user to solve engineering related problems. The Femlab program is called by a main program, which was written in Matlab, to calculate the transient temperature distribution for the solid. A 2-dimensional geometry, referred to as a solid subdomain, is created in Femlab to represent a cross section of the concrete collector. The differential equations and boundary conditions described in Section 3.1 are imposed upon the solid subdomain. A mesh is generated using Femlab, which automatically partitions the solid subdomain into triangular elements. The solid model is then solved using a transient ordinary differential equation solver, ODE 15 [19]. From this solid model temperature distribution, the inner solid boundary temperature and the top surface temperature can be extracted and used in solving the overall loss coefficient and the fluid temperature exiting the segment.

Figure 19 illustrates how the solution procedure moves forward in length as well as with time.

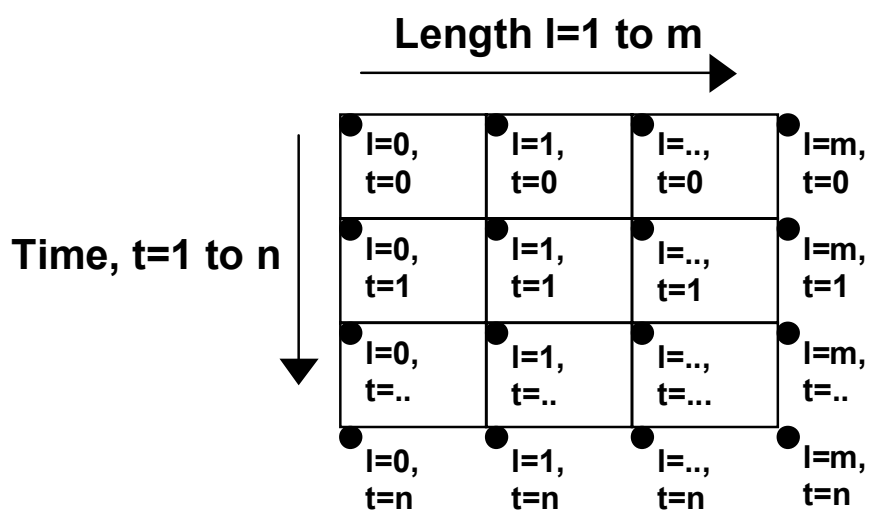

Figure 19: Coding Diagram for Forward Movement in Time and Length

The program execution progresses down the channel to the final axial node and then returns to the inlet node, while moving forward one step in time. This process repeats 
until a full hour is finished. After an hour is finished, new hourly inputs are entered and the whole looping process repeats.

The program begins by calling an initialization function, which retrieves the weather data for the current iteration, establishes the geometry, the subdomain, the boundary conditions, and the mesh for a segment of the precast collector. Next, the Femlab program runs for a specified interval which is denoted as the segment timestep, $\Delta \mathrm{t}_{\mathrm{sg}}$. During this interval, Femlab is used to determine the two-dimensional transient temperature distribution in the segment of precast collector, while assuming that the fluid temperature, $T_{f}$, remains constant at the segment inlet temperature. The initial temperature distribution in the segment is known from the previous timestep.

At the conclusion of the segment timestep, the temperature of the fluid leaving the segment is calculated using Equation 5 and is used as the inlet temperature for the next segment. The program proceeds down the channel until all the segments are solved. At this point, the temperature distribution in each segment and the fluid temperature leaving each segment is known for the current timestep. The entire procedure is repeated for the next time $\left(\mathrm{t}^{\mathrm{k}+1}=\mathrm{t}^{\mathrm{k}}+\Delta \mathrm{t}_{\mathrm{sg}}\right)$.

Once the program has traveled entirely down the channel for the given fluid timestep, the fluid temperature leaving the final segment is compared to the final tank temperature from the previous timestep. If the fluid temperature exceeds the storage tank temperature, the fluid is circulated to the tank. If storage tank temperature is higher, then the flow is stopped through the collector until the stagnant water in the collector gains enough thermal energy to raise the temperature above the storage tank.

Simultaneously, the heat pump model is running for each fluid timestep for which there is a heating load from the house. If a heating load is present, the water temperature exiting the storage tank is sent as the inlet to the heat pump evaporator. Heat is removed from the water and recirculated back to the storage tank in order to continue the cycle for each fluid timestep. Figure 20 presents a flowchart for the entire program. 


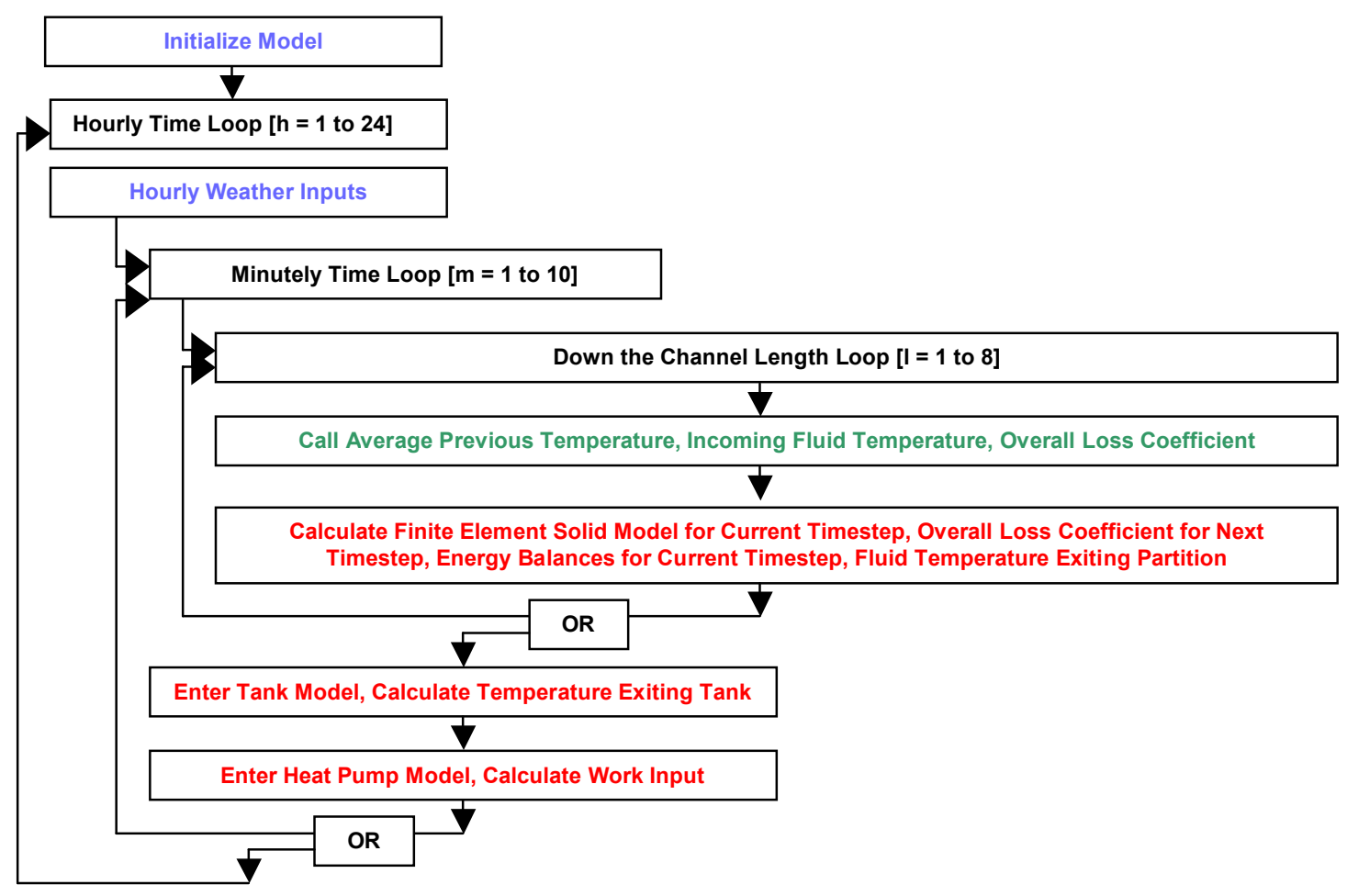

Figure 20: Flowchart for the Matlab Program

\section{Initial Condition:}

In order to determine an initial temperature distribution for the precast solar collector, the program was run twice. Initially, the weather conditions for the month and location specified are imposed upon the solid model. The initial segment temperature distribution for the first timestep is just set to ambient temperature. However, under normal conditions the concrete collector would never see these initial conditions unless it was the first time it was ever exposed to the weather. Instead, the effects from the previous day would still be captured by the thermal mass of the concrete. In order to capture these effects, the solid model temperature distribution was saved from the last solution of the initial typical day. This provides a more accurate account of thermal mass affects of the concrete. These initial conditions are adjusted each time there is a change in location or geometry. 


\section{Chapter 4: Validation of Model and Sizing of System Parameters}

The current chapter discusses the methods by which the solid model was validated and by which the various system parameters were chosen. The solid model was validated by checking for conservation of energy during the simulation of a solar precast collector operating during a typical day in Atlanta, GA during the month of January and by comparing the predicted performance to the performance of other collectors reported in the literature. After the model was validated, parametric studies were conducted to determine a set of design and operating parameters that yielded improved performance during a typical January day in the same location.

\subsection{Precast Solar Collector Validation}

The 2-dimensional transient model was validated by calculating an energy balance every time step to check the error in the solid model. The energy balance performed on the precast solar collector is given by

$$
\gamma_{\mathrm{b}}=\dot{\mathrm{Q}}_{\mathrm{I}}-\dot{\mathrm{Q}}_{\mathrm{L}}-\dot{\mathrm{Q}}_{\mathrm{S}}-\dot{\mathrm{Q}}_{\mathrm{f}},
$$

where $\gamma_{\mathrm{b}}$ is the error in the energy balance, $\dot{Q}_{I}$ is the rate of incident solar energy, $\dot{Q}_{L}$ is the rate of energy lost to the ambient air by convection and radiation, $\dot{Q}_{S}$ is the rate of energy stored in the solid, and $\dot{Q}_{f}$ is rate of energy convected to the fluid through the inner boundary. For this study the velocity of the fluid was assumed to be constant at $0.1524 \mathrm{~m} / \mathrm{s}$ and the inlet fluid temperature was assumed to be at a temperature of 298.15 $\mathrm{K}$.

If each of the terms in Equation 36 is expanded, it becomes

$$
\begin{aligned}
& \gamma_{b}=I w L-U_{L} w L\left(T_{A}-\overline{T_{P}}\right) \\
& -\rho_{C} C_{P, C}\left(w h L-\pi r^{2} L\right) \frac{\left(\bar{T}_{S}^{k}-\bar{T}_{S}^{k-1}\right)}{\Delta t}-2 h_{w} \pi r L\left(\overline{T_{S B}}-\overline{T_{f}}\right)
\end{aligned}
$$


In Equation 37 the first term on the right is the rate of solar energy incident upon a collector area of $\mathrm{w} \times \mathrm{L}$ when the irradiance is I. The second term on the right is the rate of heat loss from the top of a collector area of $\mathrm{w} \times \mathrm{L}$ when the overall loss coefficient is $\mathrm{U}_{\mathrm{L}}$. The third term on the right side of Equation 37 is the rate of energy storage in the solid. The last term is the rate of energy convected to the fluid over the surface area, $2 \pi \mathrm{rL}$ from the inner boundary of the solid. To determine the significance of the error, a scaled error is found by dividing the energy error by the average rate of incoming solar radiation for the entire day, which is given by

$$
\hat{\gamma}_{b}=\frac{24 \gamma_{b}}{w L \sum_{i=1}^{24} I_{i}}
$$

where $I_{i}$ is the incident radiation in $\mathrm{W} / \mathrm{m}^{2}$ for hour $\mathrm{i}$ and goes from the first hour to 24 hours to represent the entire day.

\section{Timestep Analysis}

The program uses a solid model timestep, which represents the time step used within Femlab to calculate the solid model, as well as a segment timestep, which represents the timestep used to solve the fluid model. An analysis was conducted on both timesteps to determine the optimal time step when the fluid is flowing and when the fluid is stagnant.

The effect of the solid model timestep on the scaled energy error, $\hat{\gamma}_{b}$, was evaluated for a segment timestep of 360 seconds. The solid model timestep was varied from $0.5 \mathrm{~s}$ to $10.0 \mathrm{~s}$. For simplification, a constant fluid of $298 \mathrm{~K}$ was maintained on the inner boundary of the pipe. The overall top loss coefficient was calculated for the given conditions and held at a constant $5.6 \mathrm{~W} / \mathrm{m}^{2} \mathrm{~K}$. In addition, a constant heat flux of 726.64 $\mathrm{W} / \mathrm{m}^{2}$ was placed on the top boundary corresponding to the maximum value of the incident radiation. Figure 21 illustrates how the error varies with the solid model timestep for the first 360 seconds of the test case. The error is shown for solid model timesteps of $0.5 \mathrm{~s}, 5 \mathrm{~s}$, and $10 \mathrm{~s}$. 


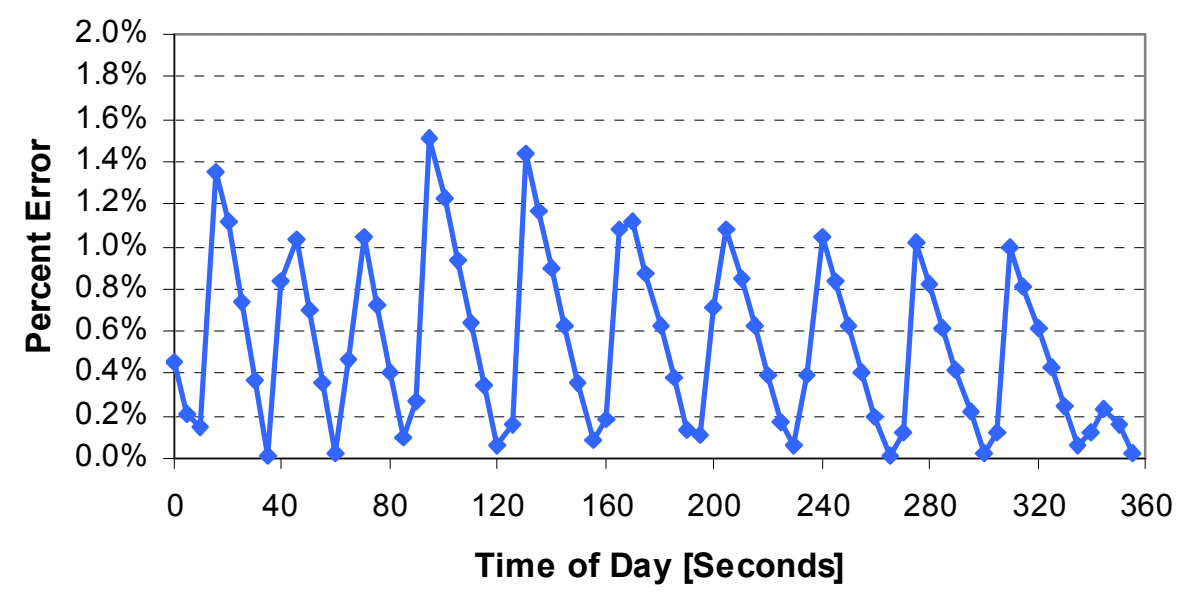

$\longleftarrow 5$ Second Balance

Figure 21: Solid Model Timestep - Flowing Fluid

For a timestep of $5 \mathrm{~s}$, the scaled energy error oscillates from $0 \%$ to $1.6 \%$. Smaller time steps yield smaller error, but longer solution times. Based on this analysis, a timestep of 5.0 seconds was chosen to minimize the solid model error, while also keeping the runtime reasonable.

The segment timestep analysis was conducted by varying the duration of the segment timestep during a 1 hour test case while the solid model timestep was held constant at 5.0 seconds. The boundary conditions were held constant for this trial test as with the solid model test. Figure 22, illustrates the scaled energy error as a function of the fluid timestep. 


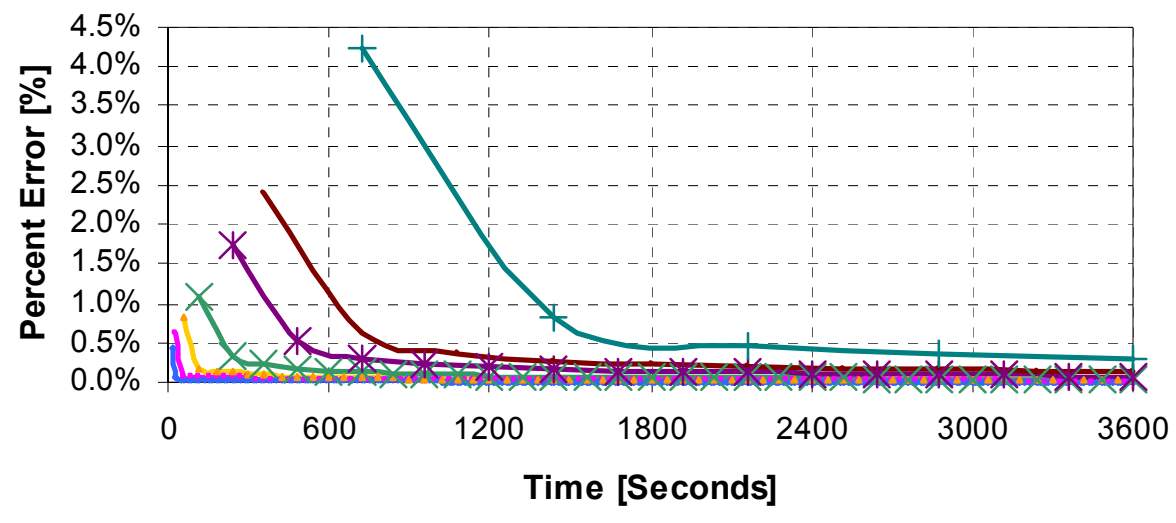

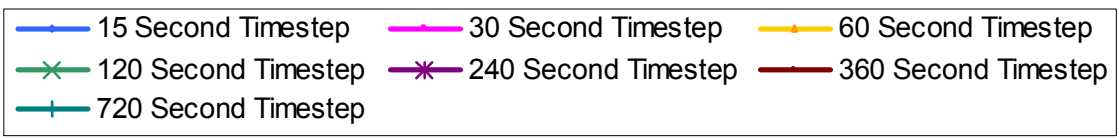

Figure 22: Segment Timestep Error - Flowing Fluid

Figure 21 illustrates that after the first timestep calculation, the scaled energy error is less than $1.0 \%$ for all values of the fluid timestep. The convective heat transfer terms, QL and Qf are evaluated based on the average of the respective surface temperatures at the beginning and end of the segment timestep. Thus, abrupt changes in surface conditions that make the average a poor representation of the temperature over the timestep can lead to relatively high errors such as those observed in the initial timesteps. A timestep of 360 seconds was chosen to run the program.

The overall solution scheme is essentially an explicit scheme and thus has a stability criterion which must be satisfied. This stability criterion becomes more important when the fluid is stagnant because the first term in Equation 2 goes to zero. This leaves a balance between the energy stored in the fluid and convected along the inner solid boundary. To determine the segment timestep that would achieve stability and a reasonably accurate solution for the stagnant fluid case, the solid model coupled with Equation 5 for the fluid (with $\mathrm{C}_{1}=0$ corresponding to stagnant conditions) was solved for varying segment timesteps. The test was run for an hour under optimal sun conditions in Atlanta, GA. 


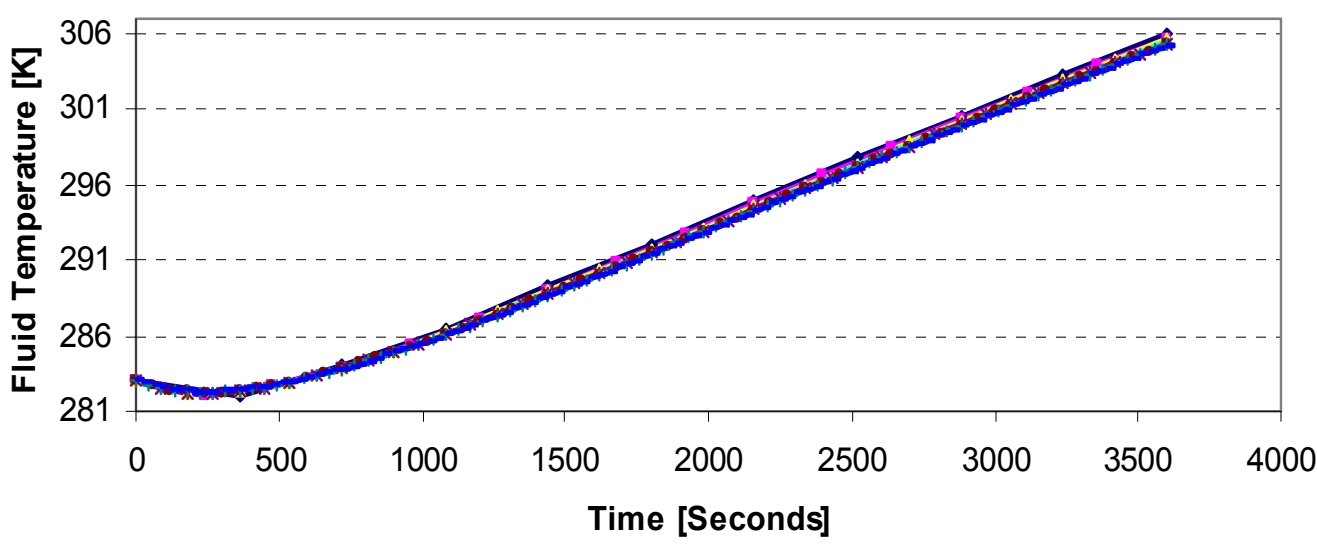

\begin{tabular}{|c|c|c|}
\hline $\begin{array}{l}\longrightarrow-360 \text { Fluid Timestep } \\
\longrightarrow-90 \text { Fluid Timestep }\end{array}$ & $\begin{array}{l}-240 \text { Fluid Timestep }-180 \text { Fluid Timestep } \\
-60 \text { Fluid Timestep } \_45 \text { Fluid Timestep }\end{array}$ & $\begin{array}{r}120 \text { Fluid Timestep } \\
-30 \text { Fluid Timestep }\end{array}$ \\
\hline
\end{tabular}

Figure 23: Stability and Error Associated with Segment Timestep - Stagnant Fluid

The results are presented in Figure 23, which shows that the temperature solution begins to oscillate when the timestep exceeds 240 seconds. A segment timestep of 180 seconds was chosen to provide an accurate, stable solution while maintaining reasonable solution time. Since the segment timestep for the stagnant condition was less than that for the flowing condition, a segment timestep of $180 \mathrm{~s}$ was used for the entire model. Thus, the timesteps used to run the model were $\Delta \mathrm{t}_{\mathrm{sm}}=15 \mathrm{~s}$ and $\Delta \mathrm{t}_{\mathrm{sg}}=180 \mathrm{~s}$.

\section{Down the Channel Partition Analysis:}

A down the channel analysis was conducted in order to determine the number of partitions needed to accurately depict the fluid behavior. The model was run with incident radiation corresponding to a typical day in July. A constant fluid velocity of $0.1524 \mathrm{~m} / \mathrm{s}$ and a constant inlet fluid temperature of $298 \mathrm{~K}$ were assumed. The interaction with the heat pump and storage tank was not considered. The net energy gained by the fluid over the course of the day was given by

$$
Q_{\text {Gained }}=\sum_{t=1}^{T_{\text {Day }}} \rho_{W} C_{P, W} V_{f} \pi r^{2}\left(T_{f_{-} \text {Out }}^{t}-T_{f_{-} I n}^{t}\right) \Delta t_{s g}
$$


where $\mathrm{T}_{\mathrm{f}_{-} \text {Out }}$ refers to the temperature of the fluid coming out of the last segment at the current timestep, $\mathrm{T}_{\mathrm{f}_{-} \text {In }}$ refers to the temperature of the fluid entering the first segment at the current timestep and $\Delta \mathrm{t}_{\mathrm{sg}}$ is the segment timestep duration and $\mathrm{T}_{\text {day }}$ is the number of seconds per day. The number of segments was increased until additional segments did not affect the energy gain by the fluid. Figure 23 shows the daily energy gained by the fluid in one tube during for a typical day in July. Once the daily energy gain by the fluid ceases to change, the number of partitions becomes irrelevant. Based on the results presented in Figure 24, eight partitions were found to be an ample number of partitions to use throughout the analysis.

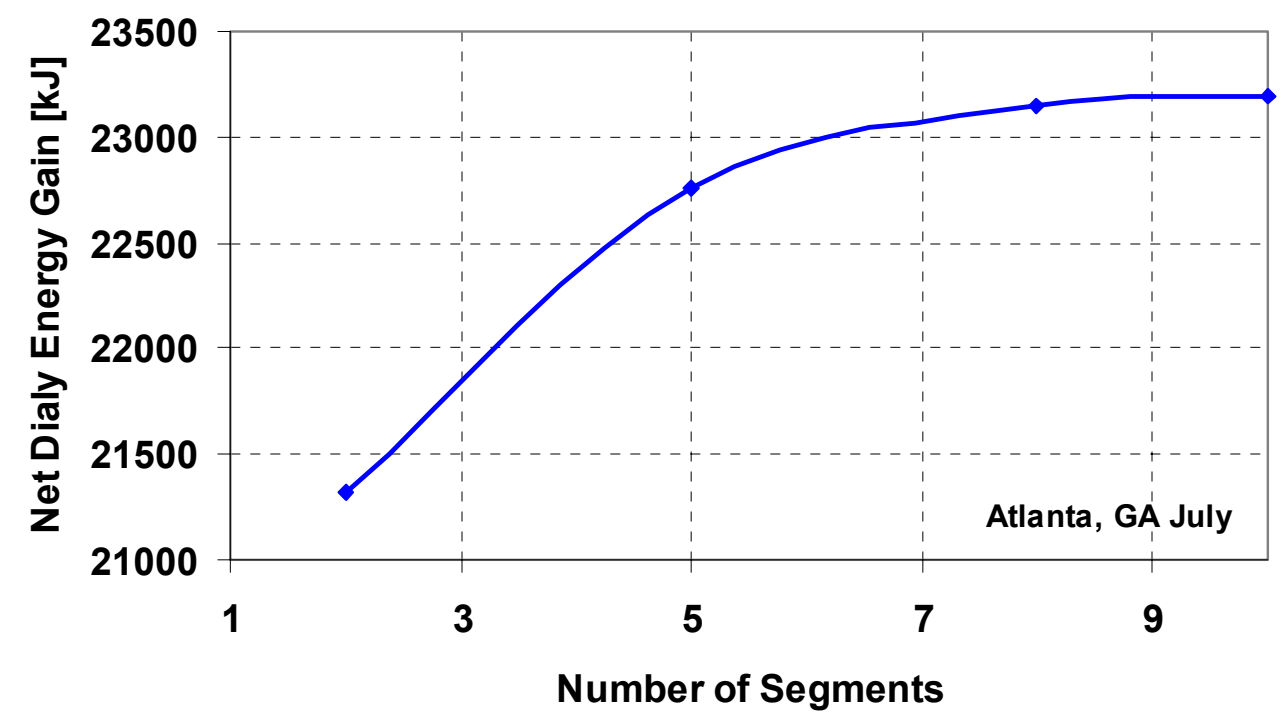

Figure 24: Effect of the Number of Segments on the Estimate of the Daily Energy Gain

\subsection{Base Case Parameters and Heat Pump Characteristics}

The performance of the precast solar collector depends on the characteristics of the other system components such as the storage tank and the heat pump and on the dimensions and operating characteristics of the collector. To begin the analysis of the collector, a heat pump was chosen and a size was established for the thermal storage tank. In addition, "base case" values were assumed for the collector dimensions and operating 
characteristics. These base case values were based on information from the literature. The collector dimensions were then expressed in the form of dimensionless groups which were varied to determine values that yielded improved performance.

\section{Heat Pump Sizing}

The heat pump was sized based on the maximum cooling and heating loads for the given city. Table 6 displays the heating and cooling requirements as calculated by Doebber for each of the cities.

Table 6: Heat Pump Sizing and Maximum Loads

\begin{tabular}{ccc} 
& Atlanta, GA & Chicago, IL \\
\hline Maximum Heating Load & $5763 \mathrm{~W}$ & $7677 \mathrm{~W}$ \\
Maximum Cooling Load & $5024 \mathrm{~W}$ & $6003 \mathrm{~W}$ \\
Nominal Heat Pump Cooling & 2 & 2 \\
Capacity, tons of refrigeration & & \\
Heating Capacity, W & 8353 & 8353 \\
Cooling Capacity, W & 6887 & 6887 \\
\hline
\end{tabular}

Data from Florida Heat Pump [14] for a nominal 2 ton ground source heat pump were used to construct the heat capacity and work input curves as described in Chapter 3, Section 3 .

\section{Tank Sizing}

The thermal storage tank was sized to store sufficient energy to heat the residence for two days in January using a tank temperature difference of 40 C. For sizing purposes, heat losses from the tank were neglected. This criterion led to a tank size of $1 \mathrm{~m}^{3}$ which provides approximately 2 days of storage for Atlanta and approximately 1.5 days of storage for Chicago. 


\subsection{Evaluation of System Performance}

The rate of heat gain by the fluid and the rate of incident radiation for each hour of the day for a single pipe in the collector array is shown in Figure 25.

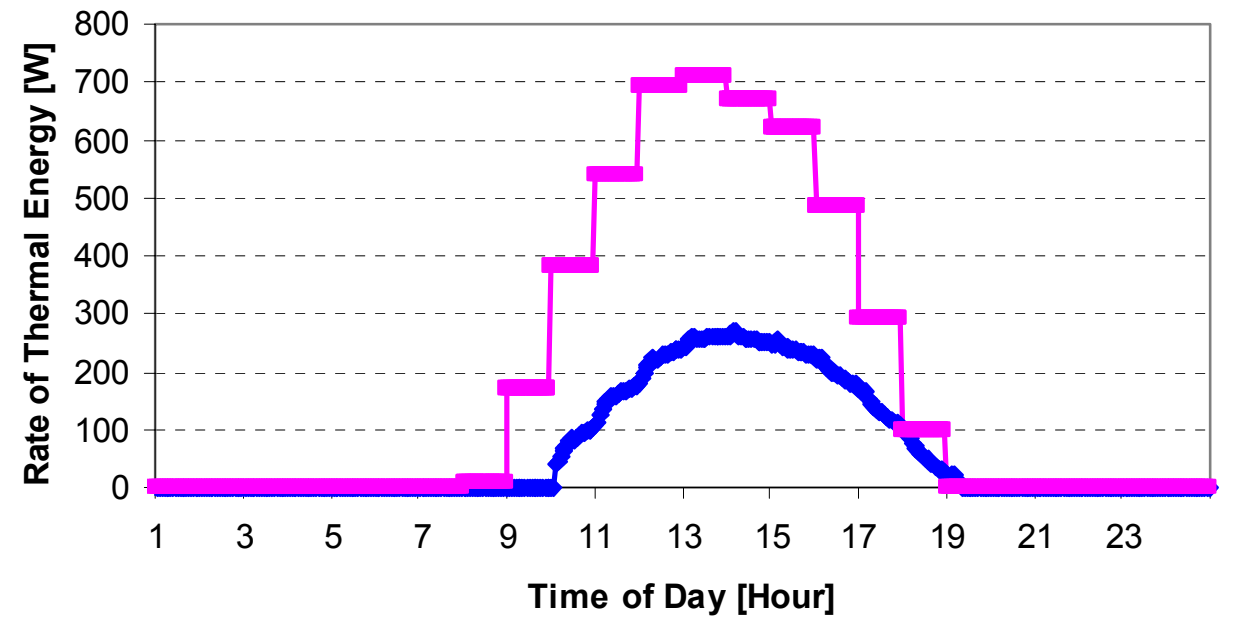

$\rightarrow$ Q_gained $[W] \rightarrow-Q \_$incident $[W]$

Figure 25: Rate of Net Heat Gained by the Fluid and Incident Radiation throughout the Day for the Base Case

Initially, the fluid loses heat to the solid when the ambient air temperature is less than the incoming fluid temperature of $25^{\circ} \mathrm{C}$. The fluid then gains heat as the day progresses and the incident energy increases. The maximum energy gained by the fluid occurs shortly after incident radiation on the concrete collector peaks. Conversely, as the sun sets in the afternoon, there is a slight lag in the decrease in heat gained by the fluid due to the effect of thermal storage.

One of the measures of a solar collector's performance is the efficiency. It is defined as the ratio of useful heat gain in the fluid compared to the incident solar radiation. The instantaneous collector efficiency was calculated by

$$
\eta_{i}=\frac{Q_{\text {Gained }, i}}{Q_{I, i}}
$$


where $\mathrm{Q}_{\text {Gained,i }}$ is the heat transfer to the fluid during the segment time interval, $\mathrm{i}$, and $\mathrm{Q}_{\mathrm{I}_{\_} \mathrm{i}}$ is the incident radiation during the segment time interval, i. Figure 26 displays the collector efficiency, $\eta_{\mathrm{c}}$, as it varies throughout the day.

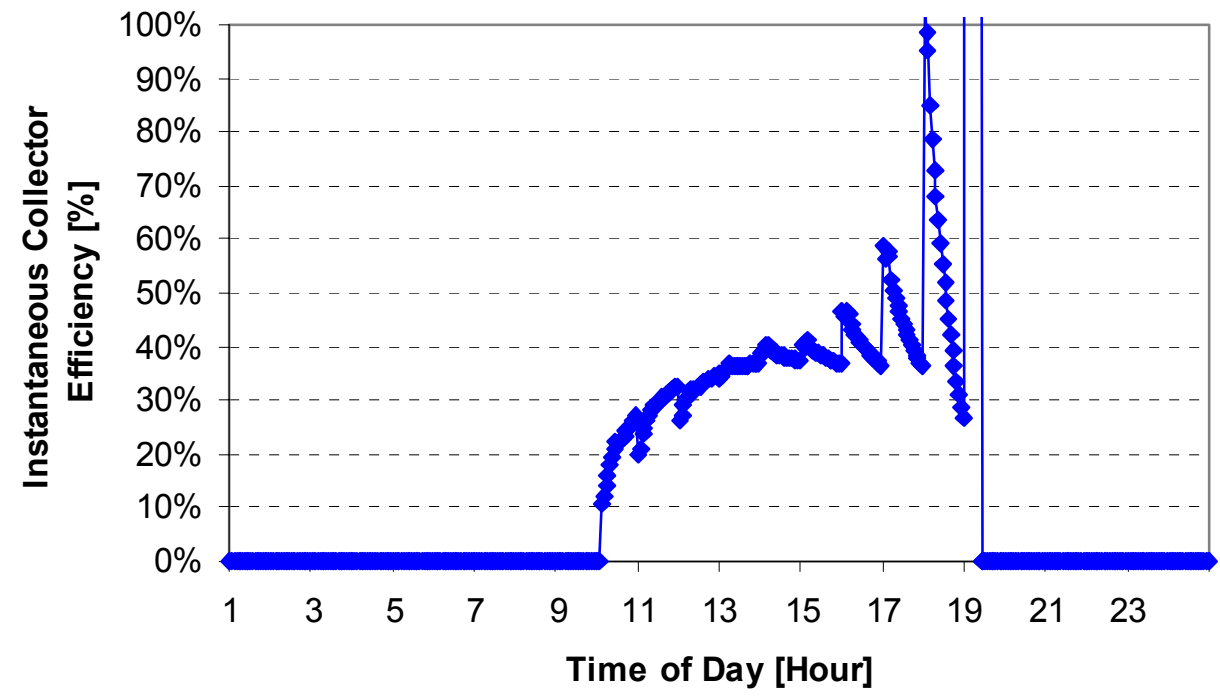

Figure 26: Collector Efficiency in Atlanta, GA during January *Note: Efficiencies above $100 \%$ reflect the energy stored in the precast concrete and are unrealistic.

In addition to the instantaneous efficiency, a daily average efficiency was calculated by integrating the heat gained by the fluid over the entire day and dividing by the solar radiation integrated over the entire day. The resulting daily efficiency for the base case design was $35.8 \%$ which is just shy of the daily efficiency of $37 \%$ determined experimentally by Jubran et al [11] for a similar concrete collector.

While collector efficiency is a common measure of collector performance, a more significant measure for a collector connected to a heat pump is the amount of work required by the heat pump. The work input needed to meet the hourly space conditioning and domestic water heating load during January using the solar collector as the heat source is shown in Figure 27 for the base case. 


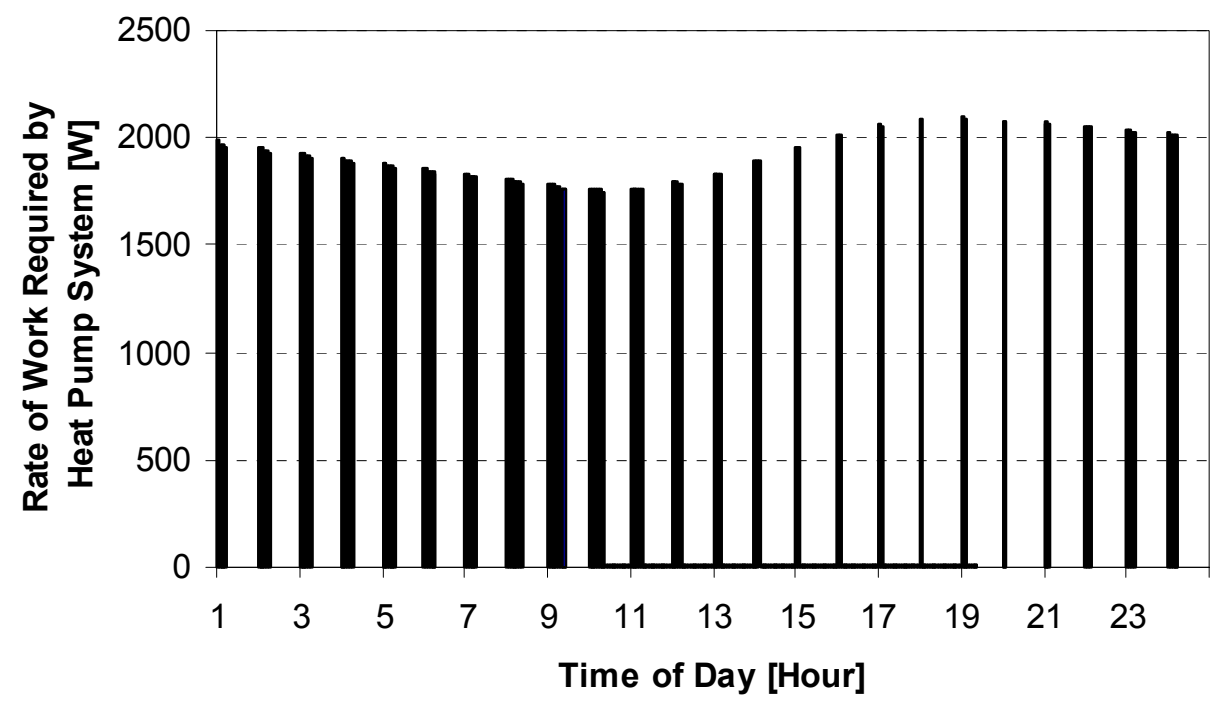

Figure 27: Work Input Needed for Heat Pump System in January (Base Case Design)

As indicated in Figure 27, the heat pump system does not run continuously during the entire hour. Instead the heat pump only runs during a fraction of the hour as required to meet the load. Because of the way the program is executed, the running times are at the beginning of each hour.

For the parametric studies both the net heat gained and the work input will be scaled by the base case as given by

$$
\begin{aligned}
& f_{Q_{-} \text {Gained }}=\frac{Q_{\text {Gained_X_Case }}}{Q_{\text {Gained_Base_Case }}} . \\
& f_{W_{-} I n}=\frac{W_{\text {In_X_Case }}}{W_{\text {In_Base_Case }}}
\end{aligned}
$$

Parameters including the collector dimensions, fluid velocity, and number of pipes are evaluated to determine their effect on these two measures. 


\subsection{Parametric Studies}

Six parameters were studied to determine optimal characteristics for the precast solar collector. Each parameter was varied over a range of values in order to determine the effect it had on system performance. Table 7 shows each of the parameters and the range over which they were varied.

Table 7: Parameters for Parametric Study

\begin{tabular}{cccc} 
Parameter & Definition & Range & Baseline Value \\
\hline $\mathrm{N}_{\mathrm{P}}$ & Number of Pipes & $1-35$ & 25 \\
$\mathrm{X}_{1}$ & Thickness / Width & $0.082-1.50$ & 0.1875 \\
$\mathrm{X}_{2}$ & Length / Width & $14.07-1.524$ & 28.15 \\
$\mathrm{X}_{3}$ & Outer Pipe Diameter / Width & $0.0392-0.1175$ & 0.0781 \\
$\mathrm{X}_{4}$ & NTU & $0.0348-0.348$ & 0.174 \\
$\mathrm{X}_{5}$ & Fo & $0.260-1.038$ & 0.519 \\
\hline
\end{tabular}

The number of pipes, $\mathrm{N}_{\mathrm{P}}$, is the number of identical parallel pipes in the collector array. The collector thickness, length, and pipe diameter were scaled by the width, resulting in the three nondimensional parameters $X_{1}, X_{2}$, and $X_{3}$. The number of transfer units, NTU, is the ratio of heat transfer at the tube wall to the advection of energy in the fluid. The Fourier number, Fo, is a ratio between the thermal diffusivity, dimensionless time, and the width of the collector. It is used to determine the effectiveness of the thermal storage in the precast solar collector. The six parameters are explained in further detail in the following subsections.

\section{Number of Pipes}

The first parameter of interest in the collector design is the number of pipes needed to meet the hourly load of the house. The pipes are assumed to be assembled in parallel such that all pipes perform identically (i.e. the inlet and outlet temperatures for all the pipes are the same and the heat gained by each pipe is the same). 
The number of pipes was increased until the ratio of the heat gained to the heat required met or exceeded 1. Figure 28 shows the ratio of heat gained to the heat required as a function of the number of tubes for Atlanta, GA during a typical day in January.

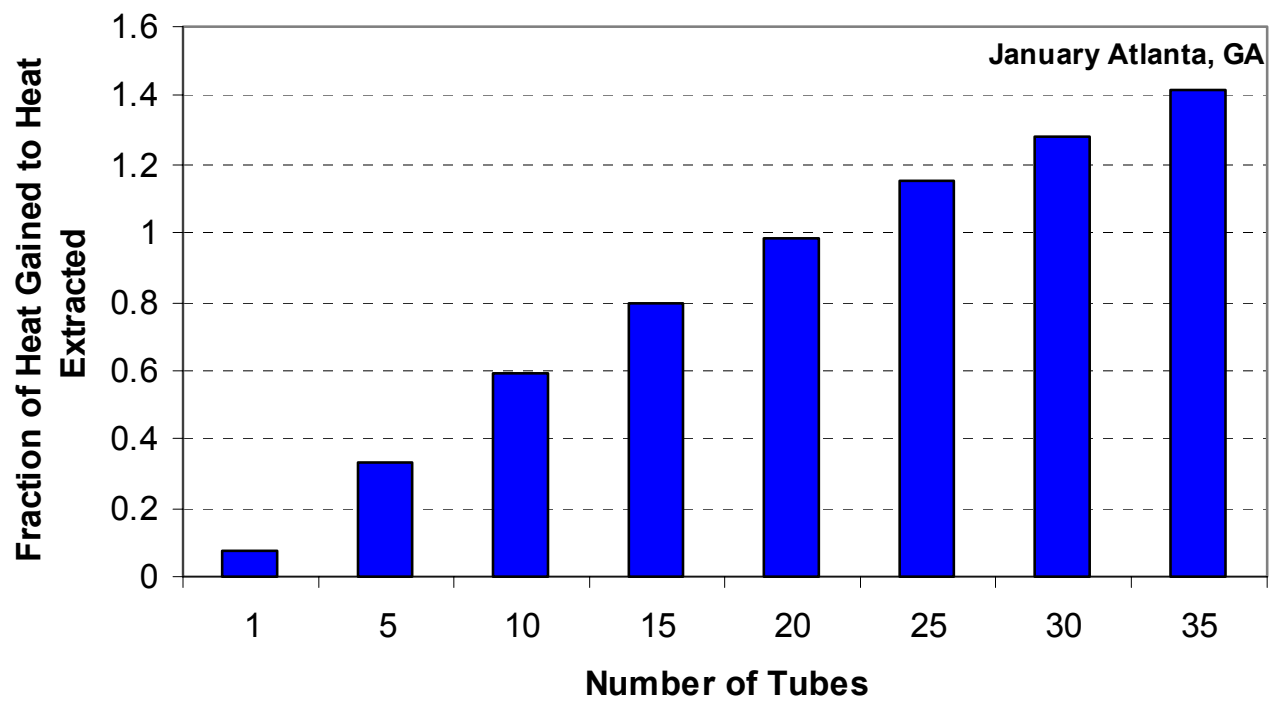

Figure 28: Ratio of Heat Extracted to Heat Gained versus Number of Tubes

As suggested by Figure 28, approximately 23 pipes are required for January in Atlanta, GA. For a 23 pipe array, the average rate of heat gained by the precast solar collector during a typical Atlanta day in January is $1.76 \mathrm{~kW}$. The remaining parametric studies will be based upon a 23 pipe array.

\section{Collector Thickness}

The collector thickness affects the resistance to heat transfer from the collector surface to the embedded pipe. Usually an increased thickness will cause a decrease in the amount of heat gained by the fluid. But increased thickness also causes an increase in the thermal storage effects. The energy stored in the concrete continues to heat the fluid even when the solar radiation is absent. Conversely, a thinner concrete collector offers decreased resistance to heat transfer through the solid, but less thermal capacitance. The decrease in resistance increases heat transfer to the fluid. Higher temperatures resulting from 
reduced thermal capacitance will cause an increase in the convective losses from the top of the collector.

The precast collector thickness was varied from $0.0167 \mathrm{~m}$ to $0.3048 \mathrm{~m}$. The lower number is approximately 5 percent bigger than the base case outer diameter of the pipe embedded at the centerline of the concrete. Thus, all cases contained a pipe that was completely covered by concrete on all sides. The effect of varying the thickness of the concrete on thermal performance is illustrated in Figure 29.

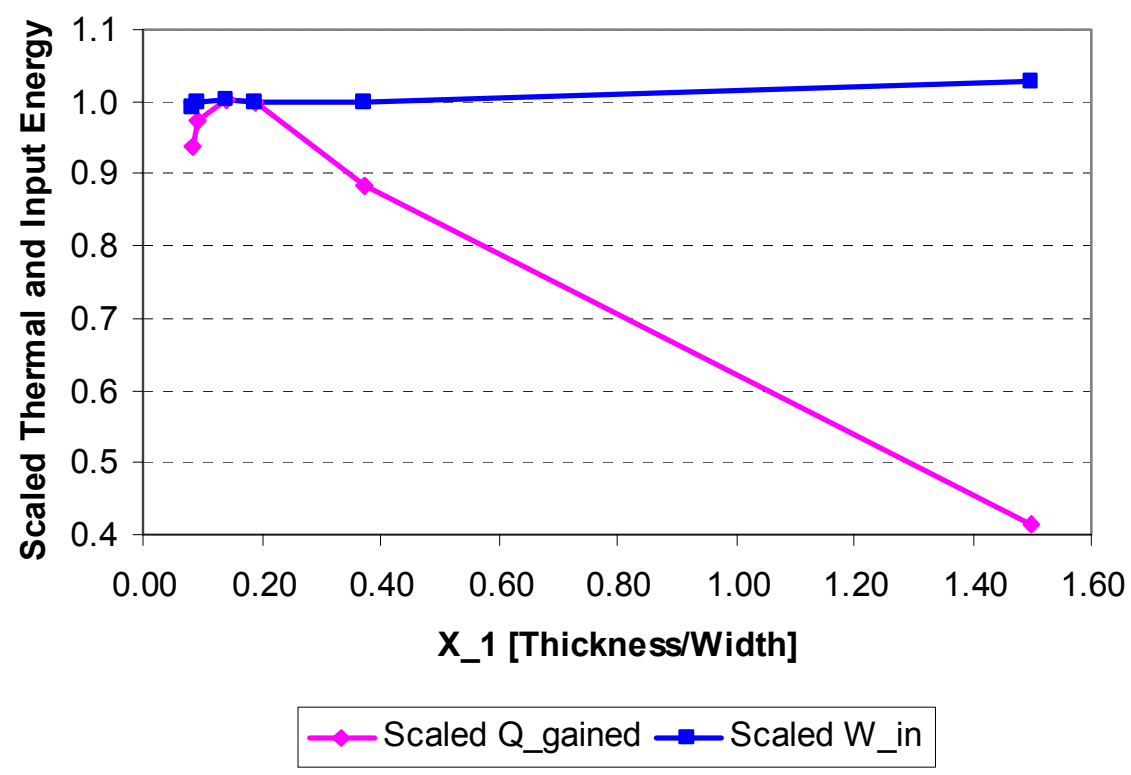

Figure 29: Effect of Dimensionless Thickness on System Performance

The above graph shows that for energy collection there is an optimal thickness to width ratio for the precast solar collector. Thermal storage associated with increased thickness mitigates the temperature swings of the collector thus reducing losses associated with high collector temperatures. On the other hand, the increase in thickness required to achieve this storage leads to grater resistance between the surface and the tube. For this collector, the optimal thickness occurred in the range of $0.14<\mathrm{X}<0.1875$.

The work needed to run the heat pump system varied only slightly in the range $0.08<\mathrm{X}_{1}$ $<0.20$. Likewise, the energy collected did not vary significantly within the optimal range 
of $0.14<\mathrm{X}_{1}<0.1875$. The thicker value was chosen for $\mathrm{X}_{1}$ to add structure to the concrete collector and to allow the use of a larger diameter pipe.

\section{Collector Length}

The amount of radiation incident upon the surface of the precast collector is directly affected by the length of the collector. An increase in the length of the collector will increase the amount of heat gained from the top boundary exposed to the sun and will also increase the amount of storage due to an increase in thermal mass. However, the collector length is limited by practical limitations such as collector cost or roof size.

The dimensionless length of the precast solar collector length was varied from 15 to 265 . To isolate the effects of the length, the fluid velocity was altered to keep parameter $\mathrm{X}_{4}$, the NTU, constant throughout the study. For the house considered here, the length of the south facing roof is $5.72 \mathrm{~m}$ yielding a maximum possible value of 28.1 for $\mathrm{X}_{2}$ if the width corresponds to the base value of $0.2032 \mathrm{~m}$. Thus, $\mathrm{X}_{2}$ was chosen to be 28.1

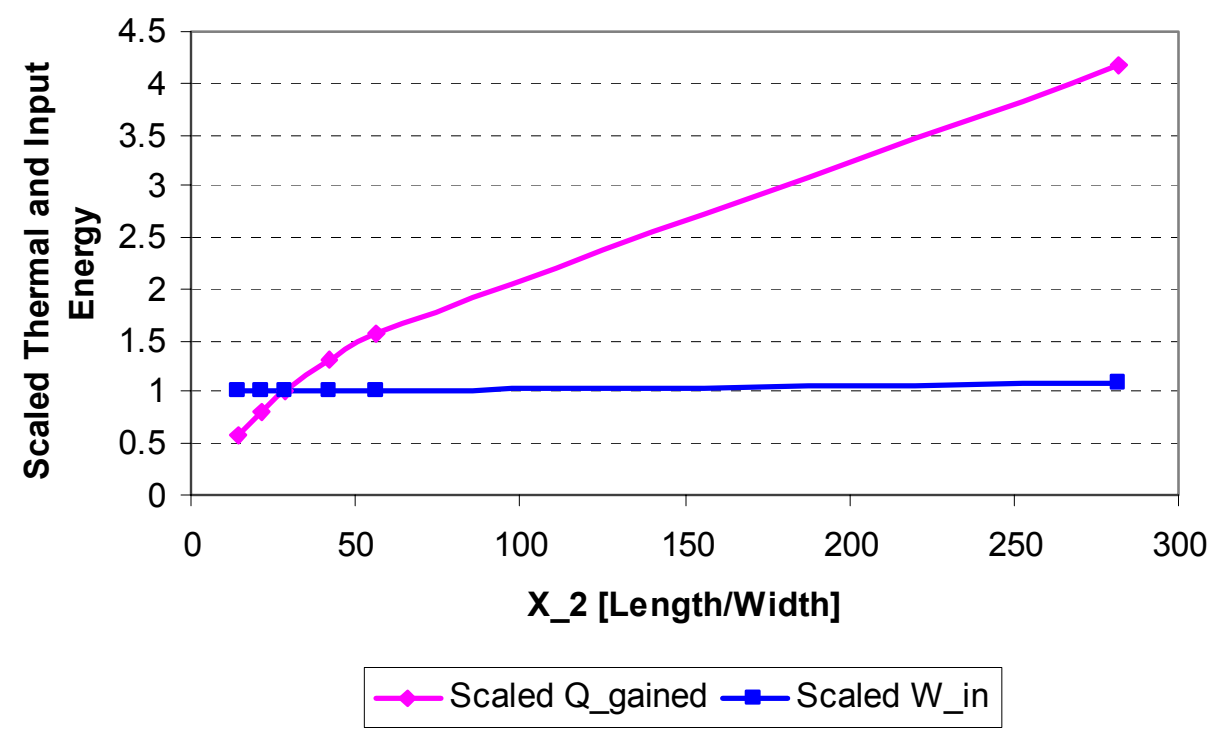

Figure 30: Effect of Dimensionless Length on System Performance

Figure 30 reveals that even at a length 100 times the base case the heat gained by the fluid continues to increase. This trend is a consequence of increasing the fluid velocity to maintain a constant NTU. At extreme values of length, the work input ceases to change 
because additional thermal energy is not required and adding length beyond this point does not change the leaving fluid temperature. Clearly, very large length to width ratios are not realistic, but large values of $\mathrm{X}_{2}$ were used to verify the asymptotic behavior.

\section{Collector Pipe Diameter}

Heat transfer to the fluid is expected to increase as pipe diameter (and hence the heat transfer area) increases. The upper limit of the diameter is determined by the thickness of the concrete solar collector. The pressure drop through the pipe increases as the diameter decreases for a given flow rate. This will adversely affect the performance of the system due to an increase in pumping losses.

The outer pipe diameter was varied from $0.006048 \mathrm{~m}$ to $0.02387 \mathrm{~m}$, which corresponds to pipes sizes of $1 / 4$ of an inch to $3 / 4$ inch. The inner pipe diameter was varied based on outer pipe diameter and in accordance with manufacturer's specifications for actual pipe sizes. Changing the pipe diameter caused the heat transfer coefficient at the inside solid boundary to change since it is based on the pipe diameter. In order to isolate the effects of pipe diameter, $\mathrm{X}_{3}$, the velocity was varied to maintain a constant value for $\mathrm{X}_{4}$, the NTU. Figure 31 displays the system performance as it varies with pipe diameter.

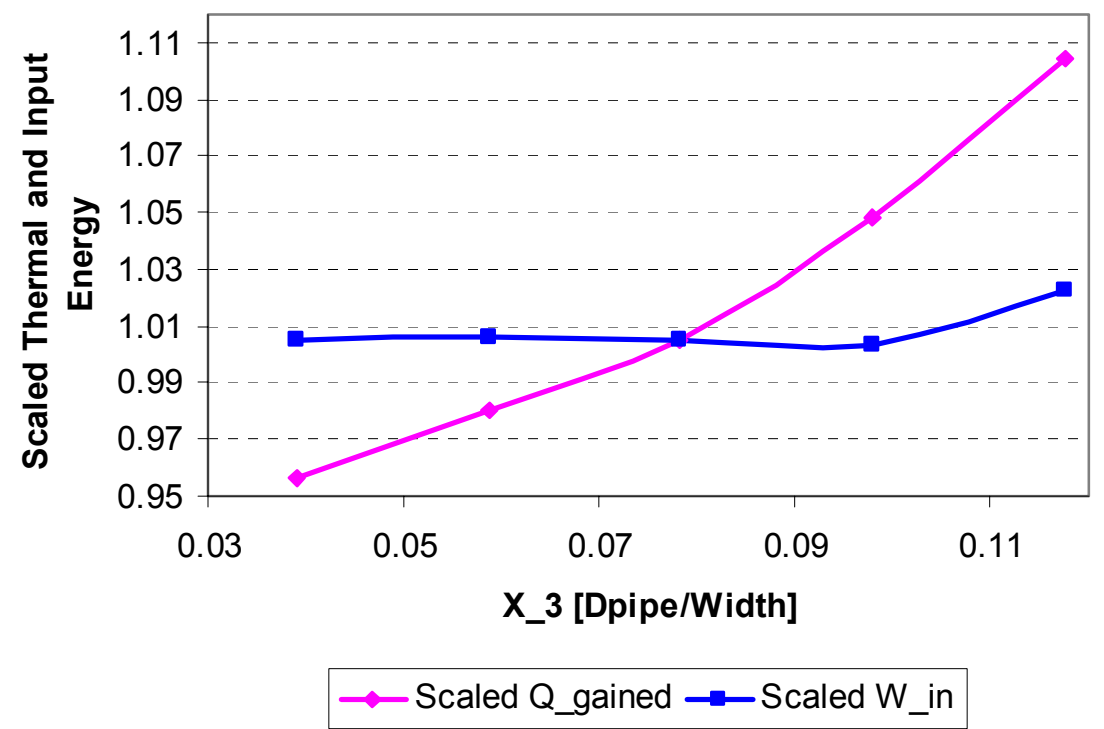

Figure 31: Effect of Dimensionless Pipe Size on System Performance 
From the above graph it is evident that a larger pipe diameter has little effect on the amount of work required by the heat pump. The net heat gained continues to increase as pipe diameter increases. This increase can be attributed to the increase in surface area over which the heat transfer takes place at the inner boundary. An increase in diameter decreases the heat transfer coefficient, but the velocity was decreased as well to make the number of transfer units equivalent from case to case. This will keep the amount of energy convected at the inner boundary of the solid equal to the amount of energy advected down the pipe equal to the base case value. The largest diameter tested was on the order of 10 percent smaller than the thickness of the concrete. This leaves little conductive resistance between the collector surface and the pipe.

The study revealed that a larger diameter yields a very small benefit. Moroever, the diameter is limited by the thickness of the concrete required to keep the precast panels structurally sound. Consequently, the optimal pipe diameter to width ratio was chosen to be 0.098 corresponding to a $5 / 8$ inch pipe, which is a standard pipe size larger than the base case.

\section{Number of Transfer Units}

The number of transfer units is the ratio of heat transfer due to convection at the inner boundary compared the heat transfer due to fluid flow down the pipe. It is defined as

$$
N T U=\frac{D L h_{f}}{\frac{D^{2}}{4} V_{f} \rho_{f} C_{f}} .
$$

This dimensionless parameter was used to characterize the effects of changing the velocity of the fluid flowing through the pipes on collector performance. An increase in velocity will cause a decrease in the number of transfer units. For the same conditions at the inner boundary of the solid, a decrease in velocity will cause a decrease in the amount of energy advected.

The NTU was varied from 0.0348 to 0.348 by chancing the velocity from $0.762 \mathrm{~m} / \mathrm{s}$ to $0.0762 \mathrm{~m} / \mathrm{s}$. Depending on the exiting fluid temperature, the fluid was either flowing 
constantly at the specified velocity or it was stagnant during the times that the tank temperature exceeded the temperature coming out of the precast solar collector. Figure 32 describes the effect of NTU on system performance.

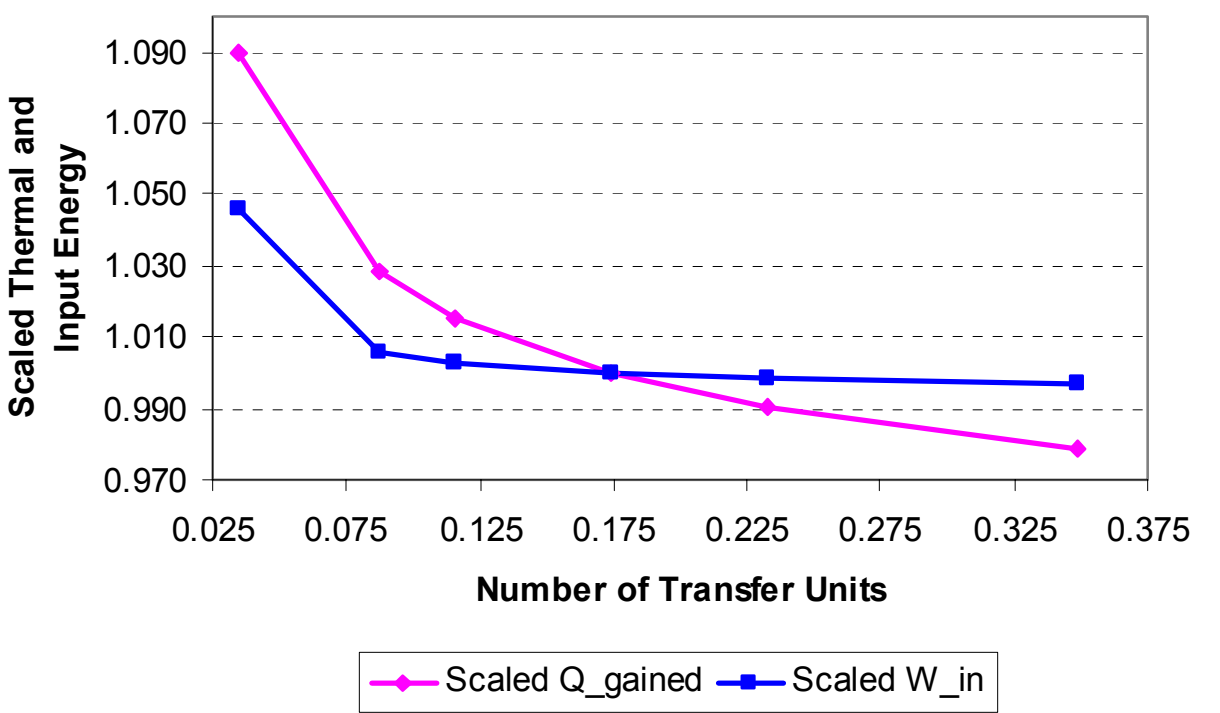

Figure 32: Effect of the Number of Transfer Unites on System Performance

The work required to run the heat pump decreases as the number of transfer units increases to approximately 0.1 . Beyond this value, the NTU has little effect on the work input. Ideally, the system would run using the lowest velocity (i.e. a higher NTU) that produced the least amount of work input. This would minimize the pumping losses associated with flowing fluids. Thus, the NTU was chosen to be 0.174 corresponding to a velocity of $0.1524 \mathrm{~m} / \mathrm{s}$. A velocity much higher than this would cause an increase in the pumping losses through the collector and the pipes because the fluid changes from laminar to turbulent flow.

\section{Fourier Number}

The Fourier number incorporates the thermal diffusivity, dimensionless time, and width of the precast solar collector and is given by

$$
F_{O}=\frac{\alpha_{C} \hat{t}}{w^{2}}
$$


By assuming the dimensionless time is equal to $36,000 \mathrm{~s}$, which is the amount of time that there is significant incoming solar radiation on the collector; the effects of varying the thermal diffusivity of the concrete can be seen. In order to vary the Fo number, the thermal conductivity of the concrete, $\mathrm{k}_{\mathfrak{c}}$, was varied from 0.001 to 8.00 . The base case value for the Fo number was 0.519. The results are presented in Figure 33.

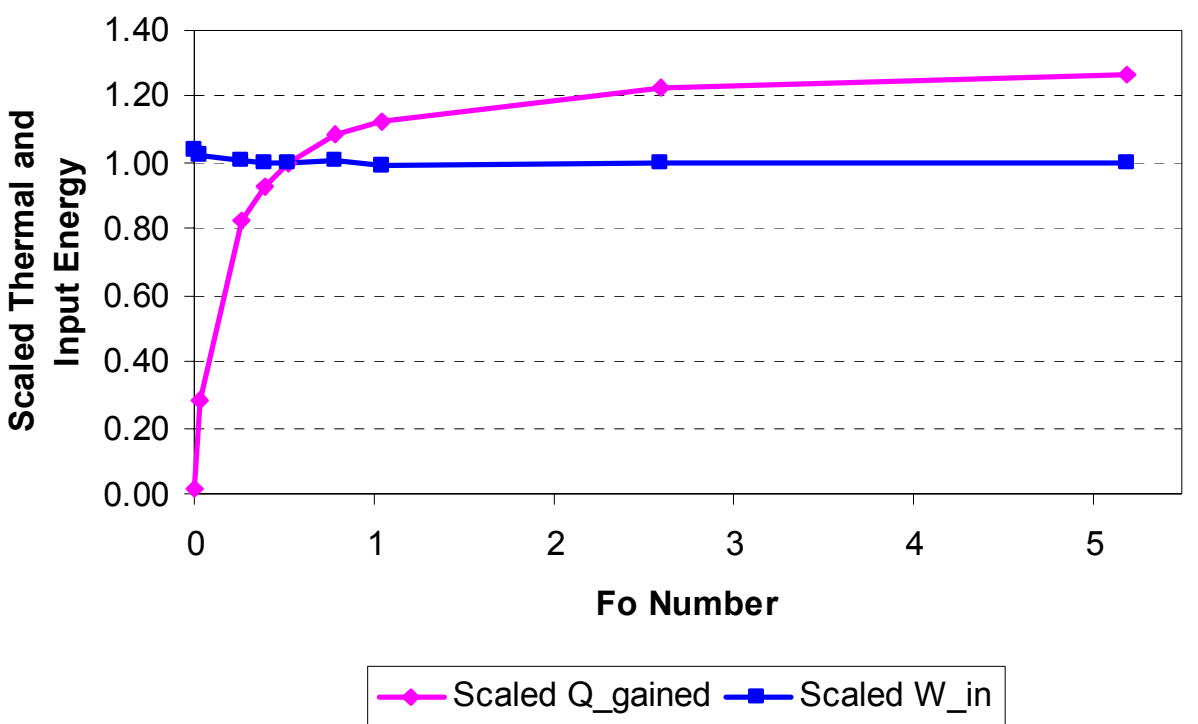

Figure 33: Effect of the Fourier Number on System Performance

The above figure reveals that changing the Fourier number has little effect on the work input required to run the heat pump. However, it has a large effect on the amount of heat gained by the fluid. An increase in the thermal diffusivity of the concrete substantially increases the amount of heat gained by the fluid. This seems to indicate that a less dense, highly conductive concrete would be ideal for this type of precast collector. In addition, a collector with a large amount of thermal storage has little effect on the overall performance on the system; consequently, the ideal precast collector would have just enough thermal mass for the panels to be structurally sound. 


\subsection{Optimal Parameters}

The parametric study suggested improved nondimensional parameters based on collector width. The collector width corresponds to the spacing between adjacent tubes. As the distance increases between the tubes, there is an increase in the amount of thermal energy transfer to the fluid. Consequently, the amount of thermal energy stored in the solid is increases. As the spacing between tubes decreases, thermal energy transfer to the working fluid is reduced.

The nondimensional parameters were constructed in a manner such that an increase in spacing between tubes would cause an increase in thickness and length of the concrete precast panel as well as the pipe diameter. The width was varied from $0.1524 \mathrm{~m}$ to 0.254 m. All of the other parameters were varied such that the nondimensional ratios were kept constant throughout each case. Figure 34 exhibits the effect of changing the width on collector performance in terms of work required by the heat pump and energy gained by the fluid passing through the collector.

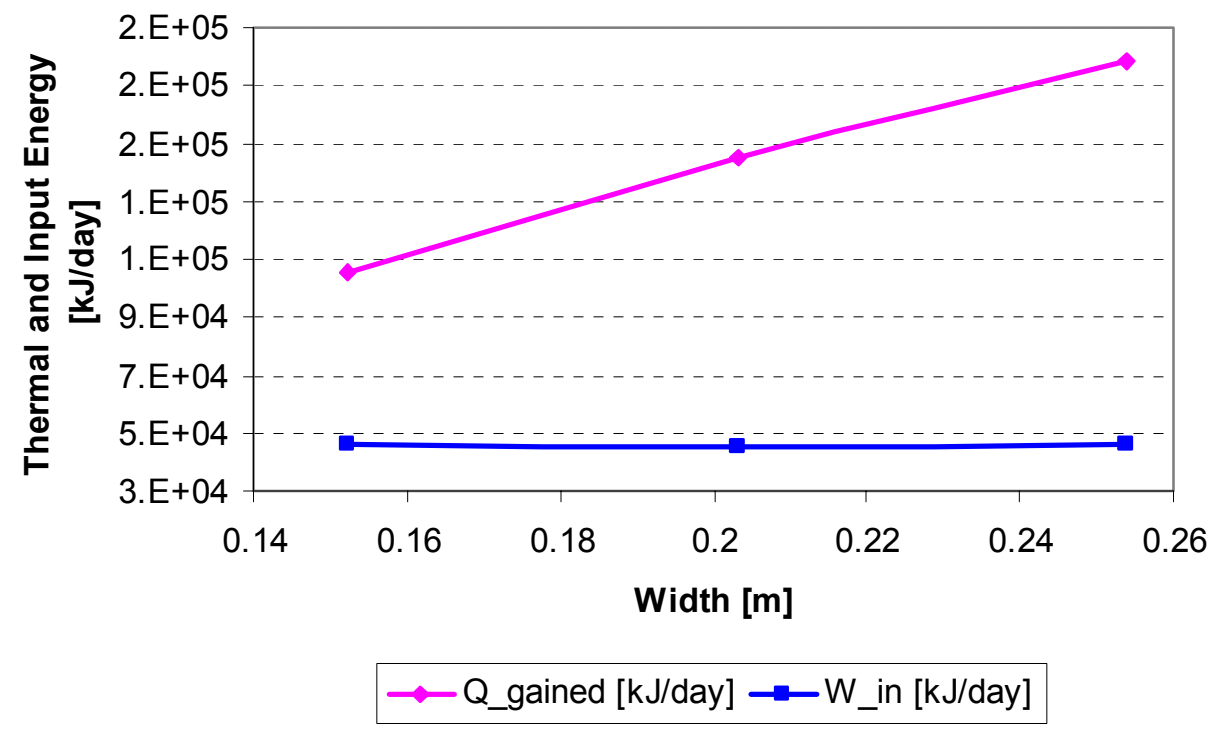

Figure 34: Effect of the Width on System Performance

The above figure demonstrates that the work required by the heat pump to meet the heating load for the residence for a given day is unchanged as the width increases. 
However, there is a substantial change in the amount of heat gained as the width of the collector increases. The increase in width increases the amount of energy that can be stored by the thermal mass. More importantly, it increases the surface area that is exposed to incident radiation. Conversely, decreasing the width of the collector would cause a decrease in the amount of heat gained by the fluid and the number of tubes needed to keep up with the daily heating load of the residence would have to be increased. Thus decreasing the width does not reduce the overall collector area. For this study, the width was set equal to the base case value of $0.2032 \mathrm{~m}$. The corresponding optimal parameters based on this width are provided in Table 8 .

Table 8: Optimal Dimensions for Concrete Collector

\begin{tabular}{|c|c|c|}
\hline Characteristic & Nondimensional Value & Dimensional Value \\
\hline Collector Width & ----- & $0.2032 \mathrm{~m}$ \\
\hline Collector Thickness & 0.188 & $0.0381 \mathrm{~m}$ \\
\hline Collector Length & 28.1 & $5.72 \mathrm{~m}$ \\
\hline Pipe Diameter & 0.098 & $0.0199 \mathrm{~m}$ \\
\hline NTU & 0.174 & ----- \\
\hline Fluid Velocity & ----- & $0.1524 \mathrm{~m} / \mathrm{s}$ \\
\hline Fo & 0.519 & ----- \\
\hline $\mathrm{k}_{\mathrm{C}}$ & ---- & $0.80 \mathrm{~W} / \mathrm{mK}$ \\
\hline
\end{tabular}

These values will be used in an annual energy study in Atlanta, GA and Chicago, IL to determine the overall system performance. During the winter months, the series solar collector heat pump system will be used to provide the space heating and domestic water heating loads for the residence. During the summer months, the series solar collector heat pump system will only be used in heating mode if the heat rejected by the condenser does not meet the total heating load of the house. This will be further described in the following chapter. 


\section{Chapter 5: Annual Energy and Cost Analysis}

The energy system of the house is comprised of a precast solar collector, storage tank, and heat pump system. The precast solar collector will be used in conjunction with the heat pump system to meet both the space heating and domestic hot water loads of the residence. An annual simulation was conducted for 2 locations: Atlanta, GA and Chicago, IL. The performance of the energy system will be compared to a typical air to air heat pump that was modeled in Energy Plus.

\subsection{System Description}

The precast solar collector was modeled using the improved dimensions and operating characteristics that were identified in the parametric studies and described in Chapter 4. The inner spacing between pipes was maintained at $0.2032 \mathrm{~m}$. The dimensions for the concrete collector were presented in Table 8 .

The heated water exiting the precast solar collector is fed into a storage tank if the temperature of the water exceeds that of the temperature of the storage tank. The new storage tank temperature is calculated based upon the water temperatures entering from the precast solar collector loop and heat pump loop as shown in Figure 10 of Chapter 3. One stream of water exiting the tank is sent to the evaporator if there is a heating load that must be met for the current timestep. The other stream of water is recirculated through the precast solar collector for heating.

A "typical" day is simulated for each month of the year at each location. The weather data and loads were described previously in Chapter 3 and represent average values for each hour of the month. 
The initial solid model temperature distribution, initial fluid temperature, and overall loss coefficient is determined by running each monthly simulation twice. The first test uses approximate initial values for both the fluid temperature and overall loss coefficient. Once the simulation is completed for the entire day, the final temperatures of the solid and fluid and overall loss coefficient are taken to be the initial conditions for the next test. By using this as the initial condition the effects of day to day operation are captured. All of the initial conditions were updated in this manner for each trial since they are location and month dependent. The initial fluid temperature entering the collector is displayed in Table 9.

\begin{tabular}{ccc}
$\begin{array}{c}\text { Table 9: Initial Fluid Temperature, K, for Atlanta, GA and Chicago, IL } \\
\text { Month }\end{array}$ & $\begin{array}{c}\text { Initial Fluid } \\
\text { Temperature } \\
\text { Atlanta, GA }\end{array}$ & $\begin{array}{c}\text { Initial Fluid } \\
\text { Temperature } \\
\text { Chicago, IL }\end{array}$ \\
\hline January & 283 & 267 \\
February & 285.6 & 274 \\
March & 289 & 277 \\
April & 296 & 283 \\
& & \\
September & 291 & 285 \\
October & 287 & 284 \\
November & 285 & 278 \\
December & 283 & 269 \\
\hline
\end{tabular}

As the ambient temperature rises throughout the year, the inlet fluid temperature and the convective and radiative losses from the top of the collector begin to rise. Chicago, IL has lower inlet fluid temperatures because the ambient conditions are colder than in Atlanta especially in the winter months. This will cause a decrease in the maximum temperature reached by the fluid in the precast concrete collector. The number of pipes was maintained at 25. With the improved collector design, this will provided more than enough heat in Atlanta, GA, while meeting the larger load in Chicago, IL. 


\subsection{System Operation Strategy}

The precast solar collector in conjunction with the heat pump system is used to meet the heating loads of the residence. The domestic water heating load is present during all times of the year. The space heating load is only present during the cooler months. The series solar meets this load as well as the space heating load. During the warm months, when heating is only required for the domestic water, heat rejected by the heat pump condenser is used to meet the load. The heat rejected by the condenser is calculated by

$$
\dot{\mathrm{Q}}_{\mathrm{Cond}}=\dot{\mathrm{Q}}_{\mathrm{C}}\left(1+\frac{1}{\mathrm{COP}_{\mathrm{C}}}\right)
$$

where $\dot{Q}_{C}$ is the cooling load in Watts and $\mathrm{COP}_{C}$ is the coefficient of performance of the heat pump during cooling mode that is assumed to be 3 . If the heat rejected by the condenser is smaller than the heating load, energy from the solar collector is used to help meet the needs of the residence. This is a more common occurrence during the inbetween months such as April and September when the climates are in-between the winter and summer extremes. If the heat rejected by the condenser is able to meet the water heating load for a particular hour, then heat is not extracted from the storage tank.

The loads for a typical day for representative months of the year are given in Figure 35 for Atlanta, GA and Chicago, IL. 


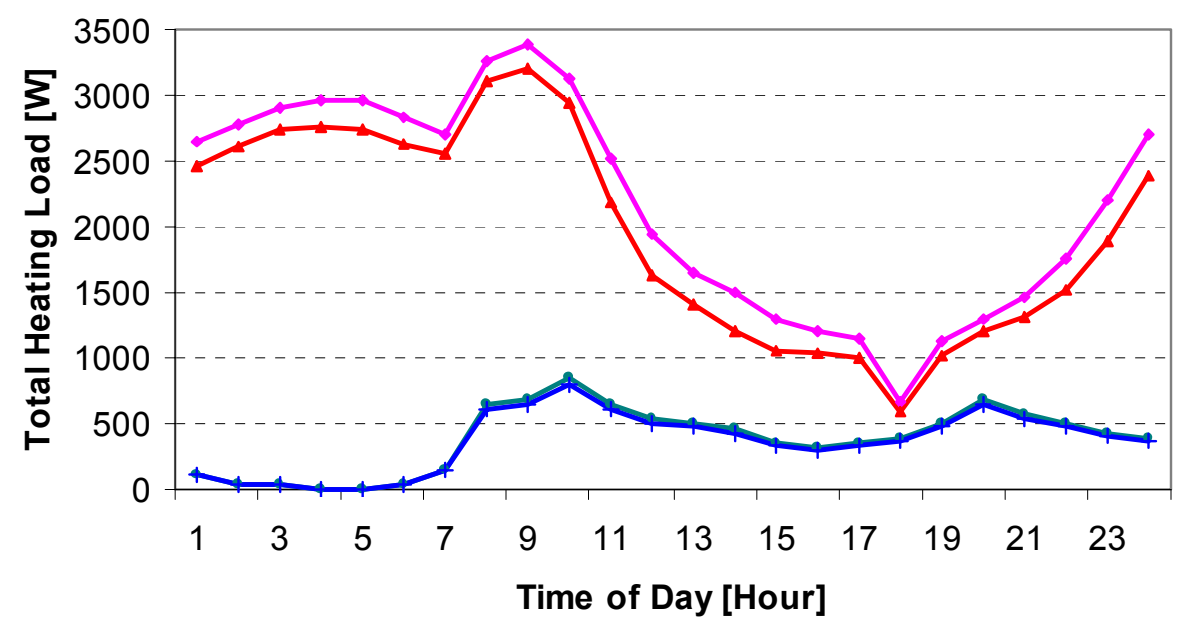

๑Jan. —Jun. —Jul. —Dec.

Figure 35: Total Heating Load for a Typical Day in Atlanta, GA During Each Month of the Year

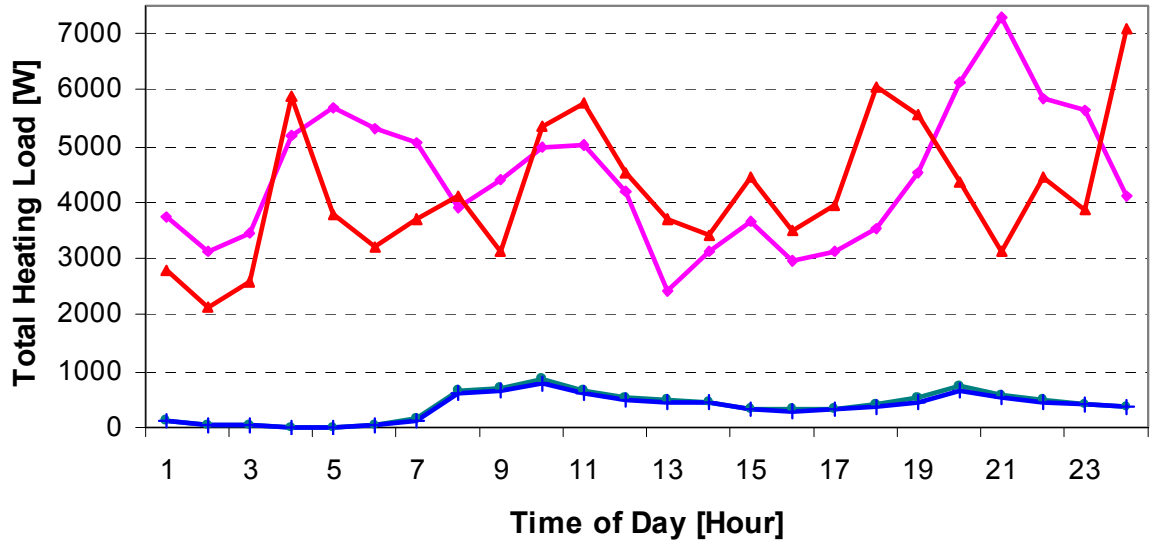

Figure 36: Total Heating Load for a Typical Day in Chicago, IL During Each Month of the Year

Figures 35 and 36 show a large distinction in heating loads between the two cities. As expected, the heating requirement is much higher in Chicago, IL than in Atlanta, GA due to the colder temperatures. 
In order to evaluate system performance, the work required to run the heat pump as well as the heat gained by the fluid in the precast solar collector are monitored throughout the day for each month of the year. The air to air heat pump and the series solar heat pump will be compared in terms of energy use and economics to determine the merits of the precast collector and heat pump system in both locations.

\subsection{Results from Annual Analysis}

An air to air heat pump was simulated using Energy Plus and compared to the precast solar collector combined with a series solar assisted heat pump. The precast solar collector was used in order to raise the temperature of the incoming fluid, water in this study, in hopes of increasing the overall efficiency of the system. The heat capacity of the heat pump increases with incoming temperature; consequently, the amount of work required to meet the load for a given hour is decreased. Annual studies were conducted in Atlanta, GA and Chicago, IL. For consistency, the air to air heat pump and the solar assisted heat pump were required to meet the same load under the same weather conditions for both cities. Results from the analysis include the temperature distribution in the precast collector, temperature of the water leaving the collector, the precast collector efficiency, and the energy use for the solar assisted heat pump. Based on the energy use and first cost of the system, the life cycle cost was determined.

\section{Temperature Distribution in Precast Collector}

The solid model constructed in Femlab determines the temperature distribution for each segment timestep in the simulation. As the incident radiation increases, the temperature distribution in the model is noticeably different from the top surface to the inner fluid boundary. Figure 37 displays 3 temperature distribution plots at varying points along the pipe. 


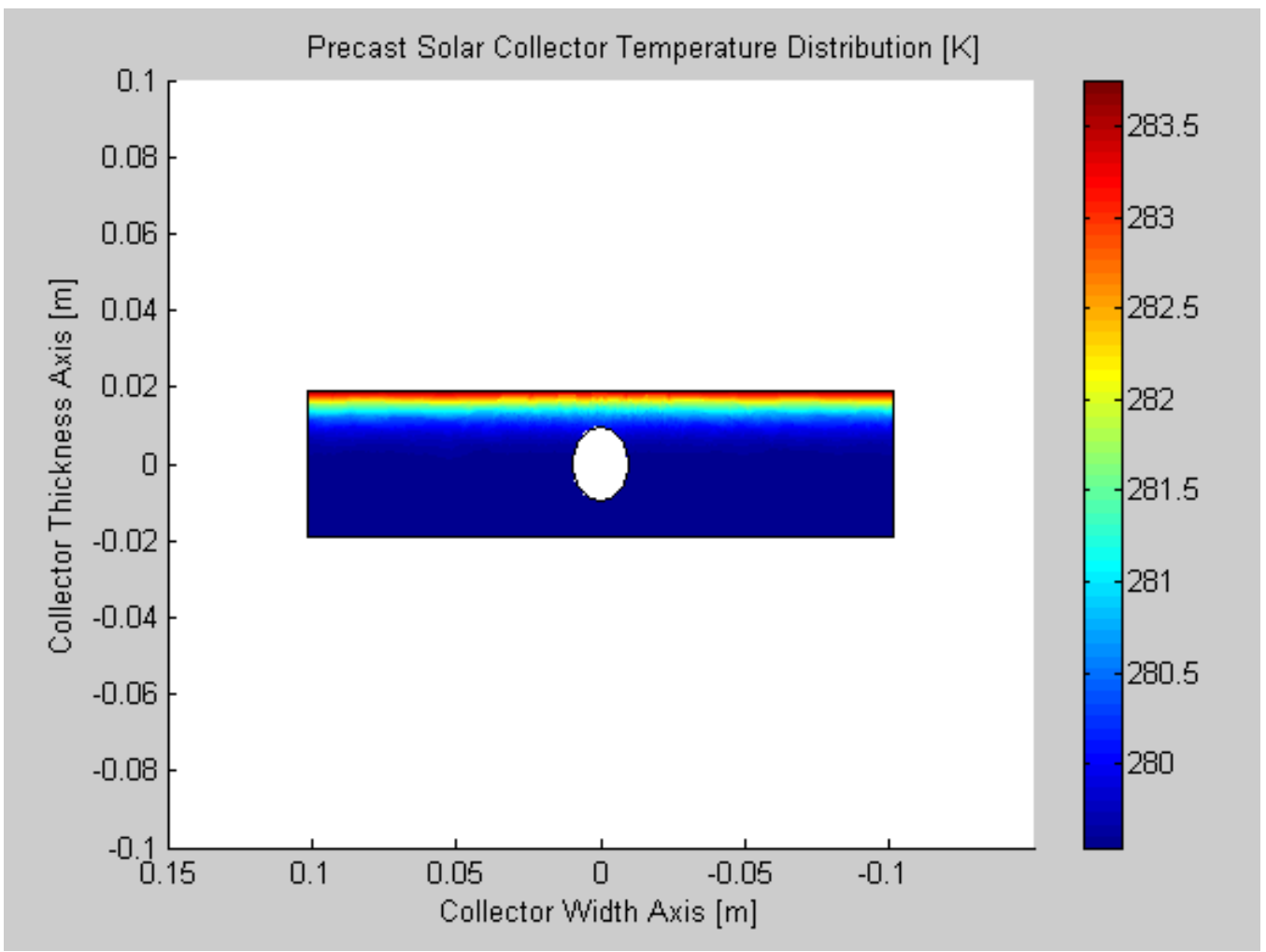

Figure 37a: Temperature Distribution in Initial Segment of the Precast Solar Collector for Hour 10 in January

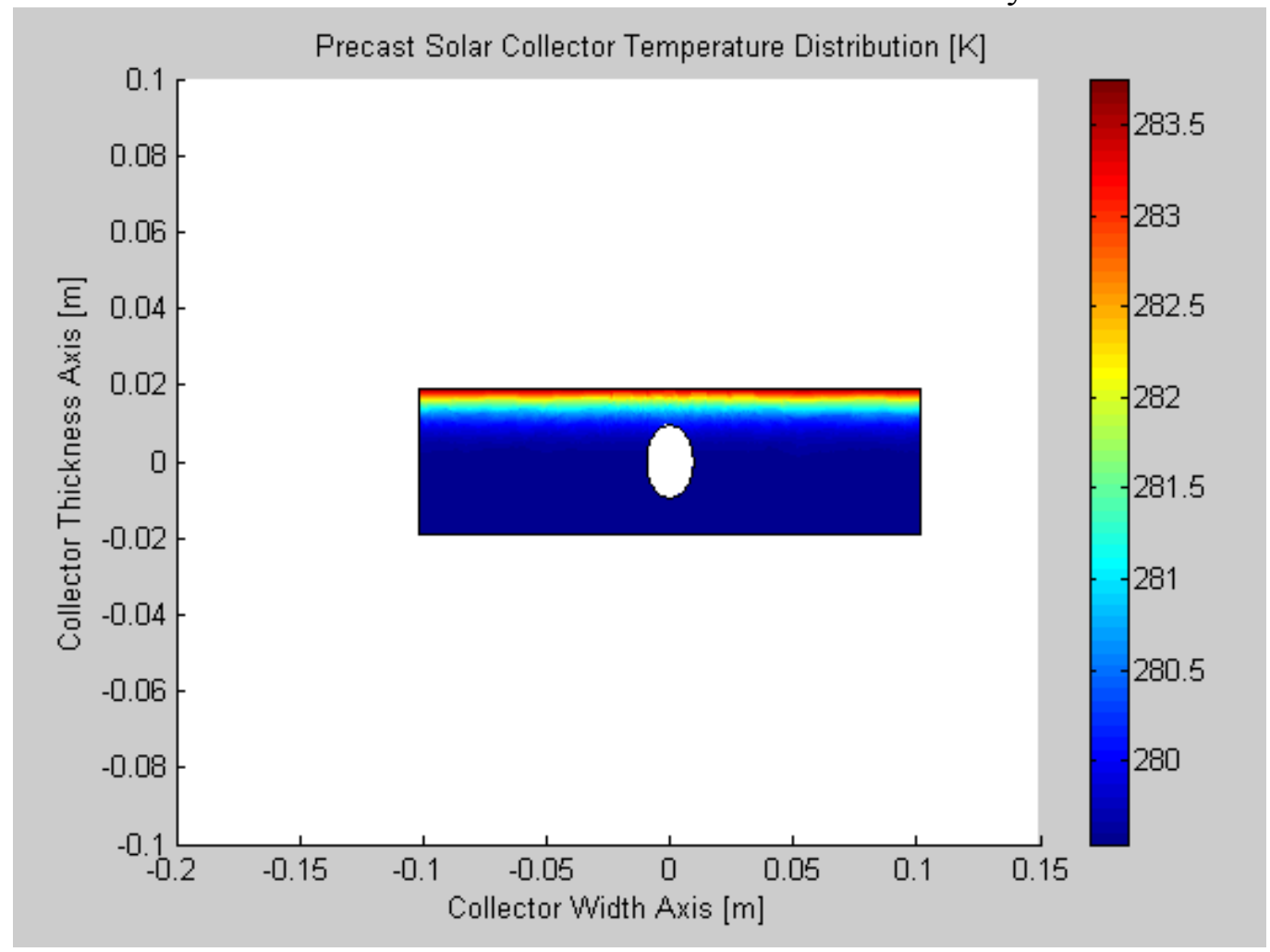

Figure 37b: Temperature Distribution in Middle Segment of the Precast Solar Collector for Hour 10 in January 


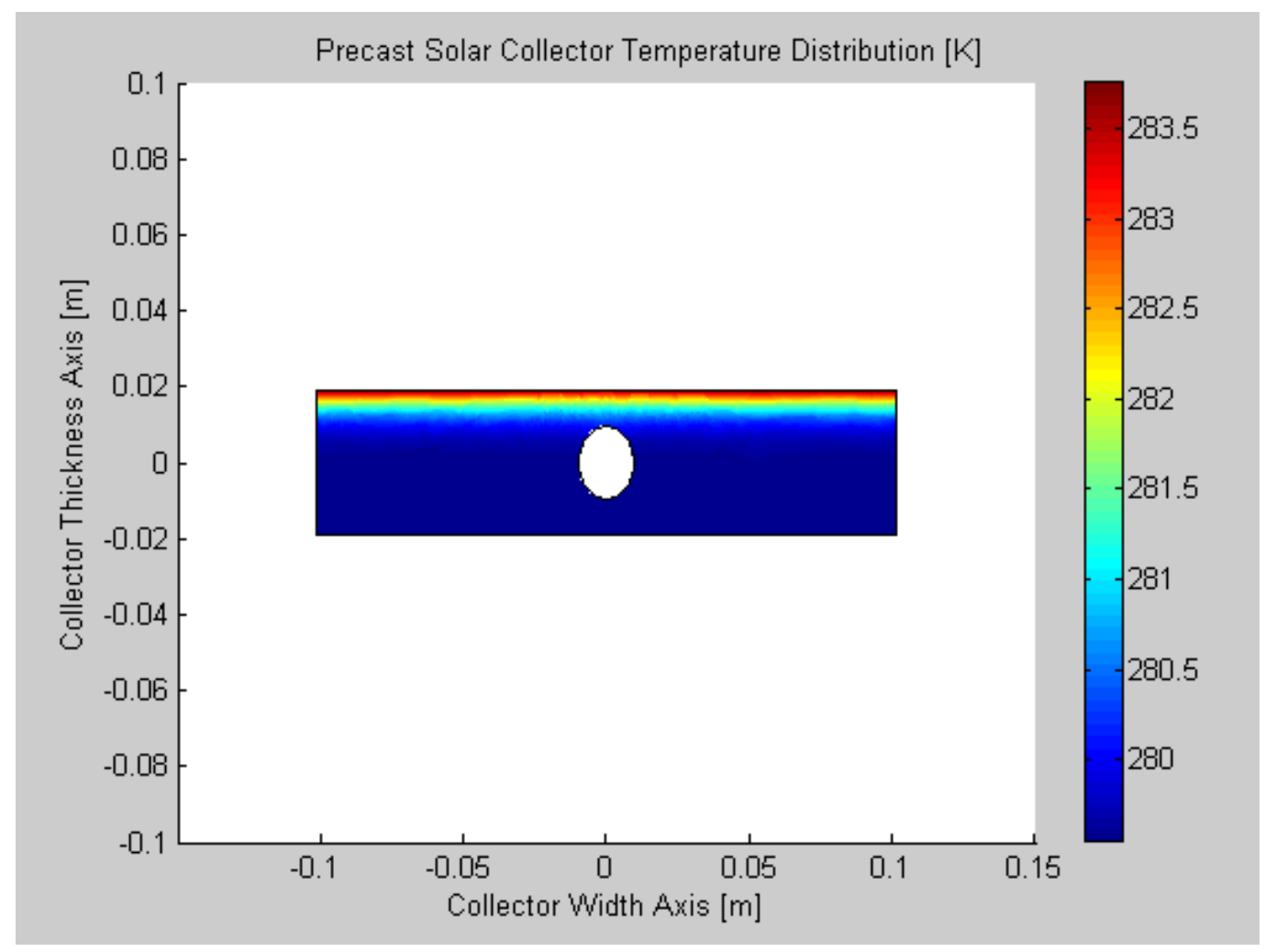

Figure 37c: Temperature Distribution in Final Segment of the Precast Solar Collector for Hour 10 in January

The first plot shows the temperature distribution in the solid of the first segment, where the fluid enters the collector. The second plot shows segment number 4 along the same channel. The only difference between the conditions imposed upon the first segment and this one is the incoming fluid temperature. The fluid temperature has traveled through 3 previous segments and has gained some heat in the process. Finally, the last segment shown, segment 8 , corresponds to the temperature distribution within the precast solar collector right before the fluid leaves the collector.

The pictures illustrate the variance in solid temperature with spatial location throughout the precast solar collector when the radiation is incident upon the collector. Figures 35a, $35 \mathrm{~b}$, and $35 \mathrm{c}$ do no reveal a distinct difference in the solid temperature distribution as expected. All three plots were created from the temperature solution at the same timestep in the month of January for Atlanta, GA. The only difference between the three would be 
the fluid temperature exiting the last segment, which ranges from $280 \mathrm{~K}$ at the inlet to $281 \mathrm{~K}$ at the exit for 1 fluid timestep of 45 seconds.

If the same segment is followed throughout the hour, a large variance in the temperature distribution of the solid is seen. Figures $38 \mathrm{a}, 38 \mathrm{~b}$, and $38 \mathrm{c}$ exhibits the effects of the time on the temperature distribution in the solid.

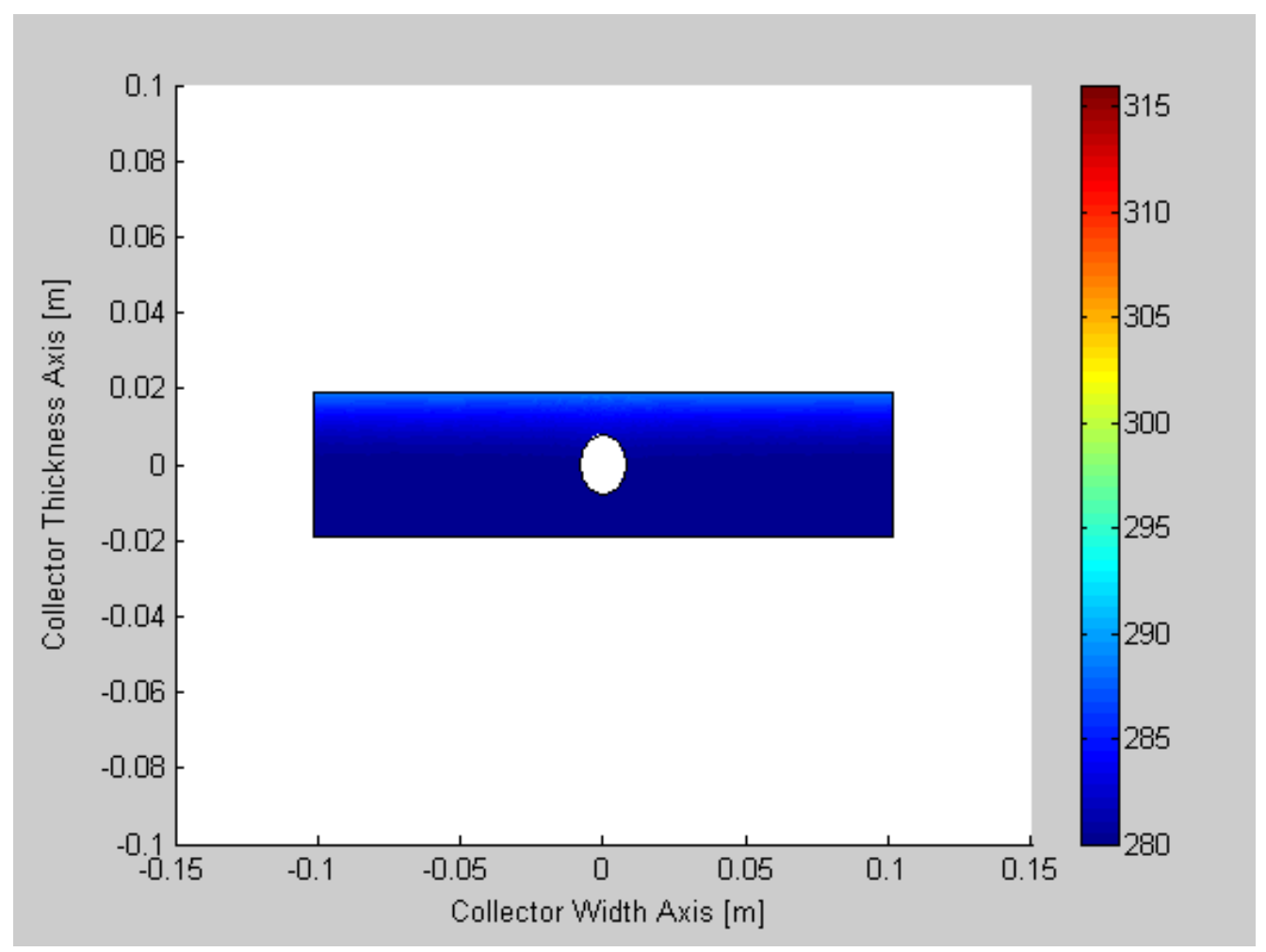

Figure 38a: Temperature Distribution in $8^{\text {th }}$ Segment of the Precast Solar Collector in January at the Beginning of the Hour 12 


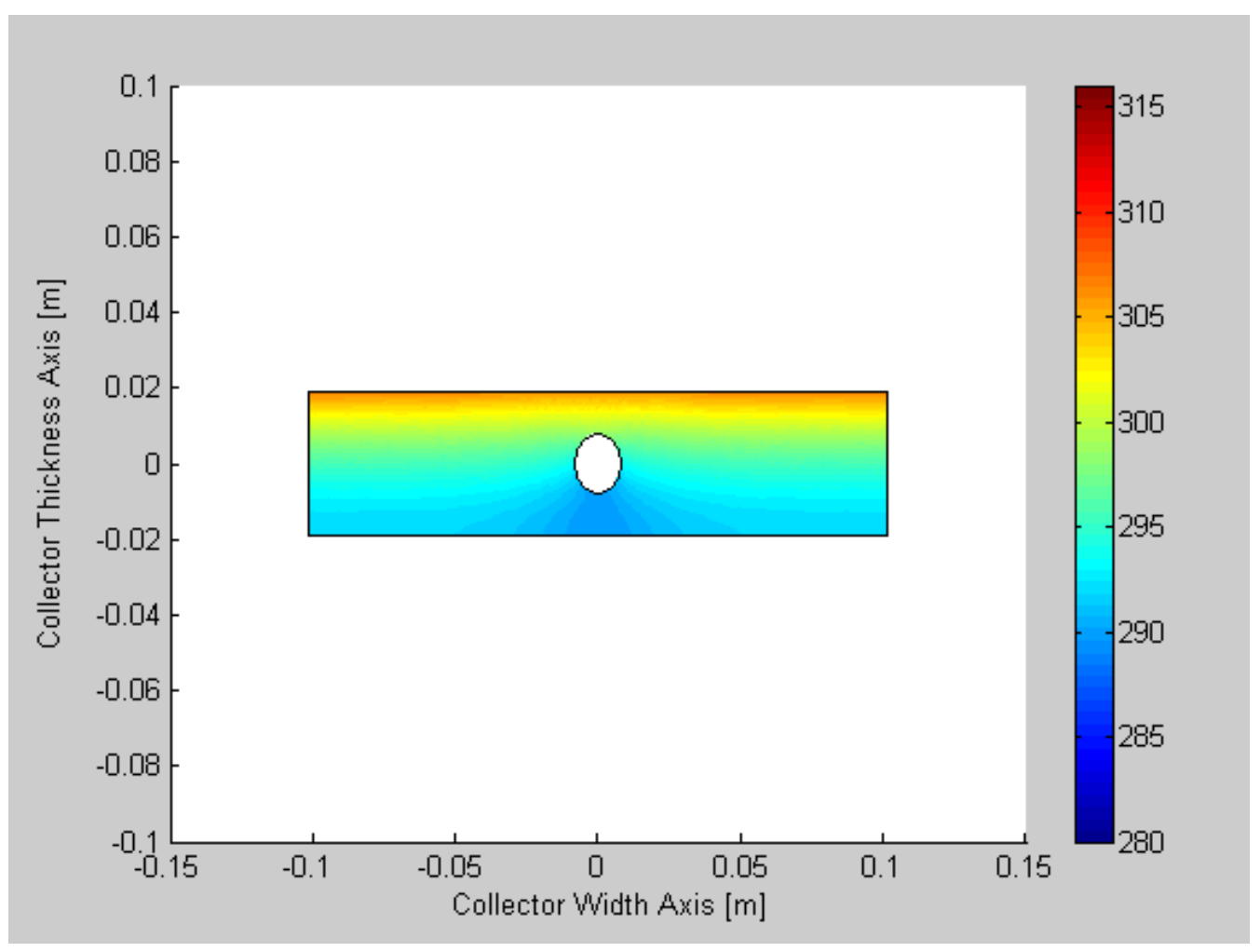

Figure 38b: Temperature Distribution in $8^{\text {th }}$ Segment of the Precast Solar Collector in January at the Middle of the Hour 12

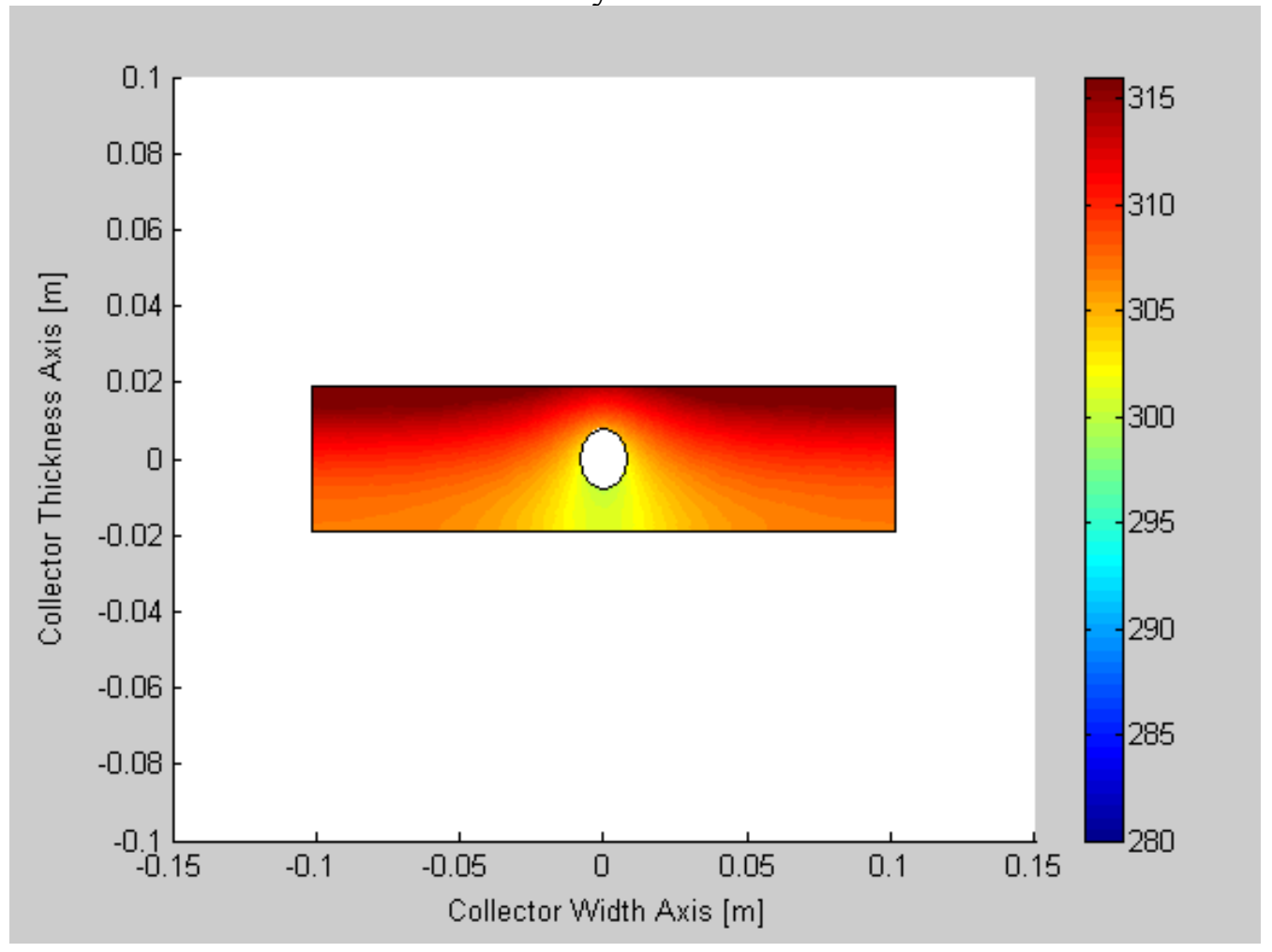

Figure 38c: Temperature Distribution in $8^{\text {th }}$ Segment of the Precast Solar Collector in January at the End of the Hour 12 
Due to the thermal capacitance of the concrete some of the heat gained during the day is stored in the solid; consequently, the solid increases in temperature until there is no incident radiation on the collector and the ambient temperature drops below the precast solar collector. The temperatures reached in the solid for Atlanta, GA were upwards of $345 \mathrm{~K}$, while they were only $330 \mathrm{~K}$ in Chicago, IL.

\section{Temperature of Water Leaving Collector}

The temperature of the water leaving the precast solar collector varies throughout the day. It is dependent upon the incident radiation, heat pump operation, and the velocity of the fluid. The previous section showed the variance in temperature of the solid with axial location and with time. Figure 39 displays the exiting fluid temperature from the precast solar collector through a typical day in January. The temperatures provided by the collector are not warm enough to directly heat the house. However, using the heat pump, the energy collected from the precast collector is boosted to a useful temperature.

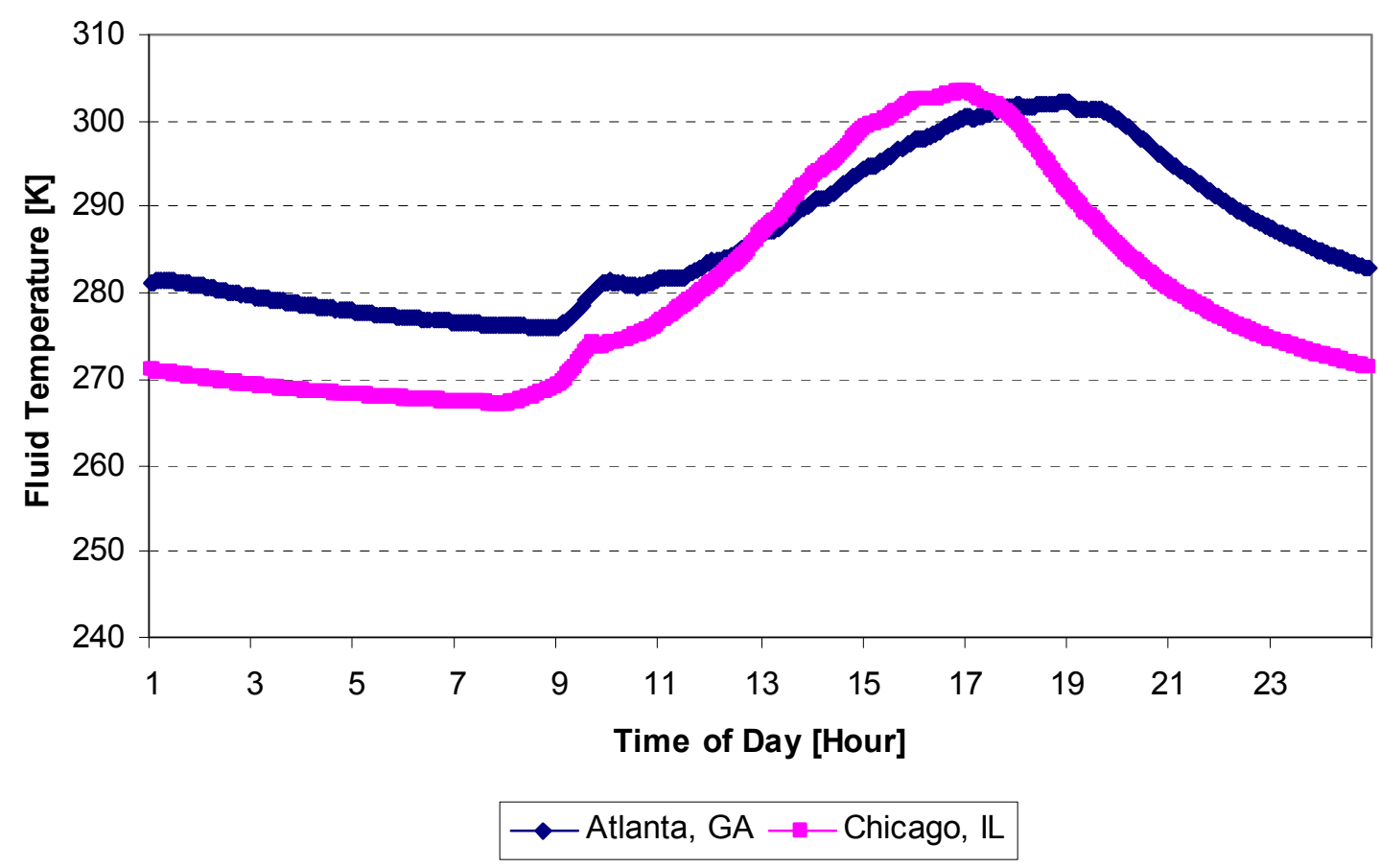

Figure 39: Temperature of the Fluid Leaving the Precast Solar Collector 


\section{Precast Solar Collector Efficiency}

The amount of heat gained by the fluid varies throughout the day as the incident solar radiation and ambient temperature increases. This increase in thermal energy causes an increase in the temperatures in the fluid. Depending on tank temperature, the fluid circulates through the collector loop when the exiting temperature of the precast solar collector exceeds that of the tank. Figure 40 exhibits the incident radiation and the heat gain by the fluid throughout the day for both locations in January using the optimal parameters.

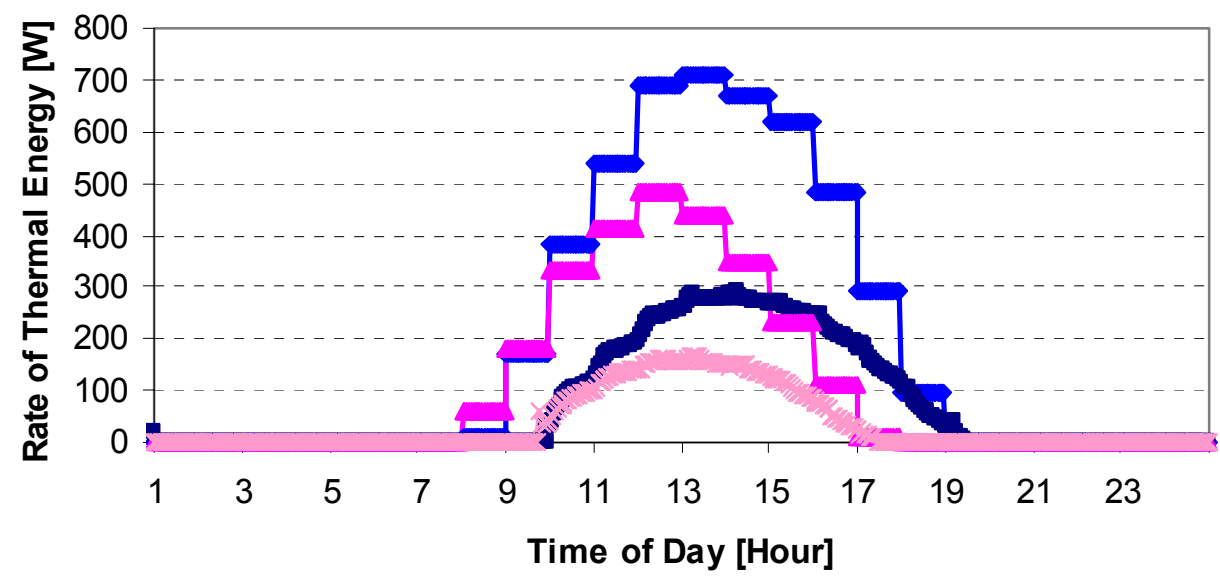

$$
\begin{aligned}
& \multimap \text { Q_incident Atlanta, GA } \rightarrow \text { Q_gained Atlanta, GA } \\
& \multimap \text { Q_incident Chicago, IL } \leftarrow \text { Q_gained Chicago, IL }
\end{aligned}
$$

Figure 40: Heat Gain in the Fluid and Incident Radiation throughout the Day in January

An increase in the heat gain in the fluid can be noticed when compared to the base case values presented in Chapter 4. This shows the advantages of using the parameters derived from the parametric study. Even though January is the only month shown for comparison, there should be an increase during each month of operation.

The efficiency of the solar precast collector is defined as the ratio of heat gained by the fluid to incident radiation and is given in Chapter 4. Figure 41 shows the instantaneous collector efficiency for hours 1 through 17. As the solar radiation begins to decline in the afternoon, the efficiency of the collector as defined by Equation 40 increases significantly 
as heat stored in the concrete is transferred into the fluid. Even after the sun sets, heat from the concrete is transferred into the fluid leading to an undefined efficiency. Results are present only through hour 17. A better measure of performance for a collector with high thermal mass is the daily efficiencies, which for the collector described were $42 \%$ in Chicago, IL and $41 \%$ in Atlanta, GA.

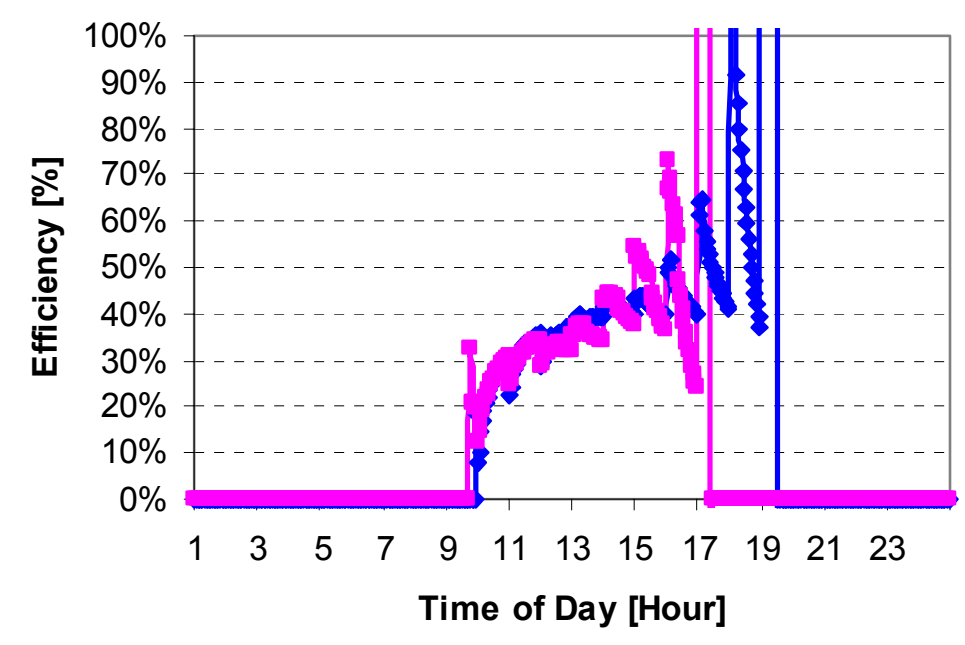

$\leadsto$ Atlanta, GA $\rightarrow$ Chicago, IL

Figure 41: Collector Efficiency in Atlanta and Chicago Note: Numbers Above 50\% Unrealistic due to Thermal Capacitance Effects

This is comparable to the efficiency presented by Nayak et al in the literature [11]. They found their daily collector to be $42 \%$ efficient under optimal conditions. A traditional solar thermal collector ranges in efficiency from 40 to 60 percent as presented by Duffie and Beckman [6].

\section{Solar Assisted Heat Pump Performance}

In order to compare operation of the air to air heat pump against the solar series heat pump, each heating month was taken into consideration. The cooling months were neglected because the solar assisted heat pump acts exactly like an air source heat pump in the summer months when it either expels the heat extracted form the conditioned space to the domestic water or the ambient air. Figure 42 shows the annual heating season comparison. 


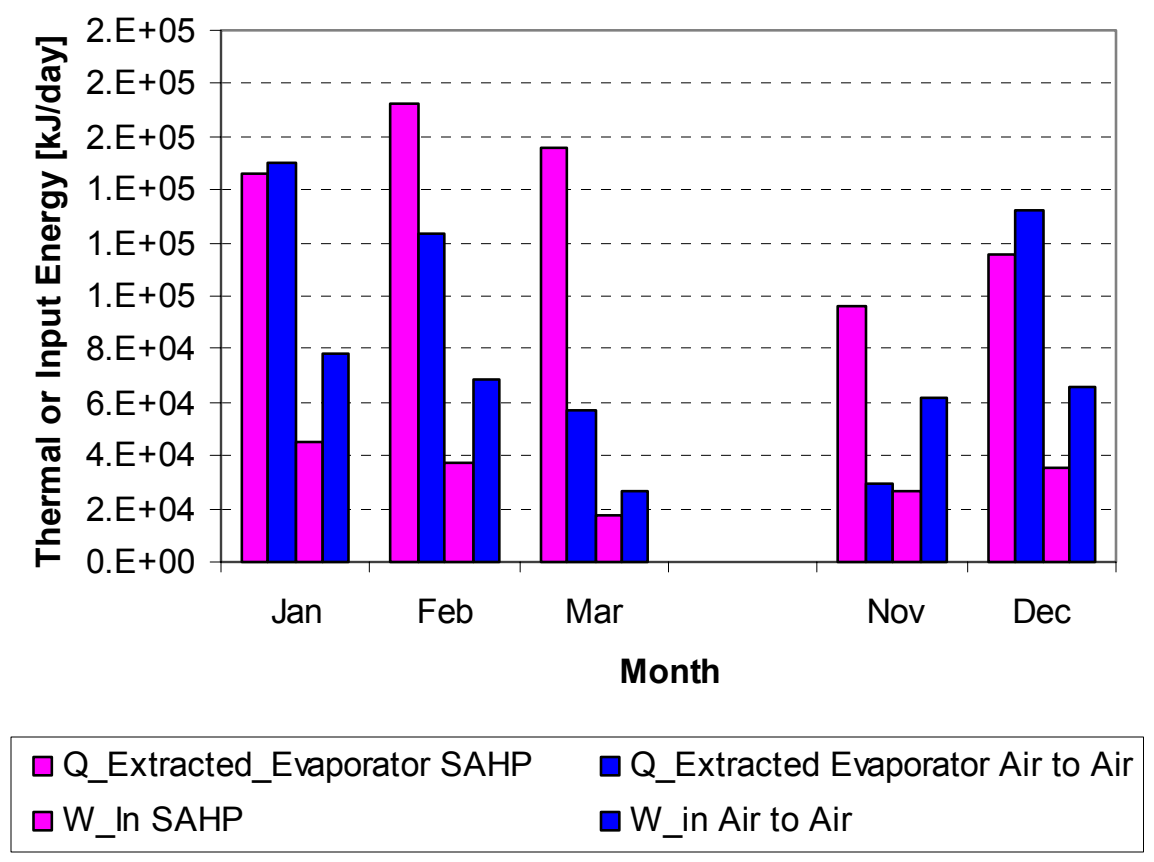

Figure 42: Annual Heating Performance in Atlanta, GA

The $\mathrm{Q}_{\text {provided Solar }}$ refers to the heat provided to the heat pump that was extracted from the incoming water to the evaporator. The $\mathrm{Q}_{\text {provided Air }}$ is the heat taken from the ambient air. The difference between those two number is the defrost energy. The work for the solar assisted heat pump is substantially less than the work for the air to air heat pump in all cases. The largest difference is seen when there is a large heating load.

Unlike Atlanta, Chicago has a long heating season. Figure 43 demonstrates the annual heating performance of the two systems in Chicago. 


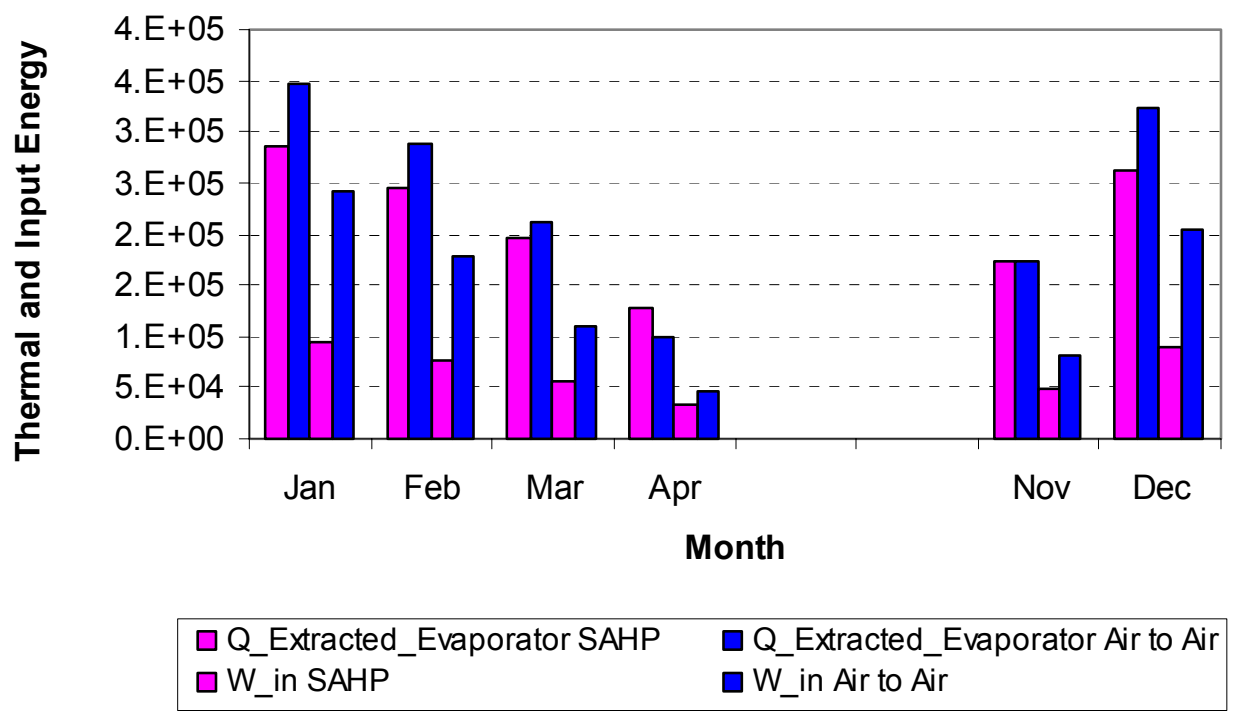

Figure 43: Annual Heat Performance in Chicago, IL

The figure above revels that there are 7 months that yield energy savings in Chicago. The work required to run the solar assisted heat pump is significantly reduced due to the increased incoming fluid temperature at the evaporator. This in turn, will cause an net electricity savings.

The annual work input required to run both the air to air heat pump and the series solar assisted heat pump in Atlanta, GA and Chicago, IL are compared in Figure 44. 


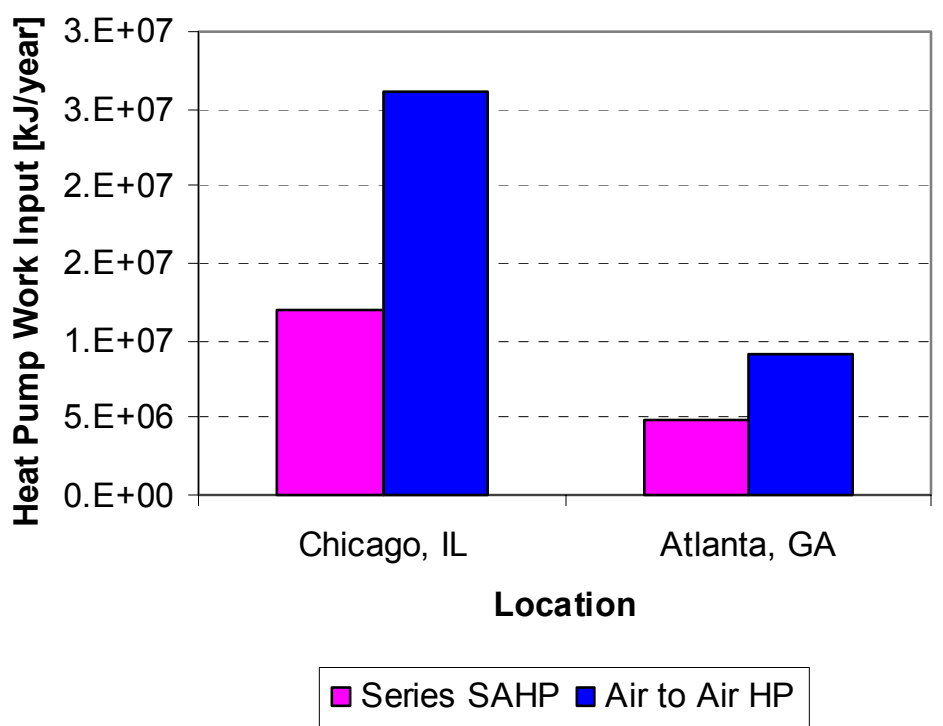

Figure 44: Annual Required Work Comparison

It is evident from the above figure, that the solar assisted heat pump yields a substantial energy savings compared to an air to air heat pump. In Chicago, IL the solar assisted heat pump using energy from the precast solar collector, requires less energy than half the electrical energy required by an air to air heat pump. Reducing the electricity by half also reduces emissions of particulates, $\mathrm{CO}_{2}, \mathrm{NO}_{\mathrm{X}}$, and $\mathrm{SO}_{\mathrm{X}}$ by a comparable amount. The next section will attempt to quantify the economic benefits of incorporating a solar series heat pump system into the house.

\subsection{Economic Analysis}

One of the main disadvantages of solar energy is the initial cost incurred when implementing the system. Although they use "free", renewable energy sources, they usually cannot compete in terms of payback with traditional exhibit lower initial costs than traditional stand along collectors mounted onto the house. Costs reduced with the precast system include collector plate and frame cost, labor cost for installation, and support structure cost. 
To determine the economic benefit of the precast collector combines with a solar assisted heat pump, a life cycle cost and payback period were calculated. The life cycle cost on a present worth basis is given by

$$
L C C=I C-S \times(P / A, r, n)+E C+S V+O M
$$

where IC is the initial cost, $\mathrm{S}$ is the savings, EC is the electricity cost, $\mathrm{SV}$ is the salvage value, and $\mathrm{OM}$ is the operating and maintenance cost. The expression $(\mathrm{P} / \mathrm{A}, \mathrm{r}, \mathrm{n})$ represents the factor for the present worth of an annuity for an interest rate $r$ and a life of $n$ years.

The initial cost considered included only the additional materials needed to add the energy collection system to concrete precast panels and to couple the system to a heat pump. Table 10 shows the initial cost for each of the items in the precast solar collector and series solar assisted heat pump.

Table 10: Initial Cost of Prototypical Energy System

\begin{tabular}{cc} 
Component & Cost \\
\hline Cover Glass $(287 \mathrm{ft})$ & $\$ 5.25 / \mathrm{ft}^{2}$ \\
Tubing Inside Concrete (PEX-c) & $\$ 0.49 / \mathrm{ft}$ \\
Storage Tank & $\$ 800$ \\
Water to Refrigerant Heat Exchanger & $\$ 250$ \\
Circulating Pump (2 pumps) & $\$ 300$ \\
Miscellaneous Pipe and Fittings & $\$ 150$ \\
Total Initial Cost & $\$ 3,244$ \\
\hline
\end{tabular}

One of the major costs in the system is the cover class on the top of the collector. The cost reflected in Table 10 is for large pieces of plate window glass. This cost reflects both the material and installation that are associated with the glass. Because of the large collector area, this cost is very large in comparison with the other costs.

The energy savings were calculated based upon the amount of energy saved in the annual simulation as represented in Figure 43. The energy saved per year in Atlanta, GA is 1164 $\mathrm{kWh} /$ year and in Chicago, IL is $3901 \mathrm{kWh} /$ year. The rate for electricity in Atlanta, GA was assumed to be $\$ 0.063 / \mathrm{kWh}$ and $\$ 0.069 / \mathrm{kWh}$ in Chicago, IL. These numbers are 
based on EIA data for each state [1]. Each year the savings are discounted to present dollars using a discount rate of $8 \%$. The electricity cost escalates at the general rate of inflation which is accounted for in the discount rate.

Furthermore, the lifetime was assumed to be 20 years for the system and the operational and maintenance costs were neglected because they were assumed to be the same as for a traditional air to air heat pump and only the incremental costs of the system are considered.

The lifecycle costs calculated for the precast solar collector and series solar assisted heat pump system were found to be $\$ 2,530$ for Atlanta, GA and $-\$ 547$ for Chicago, IL. It is obvious that these types of systems are more advantageous in colder climates, where the heating season is more expensive. In Atlanta, GA energy savings never pays for the cost of the system. However, due to the higher annual energy savings per year in Chicago, the system has a net present value of $\$ 547$ dollars. 


\section{Chapter 6: Conclusions and Recommendations}

The research presented in this thesis describes a three-dimensional transient model of a precast solar collector operating in conjunction with a series solar assisted heat pump. The solid model was based a transient conduction equation with appropriate boundary conditions, while the fluid model was based on a transient fluid convection equation. The energy system was solved using the finite element technique within the solid model of the precast solar collector, the finite difference technique for each down the channel segment in the fluid, and manufacturer's heat pump data.

\subsection{Conclusions from Model}

An evaluation of the precast solar collector and solar assisted heat pump system was conducted in several steps. First, parametric studies were undertaken to determine advantageous operating parameters. The results revealed that 23 tubes were needed in the precast solar collector to sufficiently meet the load continuously throughout the coldest month. It is noted that the heat gained by this number of tubes is probably oversized to keep up with the load in Atlanta, GA, but properly sized for the load in Chicago, IL. Results also showed that the collector should be as long as possible and the tubing as large as subject to practical constraints. In addition, the results suggested that the concrete should be relatively thin, but that below a thickness to width ratio of 0.1875 the thickness did not have a strong affect on performance.

Results from the model shows that the temperature distribution within the solid changes little down the channel, while changing significantly over time. This suggests that a simplified model that represents the solid by a single 2-dimensional cross section may give adequate results. Further, the combination of a shape factor and a lumped capacitance may be sufficient to describe the behavior of the solid. In this case, the value 
of the shape factor and the lumped capacitance could be determined by calibration with a more detailed model presented here.

Lastly, the annual performance evaluation showed the distinct variation in performance between the air to air heat pump and the series solar assisted heat pump. The daily collector efficiency was approximately 42 percent for both cities during the month of January. This is at the low end of the range reported for traditional flat plate collectors.

The energy used per heating season is significantly reduced by using the series solar assisted heat pump regardless of location. Cities with colder climates and longer heating seasons will show an added benefit from the implementation of the proposed system. In Chicago, IL the propose system exhibited a life cycles savings, while in Atlanta, GA the system exhibited a life cycle cost.

\subsection{Future Recommendations}

The implementation of a solar collector within a precast roof panel offers reduced cost and a better integration compared to traditional flat plate collectors. However, to be economically attractive, the initial cost must be further reduced. One area of further investigation is the precast solar collector cover. The design analyzed here uses glass. Since the initial cost incurred is so high using glass, it would be worth investigating a system that used plexiglass as a cover or another material that is not as expensive. The lower operating temperature of the precast collector relative to traditional flat plate collectors might mitigate some of the disadvantages normally associated with plexiglass. To evaluate this option, the model results would need to be recalculated using the base case values with updated material properties in the overall loss coefficient system of equations. 


\subsection{Closing Remarks}

The analysis presented here evaluates the annual performance of a precast solar collector combined with a series solar heat pump. The prototypical system shows a distinct savings in energy, emissions, and electricity cost over its lifetime. One of the challenges facing any type of solar energy system is overcoming the initial investment. While the proposed system is currently financially attractive only in climates with relatively long heating seasons, increases in energy prices, decreases in material cost, or incentives from government sponsored initiatives may make the system more widely applicable in the future. 


\section{References}

1. Energy Information Administration, "Housing Characteristics," http://www.eia.doe.gov, 2002.

2. Ellis, M.W. and Y.J. Beliveau, NSF Research Proposal.

3. Precast Concrete Panels, "T-mass," http://www.t-mass.com.

4. Concrete Network, "Concrete Network," http://www.concretenetwork.com.

5. U.S. Department of Energy: Energy Efficiency and Renewable Energy, "Solar Hot Water and Space Heating/Cooling," 2004.

6. Duffie, J.A. and W.A. Beckman, "Solar Engineering of Thermal Processes," John Wiley and Sons, Inc, U.S.A, 1991.

7. ASHRAE, "Applications Handbook," Chap. 32, 1999.

8. Bopshetty, S.V., J.K. Nayak, and S.P. Sukhatme, "Performance analysis of a solar concrete collector," Energy Conversion and Management, Vol. 33, No. 11, 1992, pp. 1007-1016

9. Bilgen, E. and M.-A. Richard, "Horizontal concrete slabs as passive solar collectors," Solar Energy, Vol. 72, No. 5, 2002, pp. 405-413.

10. Chaurasia, P.B.L., "Solar water heaters based on concrete collectors." Energy, Vol. 25, 2000, pp. 703-716.

11. Jubran, B.A., M.A. Al-Saad, and N.A. Abu-Faris, "Computational evaluation of solar heating systems using concrete solar collectors," Energy Conversion Management, Vol. 35, No. 12, 1994, pp. 1143-1155.

12. Reshef, M. and M. Sokolov, "Performance simulation of solar collectors made of concrete with embedded conduit lattice," Solar Energy, Vol. 48, No. 6, 1992, pp. 403-411.

13. Cengel, Y.A. and M.A. Boles, "Thermodynamics, An Engineering Approach," McGraw-Hill, U.S.A., 1998.

14. Florida Heat Pump, "Geothermal Heat Pumps," http://www.fhpmfg.com/commercial/geo/geo.htm, 2003.

15. Karman, V.D., T.L. Freeman, and J.W. Mitchell, "Simulation Study of Solar Heat Pump Systems," Proc. Joint Conference of the American Section of ISES and SES of Canada, Vol. 3, 1976.

16. Mitchel, J.W., T.L. Freeman, and W.A. Beckman, "Heat Pumps," Solar Age, Vol. 3, No. 7, 1978, pp. 7.

17. Aye, LU, W.W.S. Charters, and C. Chaichana, "Solar Heat Pump Systems for Domestic Hot Water," Solar Energy, Vol. 73, No. 3, 2002, pp. 169-175.

18. Hawlader, M.N.A., S.K. Chou, and M.Z. Ullah, "The Performance of a Solar Assisted Heat Pump Water Heating System," Applied Thermal Engineering, Vol. 21, 2001, pp. 1049-1065.

19. Mathworks Inc., "Matlab,” 2002.

20. Comsol, Inc., "Femlab," 2002.

21. National Renewable Energy Laboratory, “TMY2 Data," 2002.

22. Maui Solar, "PV Design Studio,” 2001.

23. Incropera, F.P. and D.P. DeWitt, "Fundamentals of Heat and Mass Transfer," John Wiley and Sons, Inc, U.S.A, 2002. 
24. Becker, B.R. and K.E. Stogsdill, "Development of a hot water use database," ASHRAE Journal, Vol. 32, No.9, 1190, pp.21.

25. Becker, B.R. and K.E. Stogsdill, "Domestic hot water use database," ASHRAE Transactions, Vol. 2, 1990, pp. 442.

26. ASHRAE, “Applications Handbook," Chap. 48, 1999.

27. Gunes, M. B., "Investigation of a Fuel Cell Based Total Energy System for Residential Applications," Masters Thesis, Virginia Polytechnic and State University, 2001.

28. Energy Plus, "Input Output Reference," http://www.eere.energy.gov/buildings/energyplus/documentation.html, 2004.

29. Doebber, I. R., “,” Masters Thesis, Virginia Polytechnic and State University, 2004.

30. Building America, "Buidling America Research Bechmark Definition," http://www.eere.energy.gov/buildings/building_america/, 2003.

31. Bridgers, F.H., D.D. Paxton, and R.W. Haines, "Performance of a Solar Heated Office Building." Heating, Piping, and Air Conditioning, Vol. 29, 1957, pp. 165.

32. Hassan, M.M., "Framework for Active Solar Collection Systems," Doctorate Dissertation, Virginia Polytechnic and State University, 2003.

33. Huang, B.J. and J.P. Chyng, "Integral-Type Solar-Assisted Heat Pump Water Heater," Renewable Energy, Vol. 16, 1999, pp. 731-734.

34. Nayak. J.K., S.P. Sukhatme, R.G. Limaye, and S.V. Bosphetty, "Performance studies on solar concrete collectors," Solar Energy, Vol. 42, No.1, 1989, pp. 4556

35. Spencer, D.L. and R.L. Strud, "Integration of solar collector in large prefabricated roof/wall sections," Proc. ISES Silver Jubilee Congress, 1979, pp. 348-354.

36. Turner, R.H., "Concrete slabs as winter solar collectors," Proc. ASME Solar Energy Conference, 1986, pp 9-13.

37. Wilhelm, William G., "Low-Cost Solar Collectors using thin-film plastics absorbers and glazings," Proc. of the 1980 Annual Meeting of the American Section of the International Solar Energy Society, Inc., Vol. 3.1, 1980, pp. 456460. 


\section{Appendix - Matlab Codes}

\section{Final_Program_Model.m}

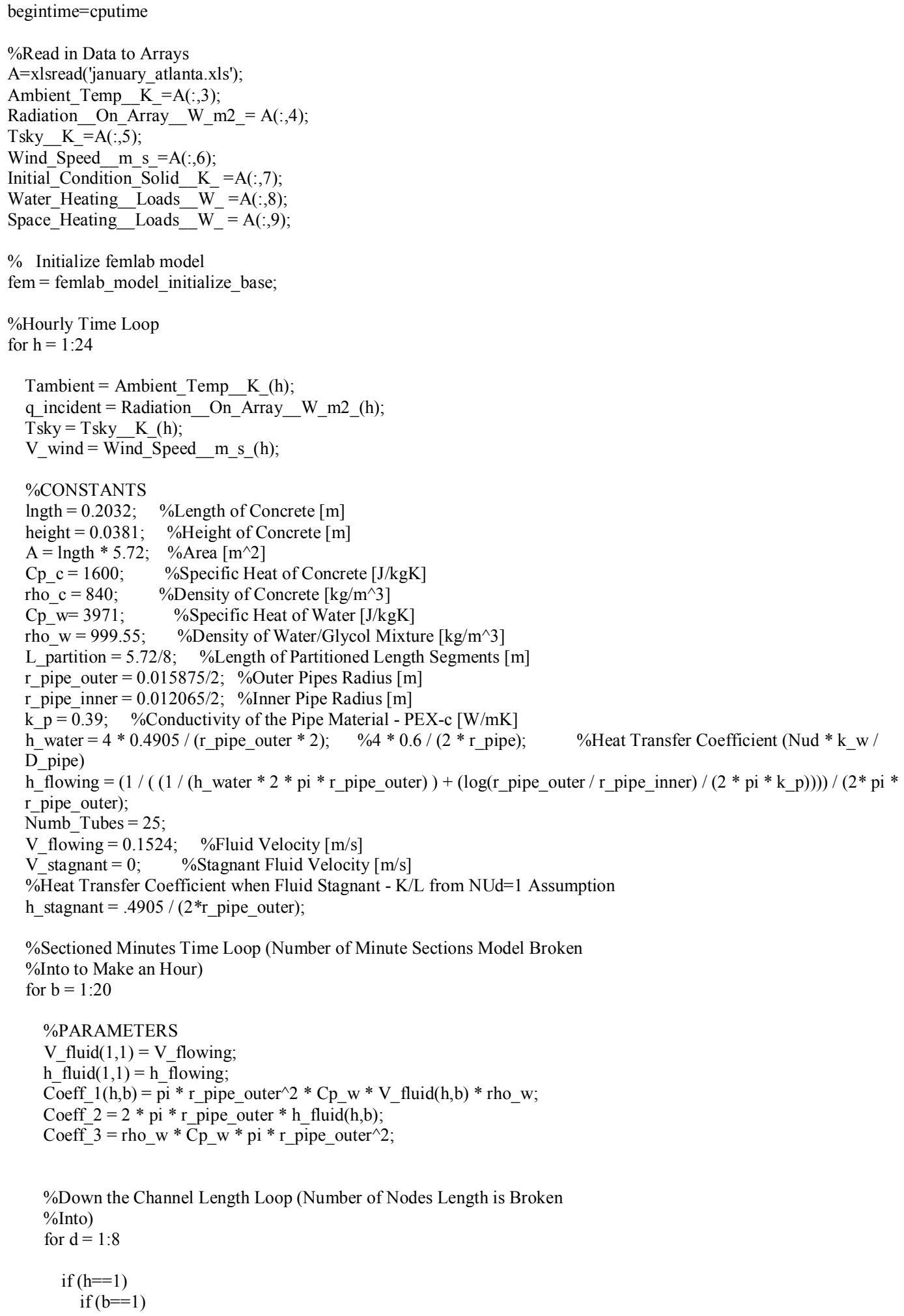




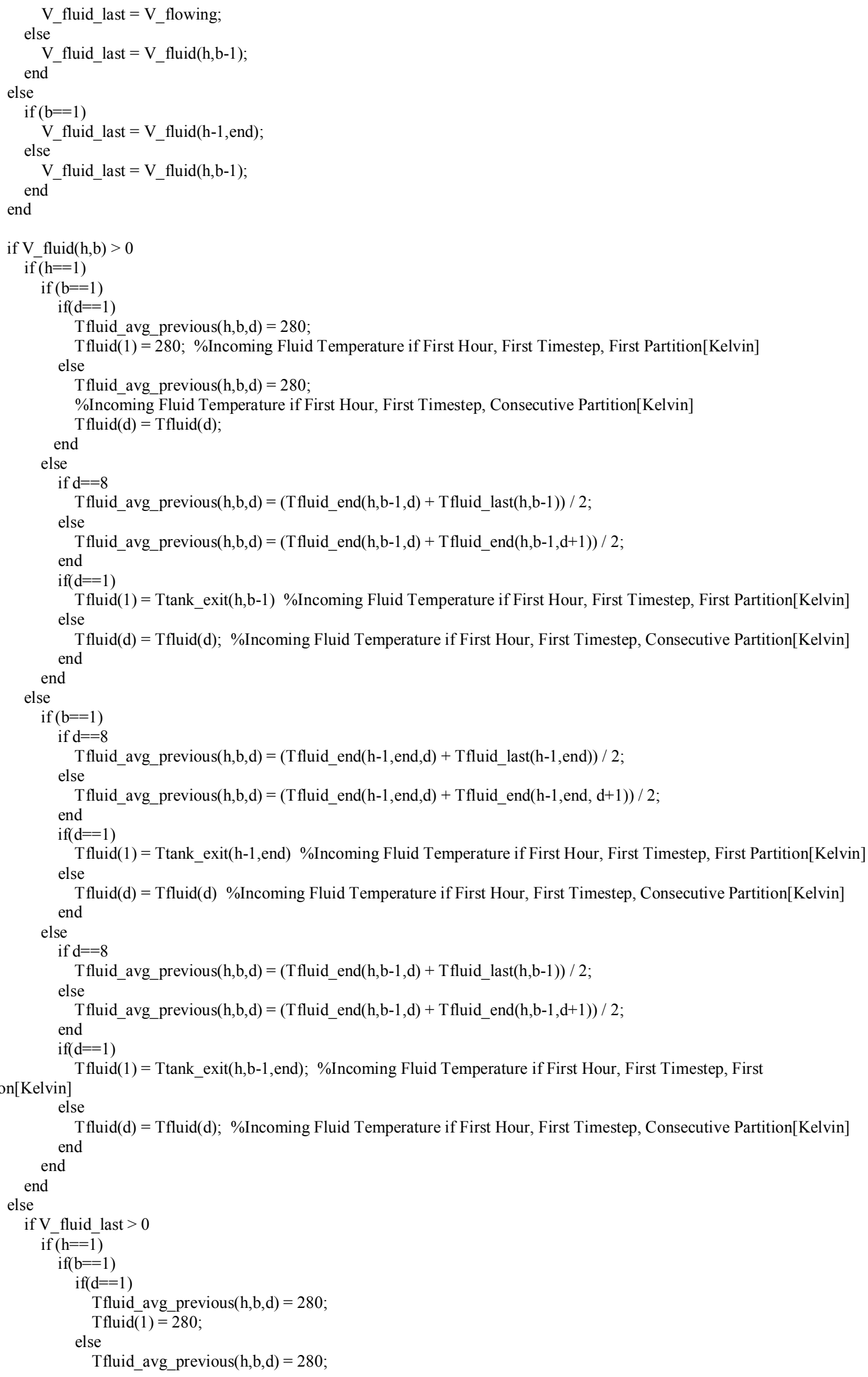




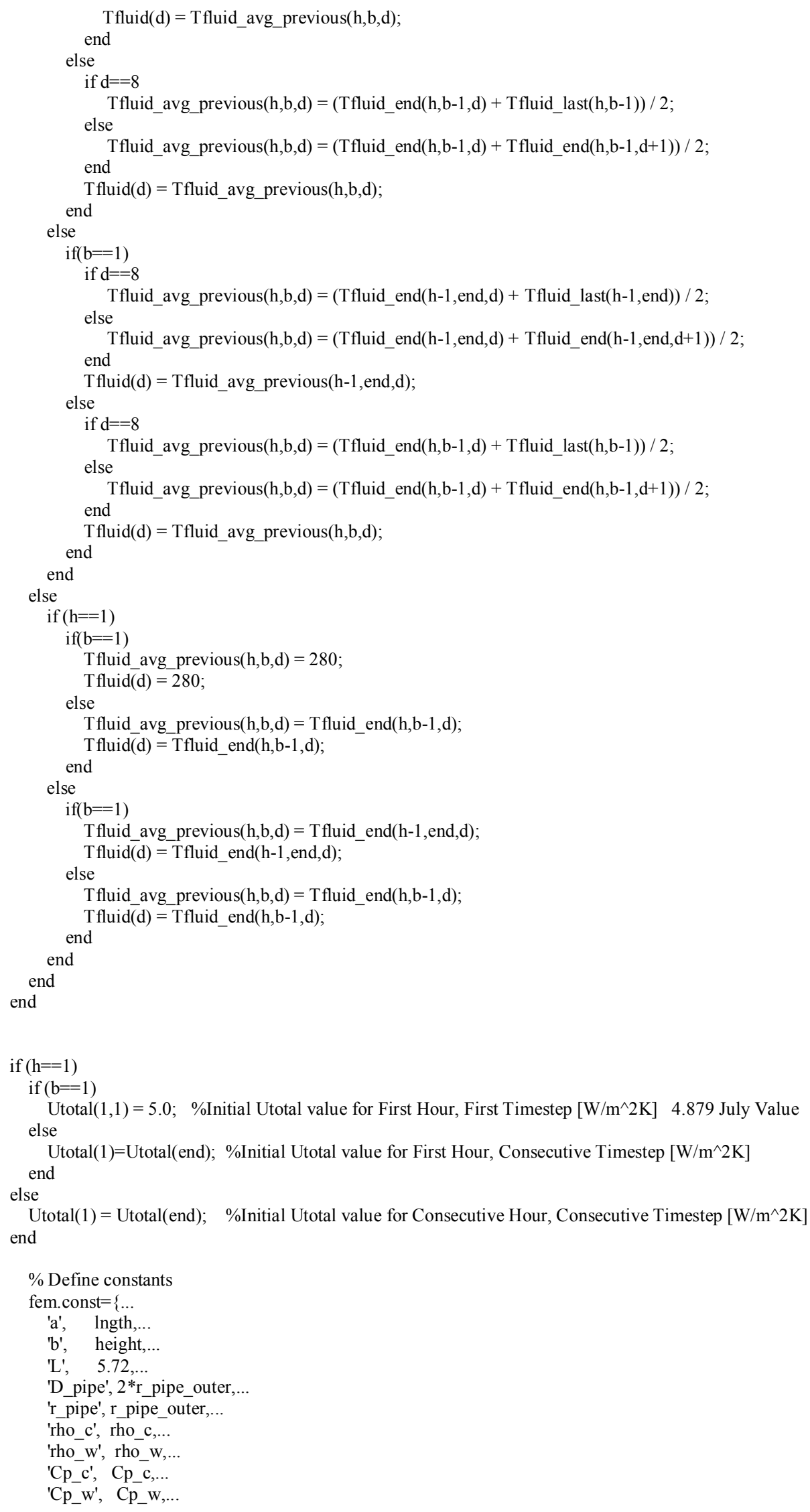




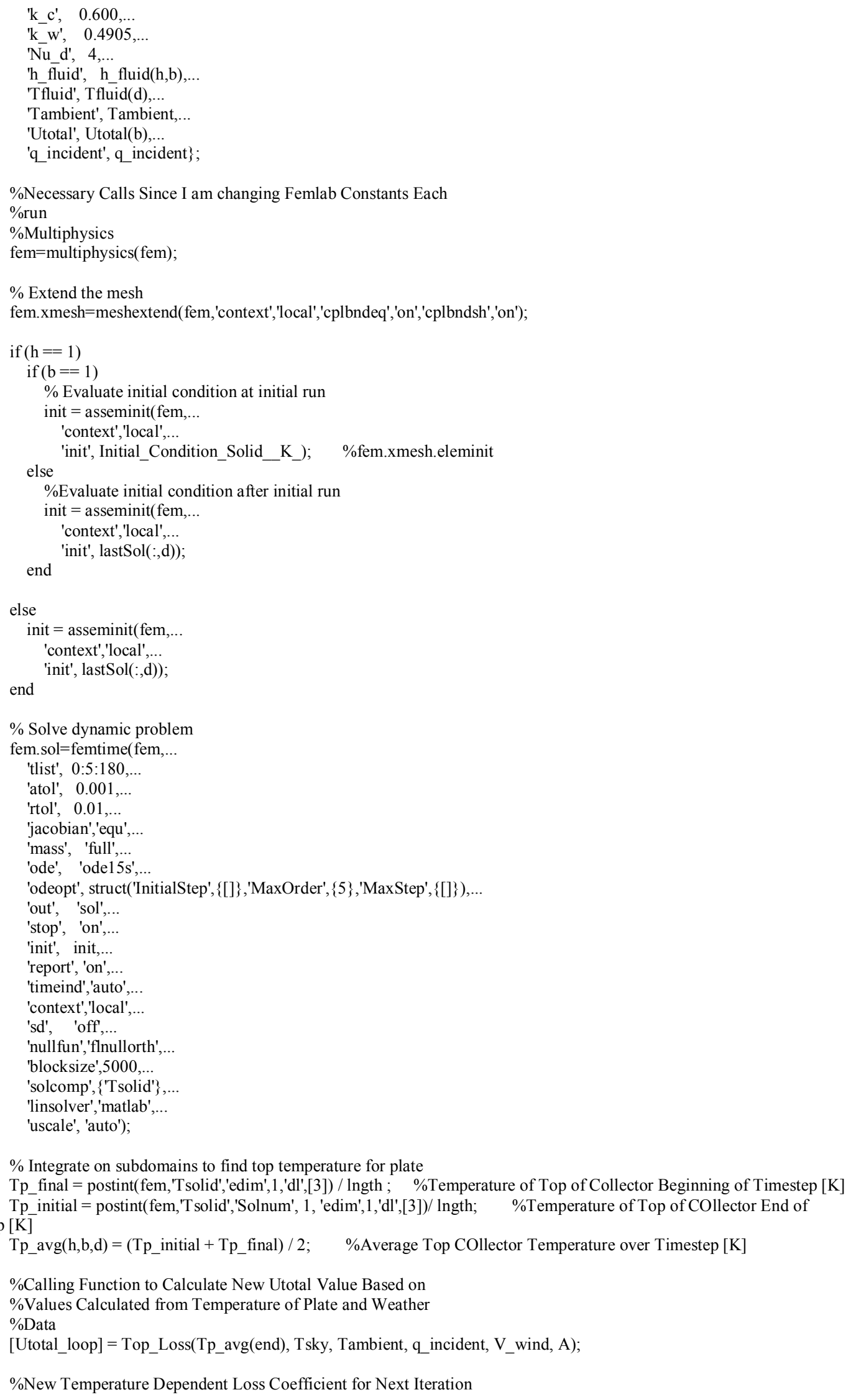


Utotal $(b+1)=$ Utotal_loop;

\%SOLID MODEL VARIABLES VARIABLES

delta $\_$th,b,d $)=$fem.sol.tlist(end) - fem.sol.tlist $(1) ; \quad$ \%Timestep $[\mathrm{s}]$

Tfluid_end(h,b,d) $=$ Tfluid(d) $\quad$ \%Fluid Temperature Along all Partitions $[\mathrm{K}]$

T_solid_boundary_initial(h,b,d)= postint(fem,'Tsolid','Solnum', 1, 'edim',1,'dl',[5 67 8])/(2*r_pipe_outer*pi); \%Average Tempearture of Solid Along Inner Boundary $(5,6,7,8)$

T_solid_boundary_final(h,b,d) = postint(fem, 'Tsolid','edim', 1, 'dl', [5 67 8 $]$ ) / ( $2{ }^{*}$ pi*r_pipe_outer);

Tavg_solid_boundary $(\mathrm{h}, \mathrm{b}, \mathrm{d})=\left(\mathrm{T} \_\right.$solid_boundary_initial $(\mathrm{h}, \mathrm{b}, \mathrm{d})+\mathrm{T} \_$solid_boundary_final $\left.(\overline{\mathrm{h}}, \mathrm{b}, \mathrm{d})\right) / 2 ; \quad$ \%Solid Boundary Temperature - Average over Timestep [K]

[W_in_loop] $=$ W_pump $\left(V_{-}\right.$fluid(h,b), r_pipe_outer, rho_w, Numb_Tubes $)$

if $\mathrm{V}$ fluid(h,b) $>0$

Tfluid(d+1) $=(($ Coeff_1(h,b) / L_partition $) *$ Tfluid(d) + Coeff_2 $*$ (Tavg_solid_boundary(h,b,d) - Tfluid(d) $)-($ Coeff_3 / (2

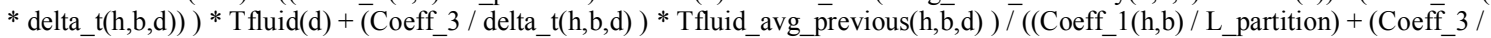

$(2 *$ delta_t $(\mathrm{h}, \mathrm{b}, \mathrm{d}))))$;

Tfluid_last(h,b)=Tfluid(end); \%Fluid Temperature Last Partition $[\mathrm{K}]$

W_in_Pump $(\mathrm{h}, \mathrm{b})=\mathrm{W} \_$in_loop;

else

Tfluid_end $(\mathrm{h}, \mathrm{b}, \mathrm{d})=(($ Coeff_2 $*($ Tavg_solid_boundary $(\mathrm{h}, \mathrm{b}, \mathrm{d})-\operatorname{Tfluid}(\mathrm{d}))) *($ delta_t $(\mathrm{h}, \mathrm{b}, \mathrm{d}) /$ Coeff_3 $))+$ Tfluid_avg_previous(h,b,d);

Tfluid_last $(\mathrm{h}, \mathrm{b})=$ Tfluid_end $(\mathrm{h}, \mathrm{b}, \mathrm{d})$;

W_in_Pump $(h, b)=0$;

end

Solid_Active_Area $=$ lngth*height - pi*r_pipe_outer^2; $\quad$ \%Active Area of the Solid [ $\left.\mathrm{m}^{\wedge} 2\right]$

Ufinal $(\mathrm{h}, \mathrm{b}, \mathrm{d})=\operatorname{Utotal}(\mathrm{b})$;

Tsolid_final(h,b,d) = postint(fem,'Tsolid') / Solid_Active_Area; \%Average Solid Temperature End of Timestep [K] Timestep [K]

Tsolid_initial(h,b,d) $=\operatorname{postint}(f e m, ' T s o l i d ', ' s o l n u m ', 1) /$ Solid_Active_Area; \%Averate Solid Temperature Beginning of

$\% \quad \%$ Energy Balances

$\% \quad \mathrm{q} \_\operatorname{loss}(\mathrm{h}, \mathrm{b}, \mathrm{d})=\operatorname{Ufinal}(\mathrm{h}, \mathrm{b}, \mathrm{d}) * \operatorname{lngth} * \mathrm{~L} \_$partition*(Tp_avg(h,b,d)-Tambient $) *$ delta_t(h,b,d); \% $\quad$ \%Loss from Plate to Ambient[J]

$\% \quad \mathrm{~g}(\mathrm{~h}, \mathrm{~b}, \mathrm{~d})=\mathrm{q}$ incident*L_partition*Ingth*delta_t(h,b,d); \%Incident Radiation [J]

$\% \quad$ if $\mathrm{V}_{-}$fluid(h,b) $>0$

$\% \quad$ if $\mathrm{d}==8$

$\% \quad$ q_fluid $(\mathrm{h}, \mathrm{b}, \mathrm{d})=\mathrm{h} \_$fluid*(2*pi*r_pipe*L_partition)*(Tavg_solid_boundary $(\mathrm{h}, \mathrm{b}, \mathrm{d})$ -

(Tfluid(d)+Tfluid_last(h,b))/2)*delta_t(h,b,d);

$\% \quad$ else

$\% \quad$ q_fluid $(\mathrm{h}, \mathrm{b}, \mathrm{d})=\mathrm{h} \_$fluid $*(2 *$ pi*r_pipe*L_partition $) *($ Tavg_solid_boundary $(\mathrm{h}, \mathrm{b}, \mathrm{d})$ -

(Tfluid(d)+Tfluid $(\mathrm{d}+1)) / 2) *$ delta_t $(\mathrm{h}, \mathrm{b}, \mathrm{d}) ; \quad \%$ Heat gained or lossed by the fluid $[\mathrm{J}]$

$\% \quad$ end

$\% \quad$ else

$\% \quad$ q_fluid $(\mathrm{h}, \mathrm{b}, \mathrm{d})=\mathrm{h} \_$fluid $*(2 *$ pi $*$ r_pipe*L_partition $) *($ Tavg_solid_boundary $(\mathrm{h}, \mathrm{b}, \mathrm{d})-\mathrm{Tfluid}(\mathrm{d})) *$ delta_t $(\mathrm{h}, \mathrm{b}, \mathrm{d}) ;$

$\% \quad$ end

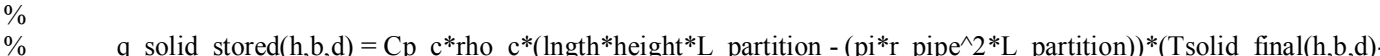
Tsolid_initial $(\mathrm{h}, \mathrm{b}, \mathrm{d}))$; \% Heat Stored over Finite Time Period [ $\overline{\mathrm{J}}]$

$\% \quad$ q balance $(h, b, d)=g(h, b, d)-q \operatorname{loss}(h, b, d)-q$ fluid $(h, b, d)-q \_$solid_stored(h,b,d); \%Energy Balance [J]

$\%$ Store last solution to use as initial value for next call to femtime. lastSol(:, d)=fem.sol.u(:,end);

end

q_gained_fluid $(\mathrm{h}, \mathrm{b})=\mathrm{rho} \_\mathrm{w} * \mathrm{Cp}{ }_{-} \mathrm{w} * \mathrm{~V} \_$fluid(h,b) $* \mathrm{r} \_$pipe_outer^2$*$ pi $*\left(\right.$ Tfluid_last $(\mathrm{h}, \mathrm{b})-\mathrm{Tfluid} \_$end $\left.(\mathrm{h}, \mathrm{b}, 1)\right)$;

$\%$ System Loop

$\%$ Storage Tank

Vol_tank $=1.00 ; \quad \%$ Tank Volume $\left[\mathrm{m}^{\wedge} 3\right]$

r_pipe_system $=0.00635 ; \quad \%$ Pipe Diameter for System $\left[\mathrm{m}^{\wedge} 2\right]$

A_pipe_system $=\mathrm{pi}^{*} 0.00635^{\wedge} 2 ; \quad \%$ Pipe Area $\left[\mathrm{m}^{\wedge} 2\right]$

V_fluid_system $=2.49 ; \quad \% 5 \mathrm{gal} / \mathrm{min}[\mathrm{m} / \mathrm{s}]$

rho_r $=$ rho_w;

Cp_r $=$ Cp_w; 
Coeff_4 $(\mathrm{h}, \mathrm{b})=$ rho_w $* \mathrm{Cp} \_\mathrm{w} * \mathrm{Numb}$ Tubes $*$ V_fluid $(\mathrm{h}, \mathrm{b}) * \mathrm{r} \_$pipe_outer^2 $*$ pi;

Coeff_5 $=$ rho_w $*$ Cp_w $*$ V_fluid_system $*$ A_pipe_system;

Coeff_6 $=$ rho_w $*$ Cp_w $*$ Vol_tank $/$ delta_t $\mathrm{t}(\mathrm{h}, \mathrm{b})$;

if $(\mathrm{h}==1)$

if $(\mathrm{b}==1)$

Ttank_int(h,b) $=298.15 ; \quad$ \%Initial Temperature of Tank if First Hour, First Timestep[K]

else

Ttank_int(h,b) = Ttank_exit(h,b-1); \%Continual Temperature of Tank if First Hour, Consecutive Timestep [K]

end

else

if $(b==1)$

Ttank_int(h,b) = Ttank_exit(h-1,end); \%Initial Temperature of Tank Consecutive Hour, First Timestep [K]

else

Ttank_int(h,b) = Ttank_exit(h,b-1); \%Continual Temperature of Tank Consecutive Hour, Consecutive Timestep [K]

end

if Tfluid_last $(\mathrm{h}, \mathrm{b})>$ Ttank_int $(\mathrm{h}, \mathrm{b})$

if $\mathrm{h}=\overline{-}$

if $b==1$

Ttank_exit(h,b) $=298.15 ; \quad$ \%Exit Temperature of the Tank $[\mathrm{K}]$

else

Ttank exit(h,b) $=($ Coeff $4(\mathrm{~h}, \mathrm{~b}) *$ Tfluid last $(\mathrm{h}, \mathrm{b})+$ Coeff $5 *$ Thp_exit(h,b-1) + Coeff $6 *$ Ttank int $(\mathrm{h}, \mathrm{b})) /($ Coeff $6+$

Coeff_4(h,b) + Coeff_5); \%Exit Temperature of the Tank $[\mathrm{K}]$ end

else

if $\mathrm{b}==1$

Ttank_exit(h,b) $=($ Coeff_4(h,b) $*$ Tfluid_last(h,b) + Coeff_ $5 *$ Thp_exit(h-1,end $)+$ Coeff_6 $*$ Ttank_int(h,b)) $/($ Coeff_6

+ Coeff_4(h,b) + Coeff_5); $\quad \%$ Exit Temperature of the Tank $[\mathrm{K}]$

else

Ttank_exit(h,b) $=($ Coeff_4(h,b) $*$ Tfluid_last(h,b) + Coeff_5 5 Thp_exit(h,b-1) + Coeff_6 $*$ Ttank_int(h,b)) / (Coeff_6 +

Coeff_4(h,b) + Coeff_5); \%Exit Temperature of the Tank [K]

end

end

if $\mathrm{b}<20$

$\mathrm{V}$ fluid $(\mathrm{h}, \mathrm{b}+1)=\mathrm{V}$ flowing;

h_fluid $(\mathrm{h}, \mathrm{b}+1)=\mathrm{h} \_$flowing;

else

V_fluid $(\mathrm{h}+1,1)=\mathrm{V} \_$flowing;

$\mathrm{h}$-fluid $(\mathrm{h}+1,1)=\mathrm{h}$ flowing;

end

else

if $\mathrm{h}==1$

if $\mathrm{b}==1$

Ttank_exit $(\mathrm{h}, \mathrm{b})=298.15 ; \quad$ \%Exit Temperature of the Tank $[\mathrm{K}]$ else

Ttank_exit $(\mathrm{h}, \mathrm{b})=($ Coeff_4(h,b) $*$ Tfluid_last $(\mathrm{h}, \mathrm{b})+$ Coeff_ $5 *$ Thp_exit(h,b-1) + Coeff_6 $*$ Ttank_int(h,b)) / (Coeff_6 + Coeff_4(h,b) + Coeff_5); \%Exit Temperature of the Tank $[\mathrm{K}]$

end

else

if $b==1$

Ttank_exit(h,b) $=($ Coeff_4(h,b) $*$ Tfluid_last(h,b) + Coeff_5 5 Thp_exit(h-1,end $)+$ Coeff_6 $*$ Ttank_int(h,b) $) /($ Coeff_6 + Coeff $4(\mathrm{~h}, \mathrm{~b})+$ Coeff_5); $\quad \%$ Exit Temperature of the Tank $[\mathrm{K}]$ else

Ttank exit $(\mathrm{h}, \mathrm{b})=($ Coeff $4(\mathrm{~h}, \mathrm{~b}) *$ Tfluid_last(h,b) + Coeff_5 5 Thp_exit(h,b-1) + Coeff_6 $*$ Ttank_int(h,b)) $/($ Coeff_6 +

Coeff_4(h,b) + Coeff_5); \%Exit Temperature of the Tank $[\mathrm{K}]$ end

end

if $b<20$

V_fluid $(\mathrm{h}, \mathrm{b}+1)=\mathrm{V} \_$stagnant;

$\mathrm{h}$-fluid $(\mathrm{h}, \mathrm{b}+1)=\mathrm{h}$ stagnant;

else

V_fluid $(\mathrm{h}+1,1)=\mathrm{V} \_$stagnant;

$\mathrm{h}$ _fluid $(\mathrm{h}+1,1)=\mathrm{h}$ _stagnant;

end

end

if Ttank_exit(h,b) $>260.95$ 


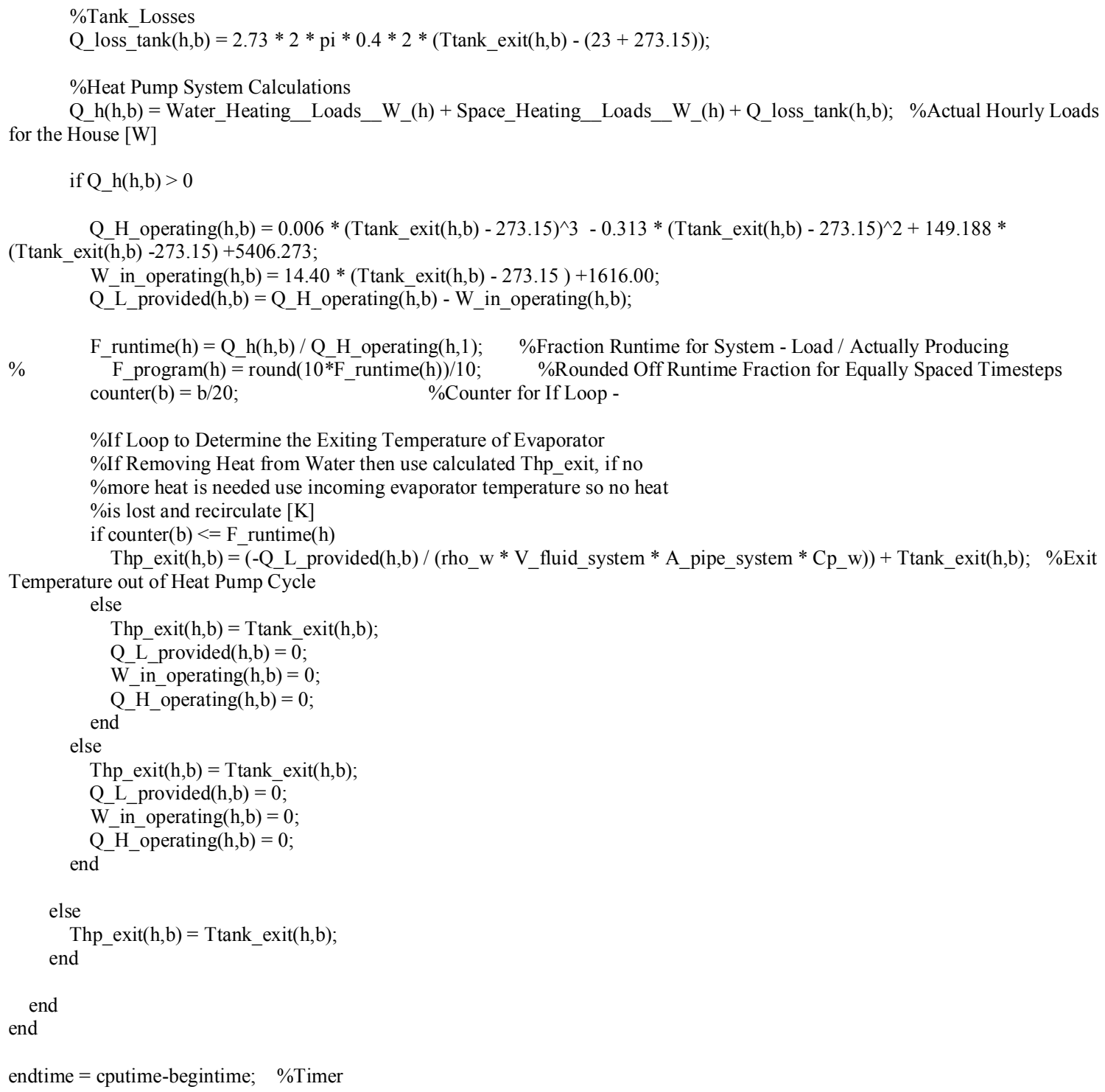

\section{Top_Loss.m}

function [Utotal_loop] $=$ Top_Loss $\left(\mathrm{Tp} \_\right.$avg, Tsky, Tambient, q_incident, V_wind, A)

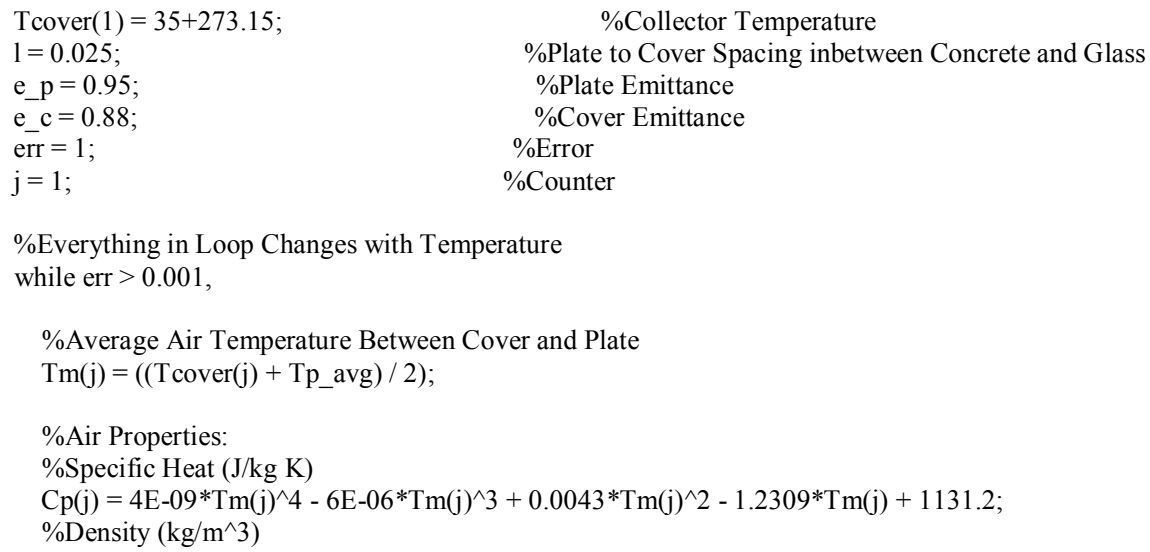

\%Everything in Loop Changes with Temperature while err $>0.001$, 


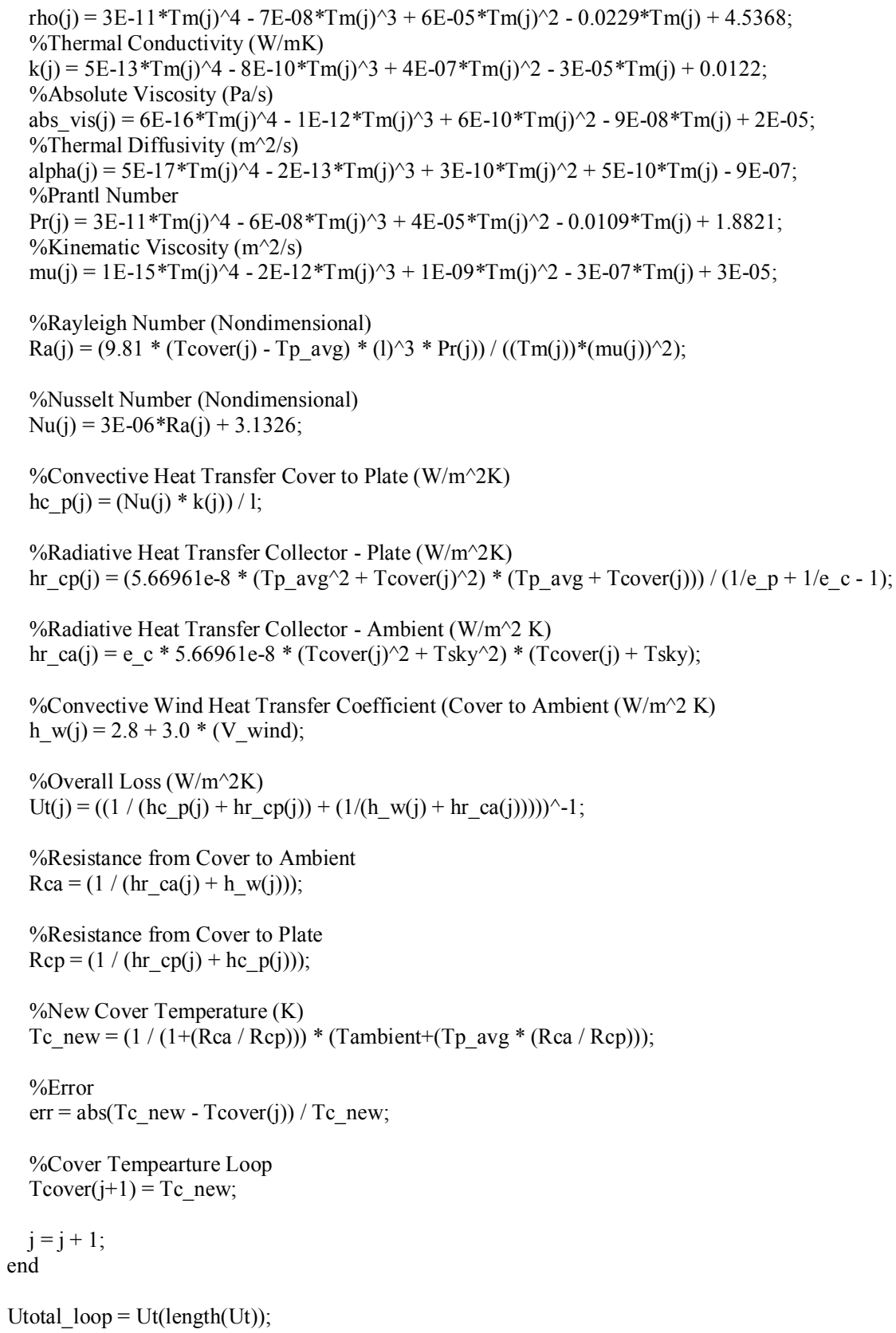

\section{Femlab_initialize_base.m}

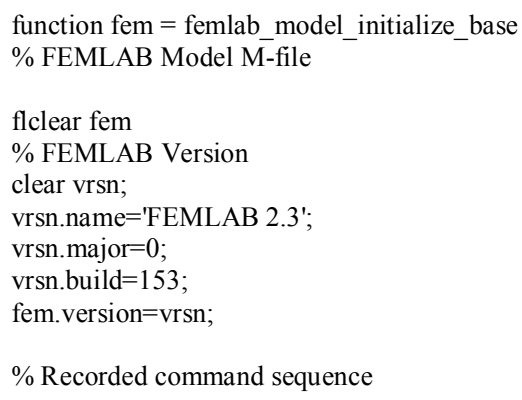


$\%$ New geometry 1

fem.sdim $=\left\{{ }^{\prime}{ }^{\prime}, y^{\prime}\right\}$;

$\%$ Geometry

clear s c p

$\mathrm{p}=[-0.1016-0.1016-0.0079375$

$-0.0079375-0.0079375000 .0079375 \ldots$

$0.00793750 .00793750 .1016 \ldots$

$0.1016 ;-0.019050 .01905 \ldots$

$-0.00793758 .6736173798840355 \mathrm{e}-0190.0079375 \ldots$

$-0.00793750 .0079375-0.0079375 \ldots$

$8.6736173798840355 \mathrm{e}-0190.0079375-0.01905 \ldots$

$0.01905]$

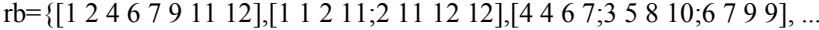

zeros $(4,0)\}$;

$\mathrm{wt}=\left\{\right.$ zeros $(1,0)$, ones $(2,4),\left[\begin{array}{llll}1 & 1 & 1 & 1 ; 0.70710678118654746 \\ 0.70710678118654746 \ldots\end{array}\right.$ $0.707106781186547460 .70710678118654746 ; 11111]$,zeros(4,0)\};

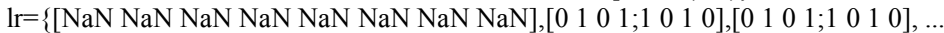

zeros $(2,0)\}$;

$\mathrm{CO} 1=\operatorname{solid} 2(\mathrm{p}, \mathrm{rb}, \mathrm{wt}, \mathrm{lr})$;

objs $=\{\mathrm{CO} 1\}$;

names $=\left\{{ }^{C O O} 1\right\}$;

s.objs $=$ objs;

s.name $=$ names;

objs $=\{\} ;$

names $=\{\}$;

c. objs $=$ objs;

c.name $=$ names;

objs $=\{\} ;$

names $=\{\}$;

p.objs $=$ objs;

p.name $=$ names;

drawstruct=struct('s',s,'c',c,'p',p);

fem. draw $=$ drawstruct;

fem.geom=geomcsg(fem);

clear appl

$\%$ Application mode 1

appl $\{1\}$. mode=flpdeht2d('dim', \{'Tsolid'\},'sdim', \{'x','y'\},'submode','std', ...

'tdiff,'on');

$\operatorname{appl}\{1\} . \operatorname{dim}=\{$ 'Tsolid' $\}$;

appl $\{1\}$.form='coefficient';

appl $\{1\}$.border $=$ 'off';

appl $\{1\}$.name='ht';

appl $\{1\}$.var $=\{\}$;

appl\{1\}. assign=\{'C';'C';'Const';'Const';'Ctrans';'Ctrans';'Q';'Q';'Tamb'; ..

'Tamb';'Tambtrans','Tambtrans';'Text';'Text';'Tinf;'Tinf';'flux';'flux'; ...

'flux_x';'flux_x';'flux_y';'flux_y';'gradT';'gradT';'gradTx';'gradTx'; ...

'gradTy';'gradTy';'h';'h';'htrans';'htrans';'n_flux';'n_flux';'q';'q';'rho'; ...

'rho'\};

appl $\{1\}$.elemdefault='Lag2';

$\operatorname{appl}\{1\}$.shape $=\{\operatorname{shlag}(2, " T$ solid")' $\}$;

appl $\{1\}$.sshape $=2$;

$\operatorname{appl}\{1\}$.equ.rho $=\{$ 'rho_c' $\}$

appl $\{1\}$.equ.C $=\left\{\mathrm{Cp}_{-} \mathrm{c}^{\prime}\right\}$;

appl $\{1\}$.equ.k $=\left\{\left\{\left\{\right.\right.\right.$ 'k_c' $\left.\left.\left.^{\prime}\right\}\right\}\right\}$;

$\operatorname{appl}\{1\}$.equ. $Q=\left\{0^{\prime}\right\}$;

appl $\{1\}$.equ.htrans $=\left\{0^{\prime}\right\}$;

$\operatorname{appl}\{1\}$.equ.Text $=\left\{0^{\prime}\right\}$;

appl $\{1\}$.equ. Ctrans $=\left\{0^{\prime}\right\}$;

appl $\{1\}$.equ.Tambtrans $=\left\{{ }^{\prime} 0^{\prime}\right\}$;

appl $\{1\}$.equ.gporder $=\{\{4\}\}$;

appl $\{1\}$.equ.cporder $=\{\{2\}\}$

appl $\{1\}$.equ. shape $=\{1\}$;

appl $\{1\}$.equ.init $=\{\{\{$ Tambient' $\}\}\}$; 
$\operatorname{appl}\{1\}$.equ.usage $=\{1\}$;

appl $\{1\}$.equ.ind $=1$;

$\operatorname{appl}\{1\}$.bnd.q $=\left\{{ }^{\prime} 0^{\prime}, ' q\right.$ incident', $\left.{ }^{\prime}\right\}$;

appl $\{1\}$.bnd.h $=\left\{{ }^{0} 0\right.$ ','Utotal','h_fluid' $\}$;

appl $\{1\}$.bnd.Tinf $=\left\{0^{\prime}\right.$, 'Tambient','Tfluid' $\}$;

appl $\{1\}$.bnd.Const $=\left\{0^{\prime},{ }^{\prime} 0^{\prime}, 0^{\prime}\right\}$;

appl $\{1\}$.bnd.Tamb $=\left\{0^{\prime},{ }^{\prime} 0^{\prime}, 0^{\prime}\right\}$;

appl $\{1\}$.bnd. $T=\left\{0^{\prime},{ }^{\prime} 0^{\prime}, 0^{\prime}\right\}$;

appl $\{1\}$.bnd.type $=\{$ 'q0','q','q' $\}$;

appl $\{1\}$.bnd.gporder $=\{\{0\},\{0\},\{0\}\}$;

appl $\{1\}$.bnd.cporder $=\{\{0\},\{0\},\{0\}\}$;

appl $\{1\}$.bnd.shape $=\{0,0,0\}$;

appl $\{1\}$. bnd.ind=[ $\left.\begin{array}{llllllll}1 & 1 & 2 & 1 & 3 & 3 & 3 & 3\end{array}\right]$;

fem.appl=appl;

$\%$ Initialize mesh

fem.mesh=meshinit $($ fem,...

'Out', \{'mesh'\},...

'jiggle', 'mean',...

'Hcurve', $0.29999999999999999, \ldots$

'Hgrad', 1.3,...

'Hpnt', $\{10,[]\})$;

$\%$ Differentiation rules

fem.rules $=\{\}$;

$\%$ Problem form

fem. outform='coefficient';

$\%$ Differentiation

fem.diff $=\{$ 'expr' $\}$;

\% Differentiation simplification

fem.simplify='on';

$\%$ Boundary conditions

clear bnd

bnd.q $=\left\{0^{\prime},{ }^{\prime}, \mathrm{q}\right.$ incident', $\left.{ }^{\prime}\right\}$;

bnd.h $=\left\{{ }^{\prime} 0\right.$ ','Utotal','h_fluid' $\}$;

bnd.Tinf $=\left\{0^{\prime}\right.$, 'Tambient','Tfluid' $\}$;

bnd.Const $=\left\{0^{\prime},{ }^{\prime} 0^{\prime},{ }^{\prime} 0^{\prime}\right\}$;

bnd.Tamb $=\left\{0^{\prime} 0^{\prime}, 0^{\prime},{ }^{\prime} 0^{\prime}\right\}$;

bnd.T $=\left\{0^{\prime},{ }^{\prime}, 0^{\prime}, 0^{\prime}\right\}$;

bnd.type $=\{$ 'q0',''q','q' $\}$;

bnd.gporder $=\{\{0\},\{0\},\{0\}\}$;

bnd.cporder $=\{\{0\},\{0\},\{0\}\}$;

bnd. shape $=\{0,0,0\}$

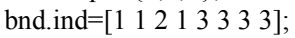

fem.appl $\{1\}$.bnd=bnd;

\% PDE coefficients

clear equ

equ.rho $=\left\{\right.$ 'rho $\left.c^{\prime}\right\}$;

equ.C $=\left\{\right.$ Cp_c' $\left.^{\prime}\right\}$;

equ.k $=\left\{\left\{\left\{\right.\right.\right.$ 'k_c' $\left.\left.\left.^{\prime}\right\}\right\}\right\}$;

equ. $\mathrm{Q}=\left\{0^{\prime}\right\}$;

equ.htrans $=\left\{0^{\prime}\right\}$;

equ.Text $=\left\{0^{\prime}\right\}$;

equ. Ctrans $=\left\{0^{\prime}\right\}$;

equ.Tambtrans $=\left\{0^{\prime}\right\}$;

equ.gporder $=\{\{4\}\}$;

equ.cporder $=\{\{2\}\}$;

equ. shape $=\{1\}$;

equ.init $=\{\{\{$ Tambient' $\}\}\}$;

equ.usage $=\{1\}$

equ.ind $=1$;

fem.appl $\{1\}$.equ $=$ equ; 
$\%$ Internal borders

fem.appl $\{1\}$.border='off';

$\%$ Shape functions

fem.appl $\{1\}$.shape $=\{\operatorname{shlag}(2, " T$ solid")' $\}$;

$\%$ Geometry element order

fem.appl $\{1\}$.sshape $=2$

\section{W.Pump.m}

function [W_in_loop] $=\mathrm{W} \_$pump(V_fluid, r_pipe_outer, rho_w, Numb_Tubes $)$

pipe_length $=14.11 ; \quad$ \%Length of Piping $[\mathrm{m}]$

collector length $=5.72 ; \quad$ \%Length of Collector Piping $[\mathrm{m}]$

mu_f $=0.0010395 ; \quad \%$ Viscosity of Glycol/Water Mixture $[\mathrm{Pa} s]$

ratio $\mathrm{hl}=0.03 ; \quad \%$ Head Loss Ratio [3ft heat loss $/ 100 \mathrm{ft}$ pipe]

m_dot $=$ rho_w* $\left(\right.$ r_pipe_outer $\left.{ }^{\wedge} 2\right) *$ pi $^{*}$ V_fluid $*$ Numb_Tubes ; \%Mass Flow Rate Coming Out of Manifold $[\mathrm{kg} / \mathrm{s}]$

Re_d $=$ rho_w $*$ V_fluid $* 2 *$ r_pipe_outer $/$ mu_f;

lambda_f $=64$ / Re_d; $\quad \%$ Friction Coefficient

P_loss_collector $=$ lambda_f $*$ collector_length $/($ r_pipe_outer $* 2) *($ rho_w $*$ V_fluid^2 $/ 2) ; \quad \%$ Pressure Loss Through the Collector $[\mathrm{Pa}]$

P_loss_pipes $=$ pipe_length $*$ ratio_hl $* 9.81 *$ rho_w; $\quad$ \%Pressure Loss Through the Pipes $[\mathrm{Pa}]$

P_loss_total $=$ P_loss_collector + P_loss_pipes; $\quad$ \%Total Pressure Loss From Piping System $[\mathrm{Pa}]$

$\mathrm{W}=(1 /$ rho__ $\mathrm{w}) * \mathrm{P} \_$loss_total; $\quad$ \%Specific Work

W_dot_in $=\mathrm{m}_{-}$dot $* \mathrm{w} /(0.5 * 0.9) ; \quad$ \%Rate of Work for Circulating Pumps

W_in_loop $=$ W_dot_in / 0.8; $\quad$ \%Rate of Work Assuming $[\mathrm{W}]$ 